
NBSIR 79-1619
A I1104 551590

\title{
QUALITY ASSURANCE PROGRAM FOR THE NBS \\ C, K, and Q LASER CALIBRATION SYSTEMS
}

William E. Case

Optical Electronic Metrology Group

Electromagnetic Technology Division

National Engineering Laboratory

National Bureau of Standards

Boulder, Colorado 80303

Prepared for :

Department of the Air Force

Aerospace Guidance \& Metrology Center (AGMC)

Newark Air Force Station

Newark, Ohio 43055 



\section{QUALITY ASSURANCE PROGRAM FOR THE NBS \\ C, K, and Q LASER CALIBRATION SYSTEMS}

William E. Case

Optical Electronic Metrology Group

Electromagnetic Technology Division

National Engineering Laboratory

National Bureau of Standards

Boulder, Colorado 80303

Prepared for:

Department of the Air Force

Aerospace Guidance \& Metrology Center (AGMC)

Newark Air Force Station

Newark, Ohio 43055

August 1979

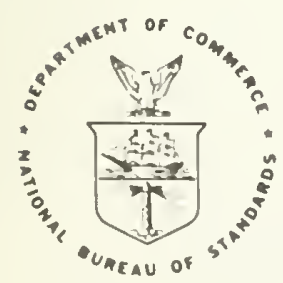

U.S. DEPARTMENT OF COMMERCE, Juanita M. Kreps, Secretary Luther H. Hodges, Jr., Under Secretary Jordan J. Baruch, Assistant Secretary for Science and Technology

NATIONAL BUREAU OF STANDARDS, Ernest Ambler, Director 



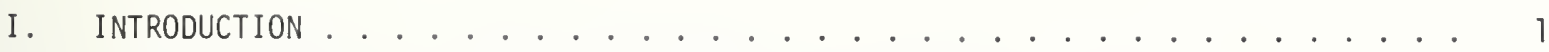

I I. UNITED STATES (U.S.) NATIONAL STANDARDS .................. 3

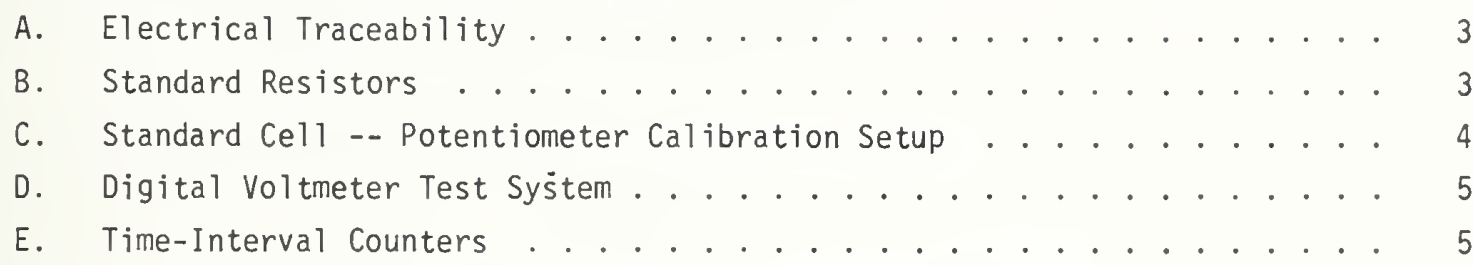

III. QUALITY ASSURANCE FOR C, K AND Q LASER CALIBRATION SYSTEMS . . . . . . . . 5

A. First-Time Operation of a System ............. . . . . . . . . .

B. First-Time Operation of a System at a New Wavelength . . . . . . . 8

C. Re-Evaluation of a System at an 01d Wavelength .......... 8

D. Quality Assurance Plans 1 and 2............... 8

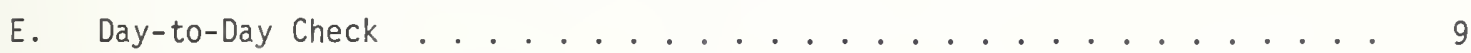

F. Monthly or Special Check .................... 12

G. Annual Check ..................... . . 12

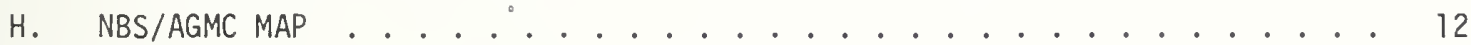

IV. BLUE BOOK . . . . . . . . . . . . . . . . . . . . . . 13

A. TABLE A - Electrical CAlibrations. . . . . . . . . . . . . 14

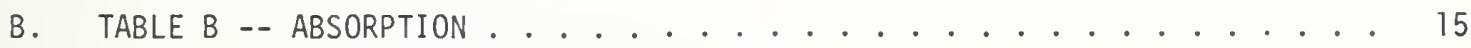

C. TABLE C - - Inequivalence . . . . . . . . . . . 16

D. TABLE D - WINDOW TRANSMISSION. ......................... 17

E. TABLE E - TRACEABILITY . . . . . . . . . . . . . . 18

F. TABLE F - D-FACTOR. . . . . . . . . . . . . . . . . 19

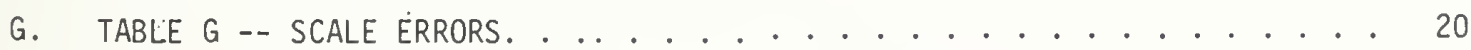

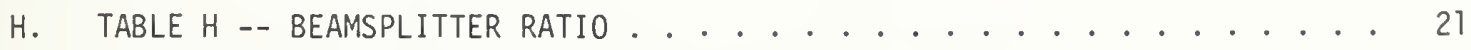

I. TABLE I -- SUMMARY OF ERRORS. . . . . . . . . . . . . . . 22

V. COMPUTER DOCUMENTATION FOR THE C, K AND Q CALIBRATING SYSTEMS . . . . . . 23

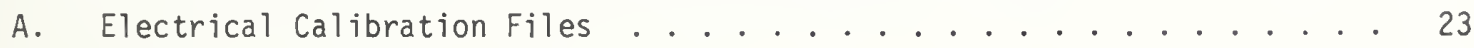

B. Beamsplitter Files ................. 23

C. Blue Book Matrix Files . . . . . . . . . . . . . . . 23

VI. USING THE $C$, K AND Q CALIBRATING SYSTEMS . . . . . . . . . . . . . . . 24

A. Transfer Standards .................... 24

B. Conventional Calibrations .................. 25

C. Measurement Assurance Programs (MAP) . . . . . . . . . . . . . 26

VII. COMPUTER DOCUMENTATION AND QUALITY ASSURANCE OF LASER POWER AND ENERGY TRANSFER STANDARDS . . . . . . . . . . . . . 27

A. Format . . . . . . . . . . . . . . . . . 27

B. Discrete Power and Energy Levels . . . . . . . . . . . . . 27

C. Separate Calibration Coefficients for Each Scale and Wavelength . . . . 27 
CONTENTS, continued

D. Direct Calibrations ....................... . . 27 27

E. Using Mean or Average Calibration Coefficients . . . . . . . . . 28

F. Two-Sided 99 Percent Confidence Interval ............. 28

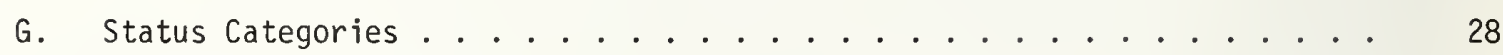

VIII. CALIBRATION AND MAP REPORTS . . . . . . . . . . . . . . . . . . . . 29

A. Regular Calibration Reports . . . . . . . . . . . . . . 29

B. MAP (Measurement Assurance Program) Reports ............. 29

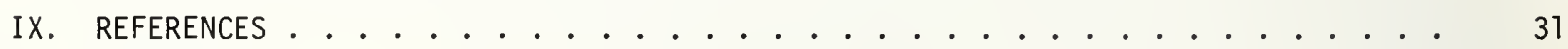

$X$. APPENDICES

A. Computer Program /SL/ for Electrical Calibration Factor . . . . . . 32

B. Beamsplitter Ratio and D-Factor Derivation . . . . . . . . . 38 .

C. Computer Program, /ST2C/ for Beamsplitter Ratio............ 41

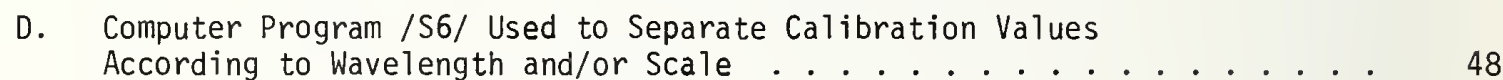

E. Computer Program, /RU/, a RUNSUM Program to Detect Trends $\quad$ in ..... 53

F. Computer Program, /PL/, a Plotting Routine for a Single

G. Computer Program /ASTM/, an ASTM Program to Provide 2 Control Charts. . . 63

H. Computer Program, /D2/, a Statistical Program to Provide Average,
$\quad$ Standard Deviation 90\%, 95\%, and 99\% Confidence Interval Data . . . 71

I. Computer Program, /S7B/, Used to Separate Beamsplitter

Ratios for Different Code Numbers . . . . . . . . . . . . 76

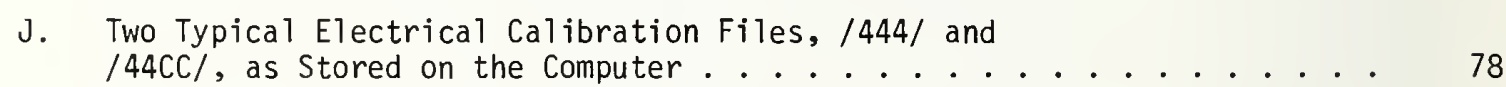

K. Computer File, /YT/, a Typical Beamsplitter File

L. Table L Defines Code Numbers for Different Beamsplitter Configurations. . 86

M. Computer File, /CMAT/, Contains All Required C-series Parameters . . . 88 
This report is a detailed procedure of how to set up and operate a Measurement Assurance Program (MAP) for a laser power and energy calibration facility. Items such as traceability, methods of self-checking measurement consistency, computer documentation and statistical analysis are discussed.

Key words: Calorimetry; laser beamsplitter system; laser calibration system; laser measurements; laser power. calibration. 

QUALITY ASSURANCE PROGRAM FOR THE NBS

$C, K$ AND Q LASER CALIBRATION SYSTEMS

William E. Case

\section{INTRODUCTION}

This report contains information pertaining to several quality assurance programs used by NBS to provide statistical control of the NBS C, K and Q Laser Calibrating Systems. Duplicates of these systems were delivered previously to the Aerospace Guidance and Metrology Center (AGMC) by the Optical Electronic Metrology Group at the National Bureau of Standards in Boulder, Colorado.

Information, previously supplied by NBS, dealt on an individual basis with the use, calibration and maintenance of the $\mathrm{C}$ - and $\mathrm{K}$-Series calorimeters. In contrast, this report emphasizes the use of the two-calorimeter/beamsplitter configuration with a system's approach for producing precisely known laser beams for calibrating purposes.

The report is organized into eight sections, which are briefly described here. Section I discusses some of the purposes and needs of $C, K$ and $Q$ laser calibrating systems. Sections II, III, IV and $V$ are concerned with the internal calibration and quality assurance performance of the systems themselves. Sections VI, VII and VIII are concerned with the calibration and statistical performance of transfer instruments assigned to $C, K$ and $Q$ systems.

One purpose of the $C, K$ and $Q$ calibrating systems is to provide accurately known laser beams for determining the calibration coefficients of a number of transfer standards at several power and energy levels at several discrete laser wavelengths.

A second purpose of the systems is to provide data for determining accuracy or uncertainty values for each and every calibrated beam run that is delivered by the three systems. The above two purposes are best served by using the two-calorimeter/beamsplitter configuration, rather than the direct substitution method. Some advantages of this configuration are:

A. To provide calibrated beams over a greater range,

B. Less stringent requirements on laser-power stability,

C. Beamsplitter runs allow self-consistency checks of the whole system. The beamsplitter ratio of a good quality beamsplitter remains very stable at a given wavelength, over a long period of time,

D. Both calorimeters can be treated equally as reference standards and provide a check against each other, and

E. Simplifies preparation of uncertainty statements by using statistics of the whole system rather than piece-meal statistics on individual components. 
Proper use of the calibrating systems is important as the certified reports with calibration values and statements of total uncertainty are based on the integrity of the calibrating systems. A complete check of a system's uncertainty involves a set of 20 to 30 measurements that are too time-consuming to do more often than once or twice a year.

While the $C, K$ and $Q$ Series calorimeters have demonstrated good instrument stability and retain their electrical and laser calibration values for long periods of time, a need still exists for a quick, simple, day-to-day check and for a slightly more comprehensive monthly test to ensure system integrity. Some examples of what can happen are as follows: (1) 0ccasionally a calorimeter temperature-control amplifier malfunctions and needs to be replaced.

(2) A calorimeter window may get slightly dirty due to the vacuum system or some other source and needs to be cleaned. (3) A fingerprint on the beamsplitter will give an inaccurate ratio and require cleaning. (4) Reversing the direction a laser beam passes through a sapphire beamsplitter may give a different beamsplitter ratio. (5) The calorimeter absorbing surface may be damaged by laser beams with excessive power density and change the calibration of the cururimeter.

Section II deals with electrical traceability to U.S. National Electrical and Time Standards. Since the laser calorimeter measurements are considered to be absolute, rather than relative measurements of energy, it is necessary to establish traceability to fundamental national standards. The electrical measurements concern standard cells, potentiometers, digital voltmeters, standard resistors and time-interval counters.

Section III contains several short- and long-term quality control plans varying from day-to-day operation to yearly calorimeter interchange evaluations. Some advantages of a NBS Measurements Assurance Program (MAP) with AGMC are discussed, which would result in a time-saving, independent appraisal of the AGMC system.

Section IV describes the Blue Book procedure used by NBS to evaluate the calibrated beam uncertainty at the $99 \%$ confidence interval for each system and laser wavelength. The Blue Book contains quantitative estimates of the error uncertainty for the electrical calibration coefficients, absorbing values, window transmission values, electrical traceability, inequivalence, D-factors (disagreement between calorimeters), amplifier gains and beamsplitter ratios.

Computer documentation of the calibrating system in Section $V$ completes the system analysis from an internal viewpoint. Electrical calibration files for each calorimeter are kept on the computer in chronological order. Beamsplitter files are stored on the computer for each beamsplitter, and for each laser wavelength being provided by the system. Computer programs are available to quickly ascertain the status of a calorimeter or beamsplitter.

Using the $C, K$ and $Q$ systems for calibrating transfer standards is discussed in Section VI. Some desirable characteristics of a good transfer standard are presented. The chronology of both NBS conventional and MAP-type calibrations are described.

Some guidelines used by NBS concerning documentation and quality assurance of laser transfer standards is discussed in detail in Section VII. Measurements at only discrete power and energy levels is emphasized to more effectively utilize the efforts of a limited staff. 
Section VIII describes the procedure used to produce regular calibration reports and MAP intercomparison reports. The total uncertainty of a report is the sum of the system uncertainty plus the imprecision of the measurements made on the transfer instrument.

\section{UNITED STATES (U.S.) NATIONAL STANDARDS}

A. Electrical Traceability

Calorimeters are the key elements of our calibrating systems. They have had a stable history, they allow reasonable error analysis, and their special design allows easy documentation of traceability to electrical standards. References 1, 2, and 3 report on earlier work, using calorimeters for the measurement of laser power and energy. The calorimeters provide the link for relating laser power or energy to electrical and time standards. Traceability to electrical standards is established by means of electrical calibration runs. The calorimeters and electrical calibrating power supplies are constructed so that two digital voltmeters, a standard resistor and a time-interval counter are required to make an electrical calibrating run. A special plug-in arrangement allows removal and individual calibration of every standard resistor, digital voltmeter, and time-interval counter that is used in the electrical calibration of the $C, K$ and $Q$ systems.

\section{B. Standard Resistors}

Documented traceability is easy to obtain for standard resistors. For instance, a certified NBS calibration is available by sending the resistors to NBS, Washington, D.C. However, standard resistors could be sent or obtained from any laboratory that has documented traceability to national standards. Some advantages of standard resistors are:

1. Stable to a few parts-per-miliion, depending on the ambient temperature,

2. Wide range of values available $(0.001$ to $10,000 \Omega)$ in decade steps,

3. Do not require a constant-temperature $0 i 1$ bath when operated under ordinary room conditions, if 10 to 20 parts-per-million variation is tolerable,

4. Long life (many years),

5. Re-calibration is not difficult because resistors are small, rugged and easily shipped,

6. Re-calibration is only necessary every few years, depending on stability required, and

7. Very useful because of four-terminal design.

At present, NBS uses approximately 20 standard resistors in the $C, K$ and $Q$ traceability programs. 


\section{Standard Cell - Potentiometer Calibration Setup}

Traceability of digital voltmeters to national electrical standards is provided by using a standard ce17/potentiometer combination. Certified NBS calibrations, to provide documented traceability, are available for both standard cells and potentiometers by sending the items to NBS, Washington, D.C. Such items could be sent to any laboratory that has traceability to national standards. Some advantages of standard cells are:

1. They give an accurate voltage reference value to within \pm 0.005 percent,

2. They give a voltage of convenient magnitude ( $1.019 \mathrm{~V})$,

3. Because of low temperature coefficient, they do not require a constant-temperature bath to maintain the output voltage to within 0.005 percent at normal laboratory temperatures,

4. The output voltage normally decreases on $7 y 20$ to $40 \mu \mathrm{V}$ per year,

5. Under normal temperature conditions $\left(23^{\circ} \mathrm{C}\right.$ ), their practical 1 ife is 12 to 18 years, (if they are not abused),

6. They only require re-calibration every one to two years depending on required stability, and

7. Their re-calibration is easier because a cell is small and is easily shipped.

At present, NBS uses three standard cells in the $C, K$ and $Q$ traceability programs.

Some features of a good standard potentiometer, such as the one used by NBS are:

1. The instrument has a high degree of accuracy $(0.007$ percent),

2. The instrument is very stable because it is passive and is based on only the ratio of resistances,

3. The instrument has its own temperature-controlled environment to improve accuracy, and

4. Re-calibration is necessary only every few years, depending on the stability required.

At present, the Optical Electronic Metrology Group uses a highly accurate, calibrated potentiometer with a recently calibrated standard cell to perform a check on the accuracy of a high-quality digital voltmeter, designated as the Standard Digital Voltmeter (DVM) for our Group. 


\section{Digital Voltmeter Test System}

The DVM test system checks the accuracy over a dynamic range $(-10 \mathrm{~V}$ to $+10 \mathrm{~V})$ of the digital voltmeters used in the data acquisition systems, against the Standard DVM that was discussed above. See reference 10 for details. The triangular wave output voltage from a function generator is sampled, simultaneously by the Standard DVM and one or two digital voltmeters being tested. The digital voltage to the Standard DVM is converted to ASCII code and punched out on Paper Tape No. 1 with the test system's own tape punch. At the same time, the above voltage is sampled by the digital test meters, converted to ASCII code, and punched out on Paper Tape No. 2, with the data acquisiton tape punch. The voltage level from the generator is set to vary from 0 to $\pm 10 \mathrm{~V}$, with a change rate of $0.002 \mathrm{~Hz}$. The changing voltage goes through a complete cycle during a data acquisition period of eight or nine minutes. Paper Tapes No. 1 and 2 are then run on a computer program to calculate an overall systematic error for each test DVM. If the error is greater than the established specifications, the test meter is re-calibrated according to the manufacturer's instructions. NBS uses approximately ten digital voltmeters in the data acquisition systems.

\section{E. Time-Interval Counters}

The electrical calibration of calorimeters involves applying an accurately known amount of electrical power for a precise period of time to produce an amount of energy that can be accurately determined. Time-interval counters provide an accurate means of measuring the time periods since these counters are readily available with crystal oscillator stabilities of better than one part-per-million. Some methods using either standard frequencies or time signals from Radio Station WWV, are used to furnish a check of the accuracy of the timeinterval counter and provide traceability to the National Standards of time. At present, NBS uses four time-interval counters for time period measurements.

\section{QUALITY ASSURANCE FOR C, K AND Q LASER CALIBRATION SYSTEMS}

\section{A. First-Time Operation of a System}

The procedure for the first-time use of a laser calibrating system involves an evaluation of electrical calibration coefficients for each calorimeter and amplifier scale being used. It is assumed at this point that the digital voltmeters, standard resistors and timeinterval counters have all been calibrated with traceability to the national standards. Section II discusses in detail the traceability procedures used by the Optical Electronic Metrology Group at NBS, Boulder.

A first-time format for the electrical calibration of two C-Series calorimeters, $\mathrm{Cl}$ and C2, can be seen in Table I. One can determine the calibration coefficient for each scale by taking a simple average or by doing a least-squares routine, assuming that the best straightline fit through a plot of the corrected rise values versus energy values goes through the origin. (See Appendix A for a discussion of computer program, /SL/.) The least-squares method has the advantage that the greater scatter of the lower-level readings does not unduly influence the calibration coefficient. 
TABLE I.

Run No.

1
2
$*$
$*$
$*$
6
7
$*$
$*$
$*$
*

12

13

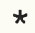

*

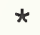

*

18

19

*

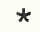

*

*

24

25

*
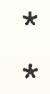

*

30

31

*
Calorimeter

C1

C1

*

*

C1

C1

*

*

*

C1

$\mathrm{Cl}$

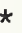

$\star$

*

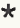

C1

C2

*

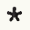

*

$\star$

C2

C2

$\star$

*

*

C2

C2

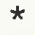

*

C2
Amplifier Scale

1E5

1E5

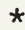

$\star$

*

1E5

$1 \mathrm{E} 4$

$\star$

$\star$

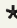

1E4

IE3

*

$\star$

*

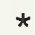

$1 E 3$

1E5
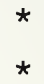

*

$\star$

1E5

IE4
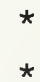

*

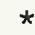

IE4

1E3

*

$\star$

1E3 
In addition to providing the calibration coefficient, the program, /SL/, also provides the uncertainty of the calibration coefficient using t-statistics at the 99 percent confidence interval for a given data set. For instance, the C-Series calorimeters use chopped-stabilized amplifiers with gains (scales) of 1,000, 10,000 and 100,000 to cover the energy range of the calorimeters. For each calorimeter, a question arises whether to have individual calibration coefficients for each scale or to combine two or more scale values for a combined calibration coefficient. The goal is to make the confidence interval as small as practical, either by making more measurements or by combining or separating data according to scale.

A question arises as to how ofter the electrical calibration runs should be made and how often the calibration coefficient should be updated. Generally, beamsplitter ratio measurements are used as the control parameter to verify that the calibration system is operating correctly. When beamsplitter ratios do not fall within the normal range of scatter, a problem exists. One test that is usually made, is to make an electrical calibration run on each calorimeter and compare the electrical calibration coefficient values with previous data. If a trend or shift is suspected, several additional electrical runs should be made. Using the electrical coefficients in computer program, RUNSUM, (see Appendix E) is helpful in deciding whether a trend really exists. Plotting the coefficients with computer program /PL/, (see Appendix F) is also very helpful in determing whether a trend exists and when the trend or shift occurred. Some judgment must be exercised in determining what old data should be discarded, if a shift has taken place. The electrical calibration coefficient would be updated if it is decided that a shift has taken place.

A calibration system should be checked out at least one a year at some operating wavelength using Plan 1 and 2 which includes a set of electrical calibration runs. The electrical calibrations, beamsplitter values and $D$ factors would be updated as a result of these measurements.

Each calorimeter uses an electrical heater made of manganin-wire for the electrical calibrations. The heater resistance can be considered to have the properties of a standard resistor because:

1. The electrical resistance of the manganin-wire is very stable at room temperatures due to its very low-temperature coefficient,

2. The calorimeter is temperature-controlled and the heater resistance operates in an environment of nearly a constant temperature, and

3. The heater was constructed as a four-terminal network to permit very accurate readings of voltage and current and the calculation of the effective heater resistance.

A plot of resistance versus time, (see /44CC/ in Appendix J, for example) for each calorimeter heater is a check of heater leakage to ground and of the DVM's used to measure the voltage and current. The percent difference of the worst case from the average value is used in the summary of errors pertaining to traceability. See Section IV for further details. 


\section{B. First-Time Operation of a System at a New Wavelength}

The initial use of a new wavelength involves checking several parameters for wavelength dependence. This is accomplished by using either Quality Assurance Plan 1 or Plan 2 as described in Part D.

1. Calorimeter Absorption: Values of absorption have been determined by earlier measurements on the $C, K$ and $Q$ type calorimeter. Some of the results of these measurements are discussed in references 3, 4, 5, 6, and 7. For instance, the values of absorption for the C-Series calorimeters are independent of wavelength from 0.4 to $1.064 \mu \mathrm{m}$.

2. Beamsplitter Ratios: $A 11$ the beamsplitter ratios used in the $C, K$ and $Q$ systems are wavelength-dependent. Beamsplitters are discussed in some detail in References 3, 4, 7,8 , and 9 . Both of the following plans, 1 and 2, are designed to determine the correct beamsplitter ratio to use for each wavelength being provided.

3. Calorimeter Windows: A11 windows used in the C-Series system are wavelength-dependent. A choice is available between Plan 1 or 2, depending on whether window transmission measurements are to be made with the calibrating system or were made before, by independent means. Proceed to Part D.

\section{Re-Evaluation of a System at an 01d Wavelength}

Either Plan 1 or 2 can be used for a periodic or special re-evaluation of a system at a previously used wavelength depending on whether the window transmission measurements were made independently or not.

\section{Quality Assurance Plans 1 and 2}

EL runs are defined as electrical calibration runs, where electrical energy is furnished to the calorimeter for determining the electrical calibration coefficient.

BS runs are defined as beamsplitter runs, where laser energy is furnished to both calorimeters via the beamsplitter to measure the beamsplitter ratio. Plans 1 and 2 assume that the electrical calibration measurements, as described in Section III.A. were completed sometime in the past and that the electrical calibration runs shown in Plan 1 and 2 are only to confirm the status quo. If the electrical measurements were recently completed, then the EL runs in Plan 1 and 2 could be deleted. Figure 1 in Appendix B shows the experimental arrangement for the beamsplitter and the low and high level calorimeter positions. The number of beamsplitter runs with $\mathrm{C} 1$ in the low level position and $\mathrm{C} 2$ in the high level position equals the number of beamsplitter runs with $\mathrm{C} 2$ in the low level position and $\mathrm{C} 1$ in the high level position. 
Plan 1, the preferred plan, is either for those calorimeters that do not use windows at all, or those calorimeters that use windows, but where the window transmission values were measured independently. For instance, the window transmission measurements for six NBS, C-Series windows, were made by the the Optical Physics Division, NBS/Washington, D.C., from 400 to $1100 \mathrm{~nm}$ in $20 \mathrm{~nm}$ steps. Linear interpolation of these data provides the values of transmission for the laser wavelengths of interest. Plan 1 for a two-calorimeter/beamsplitter system is illustrated in Table II.

$\underline{P l a n} 2$

Plan 2 is for those calorimeters that use windows and where the window transmission values are to be measured at this time with the calibrating system. The plan is for a twocalorimeter/beamsplitter system. Each calorimeter has two windows assigned to it. The onwindow is presently mounted in the calorimeter and the off-window is presently not mounted in the calorimeter and is the window being measured in the high-level beam. Calorimeter $\mathrm{C} 1$ has on-window $7 \mathrm{~A}$, and off-window $1 \mathrm{~B}$. Calorimeter $\mathrm{C} 2$ has on-window $2 \mathrm{~A}$, and off-window 2B. Plan 2 is shown in Table III.

\section{$\underline{\text { Result }}$}

The main purpose of $\mathrm{Plan} 1$ and 2 is to evaluate the correct beamsplitter ratio to use when producing an accurately known laser beam for calibration work. An average can be taken of all the beamsplitter ratios when calorimeter $\mathrm{Cl}$ is low, and calorimeter $\mathrm{C} 2$ is high. Another average can be taken of all the beamsplitter ratios when $\mathrm{C} 2$ is $10 \mathrm{w}$ and $\mathrm{Cl}$ is high. $\mathrm{A}$ derivation in Appendix $B$ shows that the geometric mean of the two averages gives the correct beamsplitter ratio to use in future calculations.

Another purpose of Plan 1 or 2 is that if we have determined the correct values for electrical calibration, absorption, window transmission, etc., for both calorimeters, then the derivation in Appendix $B$ will also give the best estimate of the disagreement between the two calorimeters. Since there is no reason to believe that one calorimeter is more accurate than another, the calorimeters are treated on an equal basis. A correction factor or D-factor for each calorimeter is determined by dividing the percent disagreement in half and adding this correction to the low-reading calorimeter and subtracting this correction from the high-reading calorimeter. When the beamsplitter data of Plan 1 or 2 is used with computer program, /ST2/, the program will calculate the absolute beamsplitter ratio and D-factor for each calorimeter as well as the 99 percent confidence intervals for the beamsplitter ratio and D-factors. See Appendix C for computer program /ST2C/.

\section{E. Day-to-Day Check}

The NBS C, K and Q Ca? icrating systems are mainly used to calibrate transfer standards that are used in the NBS MAP Programs. Measurements are done periodically on the transfer instruments to accumulate a calibration history. Measurements are taken on transfer instruments before they are shipped to MAP customers and after the instruments are returned to 
TABLE II

\begin{tabular}{|c|c|c|c|c|c|}
\hline \multirow{3}{*}{ Run No. } & \multicolumn{5}{|c|}{ Plan 1} \\
\hline & Type of & Low Lev & e] & High Leve & \\
\hline & & & Scale & & Scale \\
\hline 1 & EL & $\mathrm{C} 1$ & low & -- & -- \\
\hline 2 & EL & $\mathrm{Cl}$ & medium & -- & -- \\
\hline 3 & BS & $\mathrm{Cl}$ & $"$ & $\mathrm{C} 2$ & high \\
\hline 4 & BS & $\mathrm{Cl}$ & $"$ & C2 & $"$ \\
\hline 5 & BS & $\mathrm{Cl}$ & $"$ & C2 & $"$ \\
\hline 6 & EL & -- & -- & C2 & $"$ \\
\hline 7 & EL & C2 & low & -- & -- \\
\hline 8 & EL & C2 & medium & -- & -- \\
\hline 9 & BS & $\mathrm{C} 2$ & $"$ & $\mathrm{Cl}$ & high \\
\hline 10 & BS & $\mathrm{C} 2$ & $"$ & $\mathrm{Cl}$ & $"$ \\
\hline 11 & BS & $\mathrm{C} 2$ & $"$ & $\mathrm{C} 1$ & $"$ \\
\hline 12 & EL & -- & -- & $\mathrm{Cl}$ & $"$ \\
\hline 13 & EL & $\mathrm{Cl}$ & low & -- & -- \\
\hline 14 & EL & $\mathrm{Cl}$ & medium & -- & -- \\
\hline 15 & BS & $\mathrm{Cl}$ & $"$ & $\mathrm{C2}$ & high \\
\hline 16 & BS & $\mathrm{Cl}$ & $"$ & C2 & $"$ \\
\hline 17 & BS & $\mathrm{C} 1$ & $"$ & $\mathrm{C} 2$ & $"$ \\
\hline 18 & EL & -- & -- & $\mathrm{C2}$ & $"$ \\
\hline 19 & EL & C2 & low & -- & -- \\
\hline 20 & EL & C2 & medium & -- & -- \\
\hline 21 & BS & $\mathrm{C} 2$ & $"$ & $\mathrm{Cl}$ & high \\
\hline 22 & BS & $\mathrm{C} 2$ & $"$ & $\mathrm{Cl}$ & $"$ \\
\hline 23 & BS & $\mathrm{C2}$ & $"$ & $\mathrm{Cl}$ & $"$ \\
\hline 24 & EL & -- & -- & $\mathrm{Cl}$ & $"$ \\
\hline
\end{tabular}


TABLE III

Plan 2

Type of Low Level High Level Off-Window Run No. Run Calorimeter Scale Calorimeter Scale In Beam

\begin{tabular}{|c|c|c|c|c|c|c|}
\hline 1 & $\mathrm{EL}$ & $\mathrm{Cl}$ & low & -- & -- & -- \\
\hline 2 & EL & $\mathrm{Cl}$ & medium & -- & -- & -- \\
\hline 3 & BS & $\mathrm{Cl}$ - & $"$ & $\mathrm{C} 2$ & high & none \\
\hline 4 & BS & $\mathrm{Cl}$ & $"$ & $\mathrm{C} 2$ & $"$ & $1 \mathrm{~B}$ \\
\hline 5 & BS & $\mathrm{Cl}$ & $"$ & $\mathrm{C} 2$ & $"$ & none \\
\hline 6 & BS & $\mathrm{Cl}$ & $"$ & $\mathrm{C} 2$ & $"$ & $1 \mathrm{~B}$ \\
\hline 7 & BS & $\mathrm{Cl}$ & $"$ & $\mathrm{C} 2$ & $"$ & none \\
\hline 8 & BS & $\mathrm{Cl}$ & $"$ & $\mathrm{C} 2$ & $"$ & $1 \mathrm{~B}$ \\
\hline 9 & EL & -- & -- & $\mathrm{C} 2$ & $"$ & -- \\
\hline 10 & EL & $\mathrm{C} 2$ & low & -- & -- & -- \\
\hline 11 & $E L$ & C2 & medium & -- & -- & - \\
\hline 12 & BS & C2 & $"$ & $\mathrm{Cl}$ & high & none \\
\hline 13 & BS & C2 & $"$ & $\mathrm{Cl}$ & $"$ & $2 B$ \\
\hline 14 & BS & C2 & $"$ & $\mathrm{Cl}$ & $"$ & none \\
\hline 15 & BS & C2 & $"$ & $\mathrm{Cl}$ & $"$ & $2 B$ \\
\hline 16 & BS & C2 & $"$ & $\mathrm{Cl}$ & $"$ & none \\
\hline 17 & BS & $\mathrm{C} 2$ & $"$ & $\mathrm{Cl}$ & $"$ & $2 B$ \\
\hline 18 & $E L$ & -- & -- & $\mathrm{Cl}$ & $"$ & -- \\
\hline 19 & EL & $\mathrm{Cl}$ & low & -- & -- & -- \\
\hline 20 & $E L$ & $\mathrm{Cl}$ & medium & -- & -- & -- \\
\hline 21 & BS & $\mathrm{Cl}$ & $"$ & $\mathrm{C} 2$ & high & none \\
\hline 22 & BS & $\mathrm{Cl}$ & $"$ & $\mathrm{C} 2$ & $"$ & $1 \mathrm{~B}$ \\
\hline 23 & BS & $\mathrm{Cl}$ & $"$ & $\mathrm{C} 2$ & $"$ & none \\
\hline 24 & BS & $\mathrm{Cl}$ & $"$ & $\mathrm{C} 2$ & $"$ & $1 \mathrm{~B}$ \\
\hline 25 & BS & $\mathrm{Cl}$ & " & $\mathrm{C2}$ & $"$ & none \\
\hline 26 & BS & $\mathrm{Cl}$ & $"$ & $\mathrm{C} 2$ & $"$ & $1 \mathrm{~B}$ \\
\hline 27 & EL & -- & -- & $\mathrm{C} 2$ & $"$ & -- \\
\hline 28 & $E L$ & C2 & low & -- & -- & -- \\
\hline 29 & $E L$ & $C^{2}$ & medium & -- & -- & -- \\
\hline 30 & BS & $\mathrm{C2}$ & $"$ & $\mathrm{Cl}$ & high & none \\
\hline 31 & BS & $\mathrm{C} 2$ & medium & $\mathrm{Cl}$ & high & $2 B$ \\
\hline 32 & BS & $\mathrm{C} 2$ & $"$ & $\mathrm{Cl}$ & $"$ & none \\
\hline 33 & BS & $\mathrm{C} 2$ & $"$ & $\mathrm{Cl}$ & $"$ & $2 B$ \\
\hline 34 & BS & $\mathrm{C} 2$ & " & $\mathrm{Cl}$ & $"$ & none \\
\hline 35 & BS & $\mathrm{C} 2$ & $" 1$ & $\mathrm{Cl}$ & $"$ & $2 B$ \\
\hline 36 & $E L$ & -- & -- & $\mathrm{Cl}$ & $"$ & -- \\
\hline
\end{tabular}


ensure a stable instrument during the MAP intercomparison. A plot of calibration values versus chronological order for each transfer instrument provides a quick check of instrument stability and the calibration system validity. For instance, if the calibration values for several instruments 911 changed in the same direction at the same time, one should suspect trouble.

Day-to-day checks are easier to accomplish if all calibration runs are stored in chronological order in the computer file assigned to that instrument. Data is coded for different scales and wavelength for a particular instrument so the values can be separated for analysis. Several computer programs such as /S6/, /RU/, /PL/, /ASTM/ and /D2/, as shown in the Appendices $D$ through $H$, are available for separating, plotting and statistically analyzing the calibration factors for trends, shifts and excessive scatter.

\section{F. Monthly or Special Check}

Each month a beamsplitter run at each wavelength being maintained provides further proof that the system is performing properly. The ratio of an uncoated beamsplitter can provide a very stable parameter for control purposes. If anything happens to the beamsplitter. or electronics for either calorimeter, it is very likely to cause a change in the beamsplitter ratio. A beamsplitter run can be made anytime a special check of the system is desired. The results of the beamsplitter runs are appended in chronological order to the end of the computer file assigned to that beamsplitter. Computer Program, /S7B/, as shown in Appendix I, can be used to copy the old beamsplitter values to a single-column file so that the programs discussed above could be used to detect trends, shifts and excessive scatter. See Part A., First-Time Operation of a System, for a discussion of trends and shifts in beamsplitter and electrical calibration values.

\section{G. Annual Check}

At this point, we assume that a sufficient number of calorimeter interchanges have previously been done, as described in Section III.C., to establish the system capability at each wavelength that calibration service is being offered. Once established, a yearly interchange according to Part $C$ would be made at each of the wavelengths to verify the $D$-factor and beamsplitter ratio and re-evaluate the calibrated beam uncertainty. Electrical calibration runs would be made at the same time to verify the electrical calibration coefficient for each calorimeter.

\section{H. NBS/AGMC MAP}

A high precision MAP between NBS and AGMC would include a plan where the National Bureau of Standards would send several transfer standards to Aerospace Guidance and Metrology Center (AGMC) on a semi-annual basis for a MAP intercomparison. Some advantages of such a program would be:

1. To provide an independent check of the three AGMC systems, 
2. To provide AGMC with written documentation of the status of their measurement systems,

3. To detect and provide help in solving any measurement problems that may occur or exist, and

4. A time-saver for AGMC, by eliminating the need for so many yearly checks as discussed in Section $G$.

One possible yearly plan could be that the following number of intercomparisons would be accomplished at AGMC utilizing NBS transfer standards:

$\begin{array}{lrl}\text { 2-C-Series } & 1 \mu \mathrm{W}, & 0.6328 \mu \mathrm{m} \\ \text { 2-C-Series } & 1 \mathrm{~mW}, & 0.6328 \mu \mathrm{m} \\ \text { 2-C-Series } & 50 \mathrm{~mW}, & 0.6471 \mu \mathrm{m} \\ \text { 2-C-Series } & 500 \mathrm{~mW}, & 1.064 \mu \mathrm{m} \\ \text { 2-Q-Series } & 1 \text { to } 5 \mathrm{~J}, 1.064 \mu \mathrm{m} \\ \text { 2-K-Series } & 50 \mathrm{~W}, 10.6 \mu \mathrm{m}\end{array}$

Some other wavelengths that are maintained on the C-Series, and would be available to AGMC in a MAP Program, are $0.4880,0.5145$, and $0.5309 \mu \mathrm{m}$, in the 50 to $500 \mathrm{~mW}$ power level range.

\section{BLUE BOOK}

A Blue Book is a designated loose-leaf notebook which contains a detailed account of all the parameters needed by the computer to calculate the power and energy in the calibrated beam output of a system. These parameters include values of electrical calibration, absorption, window transmission and D-factors for each calorimeter. In addition, the Blue Book contains a detailed system analysis of errors in measuring the values of electrical calibration, absorption, window transmission, SI traceability, inequivalence, D-factor and beamsplitter ratio. A summary of the errors at the 99 percent confidence interval level can be stored and used by the computer to produce a statement of system uncertainty for each calibration run.

A Blue Book exists for each calibration system and consists of a set of tables (forms) for each laser wavelength being provided by the system. A complete set of forms is filled out each time Plan 1 or 2 in Section III-D, is completed, either for setting up a new wavelength or re-evaluating an old wavelength. For examples of these tables, see Figures 1 through 9 . 
TABLE A. ELECTRICAL CALIBRATIONS

Date

Wavelength

A summary of electrical calibration data from program /SLOPE/ for each series calorimeter and scale setting.

Calorimeter Scale Measurements $\begin{gathered}\text { Electrical } \\ \mathrm{K}\end{gathered}$ Interval in $\%^{99 \% \text { Confidence }} \begin{gathered}\text { For Period } \\ \text { From }\end{gathered}$

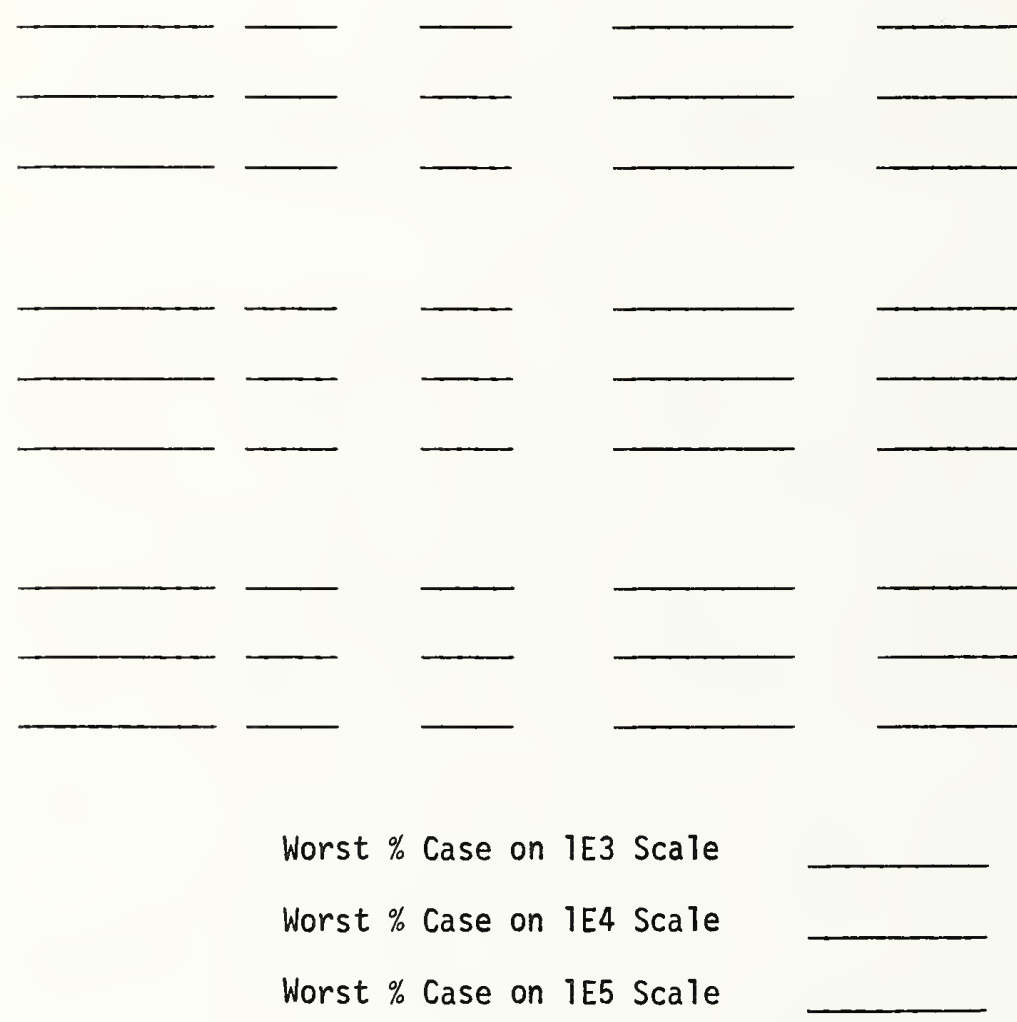

FIGURE 1. 
TABLE B. ABSORPTION

Date

Wave length

A summary of errors associated with calorimeter absorption from previous absorption measurements on calorimeters , and

Calorimeter

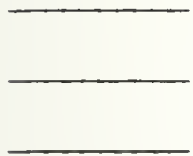

Absorption

$\%$ Error

FIGURE 2. 
TABLE C. INEQUIVALENCE

Date

Wavelength

Summary of the inaccuracy of the inequivalence between laser and electrical energy measurements, from previous measurements.

See

Calorimeter

$\%$ Inaccuracy

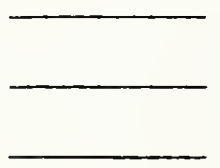

FIGURE 3. 
TABLE D. WINDOW TRANSMISSION

Date

Wavelength

The window transmission values at the $99 \%$ confidence interval level for the above wavelength, include the correction for the second transmitted beam.

Data Source

Data Source Date

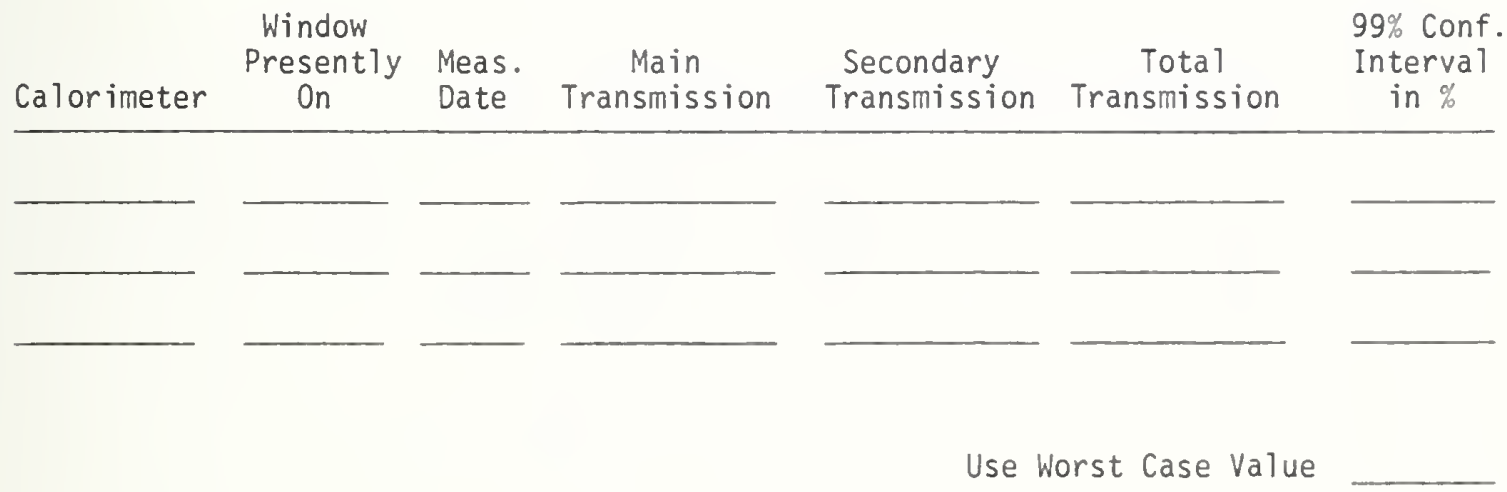

FIGURE 4. 
Date

Wavelength

Summary of errors pertaining to the traceability of our electrical measurements to the United States (U.S.) National Standards. See Section II for further discussion.

Source of Error

Time Interval Measurement

$\begin{array}{ll}\text { Standard Resistor } & \text { Calibration Report } \\ \text { Standard Cel1 } & \text { Calibration Report } \\ \text { Potentiometer } & \text { Calibration Report } \\ \text { Standard DVM } & \\ \text { DVM \#1 } & \\ \text { DVM \#2 } & \\ \text { Calorimeter Resistance } \\ \text { (Worst Case) }\end{array}$

Source of Information
\% Inaccuracy

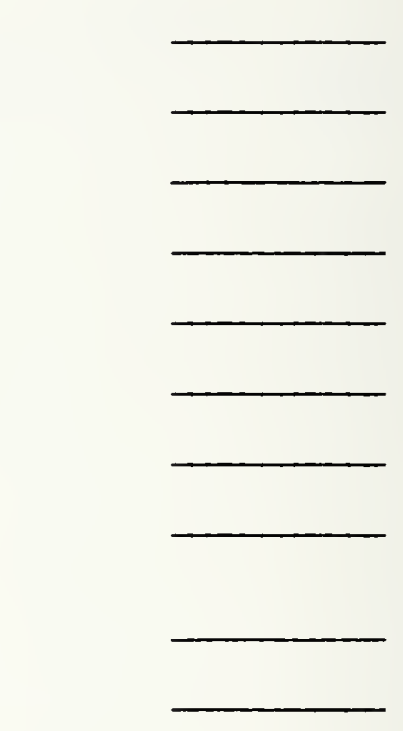

Tota 1

FIGURE 5. 
TABLE F. D-FACTOR

Date

Waverength

Summary of the absolute laser energy standard corrections (D-factors) for each series calorimeter. See Section III for further discussion.

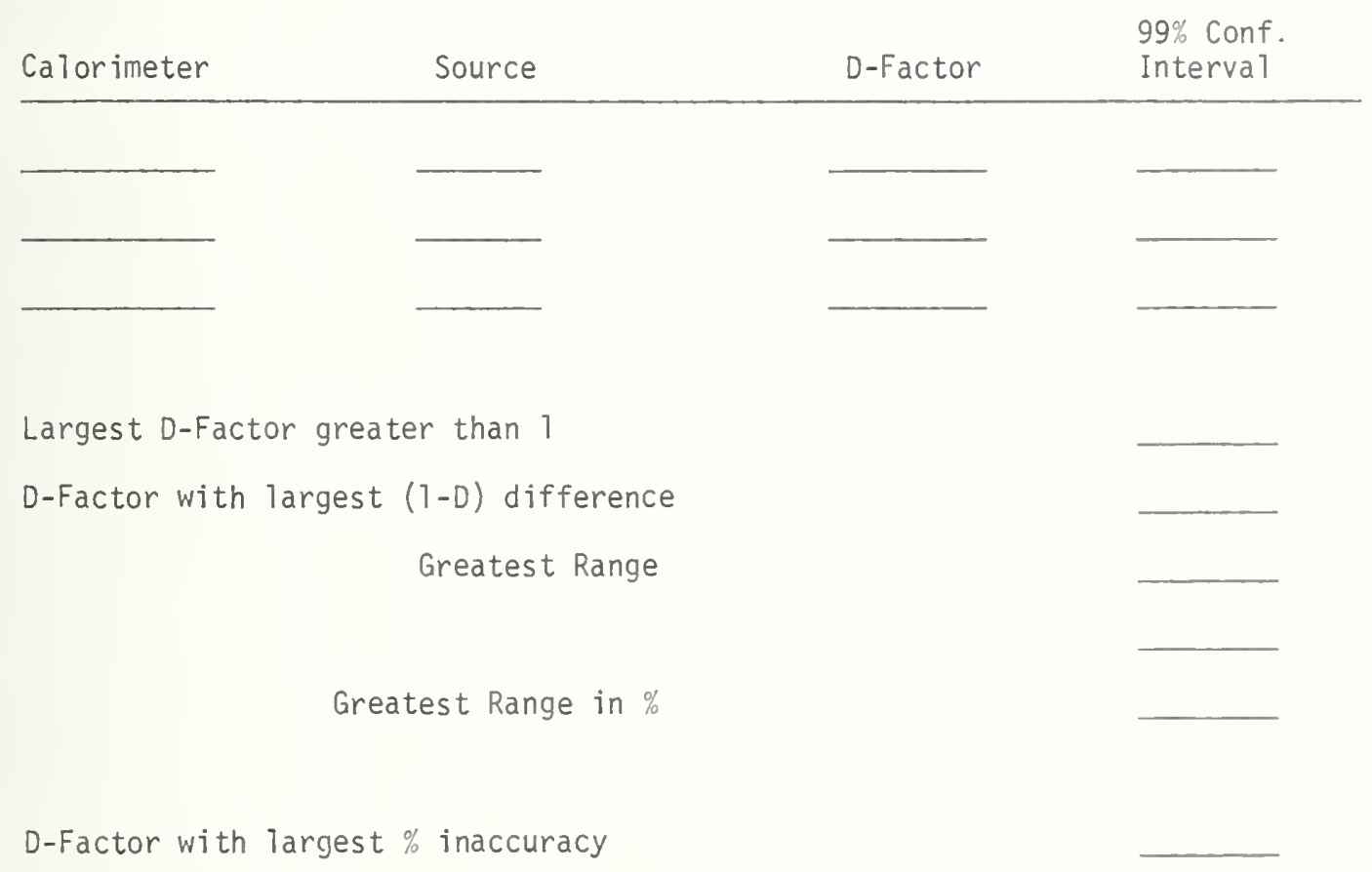

FIGURE 6 . 
TABLE G. SCALE ERRORS

Date

Wave length

Additional errors due to using different scales on the calorimeter amplifiers from Table A.

Largest Inaccuracy on 1E4 Scale

Largest Inaccuracy on 1E5 Scale

FIGURE 7. 
TABLE H. BEAMSPLITTER RATIO

Date

Wavelength

Use to obtain the absolute beamsplitter ratio and the associated $99 \%$ confidence interval in percent.

$\begin{array}{rccc}\text { Absolute } & 99 \% \text { Confidence } & \text { Estimated } & \\ \text { Beam Ratio } & \text { Interval } & \text { Error } & \text { Total } \\ & & \text { Errotion } & \text { Error }\end{array}$

FIGURE 8. 
TABLE I. SUMMARY OF ERRORS

Date

Wavelength

Summary of Errors

Percent at the $99 \%$ Confidence Interval

1E3

1E4

$1 E 5$

Table A Electricals

Worst Case for Scale

Table B Absorption

Table C Inequivalence

Table D Window Transmission

Table E Electrical Traceability

Table F D-Factors

Greatest Range in Percent

Greatest Percent Inaccuracy

Table G Amplifier Scale Error

Table H Beamsplitter Error

TOTAL PERCENT ERROR

FIGURE 9. 
A computer is required to calculate the corrected rise value which is directly proportional to the joule energy input to a calorimeter. Since the use of a computer is required for part of the calculation anyway, there is a strong incentive to expand the use of the computer for all the calculations.

A computer with an interactive terminal and permanent file storage can be very effective for storing calibration data and for providing immediate access by the computer for evaluating some of the Blue Book parameters. Separate permanent computer files should be created for the following categories.

A. Electrical Calibration Files

Electrical calibration runs for each calorimeter and, in some cases, for each scale. See Appendix J for samples of electrical calibration files.

B. Beamsplitter Files

Beamsplitter runs for each beamsplitter for each wavelength are maintained. See Appendix $K$ for samples of beamsplitter calibration files. Table L.1, as shown in Appendix L, can be used to supply code numbers which describe the different calorimeter/ beamsplitter configurations.

When an electrical or beamsplitter run is made, the calibration value and other pertinent information is appended to the end of the appropriate file. Code numbers are often used in individual files to identify and allow the separation of unique sets of data for plotting and statistical purposes. When a status report of a calorimeter or a beamsplitter at one of the laser wavelengths is desired, the computer can be used to query the file and print out information pertaining to data trends, shifts and scatter. For convenience, the deviation for each calibration value, in percent, from the average calibration value is usually plotted versus run number on an interactive terminal. Such a plot can then be used as a guide to determine whether the instrument is, or is not, in statistical control.

C. Blue Book Matrix Files

After assigning the Blue Book parameters, the values are stored in permanent matrix files which are then accessed by the computer for future calculations of power and energy in the calibrated beam. Blue Book values are kept in separate matrix files to allow for easier file updating. The size of the matrix varies with the calibrating system. A $4 \times 6$ matrix may be adequate for a two-calorimeter/beamsplitter system at one wavelength. On the other hand, a C-Series three-calorimeter/beamsplitter system at six different wavelengths may use a $4 \times 20$ matrix. Such a matrix is shown in Appendix $M$. In addition, a description of how the Blue Book parameters are represented by the matrix is shown in a run of computer program, /DOC/. A zero in the matrix means that this location is not being presently used. 
As can be seen, the matrix contains values of electrical calibration, absorption, beamsplitter ratios, window transmission, delivered beam uncertainty and beamsplitter code numbers. There is less chance of error in the calculations if the parameter values are supplied by such a computer file rather than being supplied directly by an operator.

\section{USING THE $C, K$ AND Q LASER CALIBRATING SYSTEMS}

The first five sections of this report were involved in getting the calibration systems in order, so they could be used for calibrating Laser Power and Energy Transfer Standards. Some subjects to consider when using the above calibrating systems are:

\section{A. Transfer Standards}

Some desirable characteristics of a good transfer standard are:

1. Short-term stability should be good. The calibration constant should at least remain stable to a few tenths of a percent for a six to twelve month period.

2. The instrument should have a small temperature coefficient, relative to responsivity, at normal room temperatures.

3. The output responsivity should be as uniform as possible over the surface of the detector.

4. The detector response should be relatively insensitive to wavelength.

5. The detector response should be linear. At the very least, the response should be linear on each scale.

6. The effects of detector saturation are very small at the power density level of operation.

7. The detector response time is fast relative to the experiment time.

8. The instrument's response is relatively insensitive to environmental effects such as humidity, pressure, line voltage, temperature, etc.

9. A self-contained digital readout is desirable for ease in reading and for saving time in establishing calibration traceability.

10. The head and readout unit should be a convenient size for shipping.

11. The head and readout unit should be of rugged construction to prevent damage in shipping. 
12. When possible, use commercially-made transfer standards which can be purchased and used by the general public.

\section{B. Conventional Calibration}

The following chronology of a regular NBS calibration is an example of how a standards laboratory such as AGMC may conduct a conventional calibration.

1. As pre-arranged, the customer sends their laboratory transfer standard to NBS. The instrument may include a head unit with attached readout meter, or with only the head unit, in which case NBS furnishes the readout meter.

2. Before making any calibration runs, the status of the calibrating system at the appropriate wavelength must be ascertained. If recent measurements on other transfer standards at this wavelength indicate statistical control, we would assume a ready system status. For an alternative check, a beamsplitter run could be used to confirm a ready status. For a new wavelength, see Section III.B.

3. Assuming a ready status, a set of at least five calibrated beam runs is made where a known power or energy beam is supplied to the transfer standard. The calibration factor is equal to the net meter reading of the test instrument divided by the calibrated beam power or energy.

4. Statistics at the 99 percent confidence interval level for the average of the calibration runs is then obtained and compared with the transfer standard meter specifications or with previous data. If needed, additional runs mav be made to improve the precision of the measurements.

5. The transfer standard is sent back to the customer.

6. A signed calibration report is sent to the customer based on the NBS system beam uncertainty plus the 99 percent confidence interval level of the measurements taken in step 3.

7. The customer uses the transfer standard as he sees fit. Since conventional calibrations do not involve any customer measurements, there is little opportunity for an intercomparison of measurements to detect trends, shifts, excessive scatter or other problems relating to the customer's measurements. 


\section{Measurement Assurance Program (MAP)}

The following chronology of a typical NBS MAP Program is an example of how a standards laboratory such as AGMC may participate in a MAP Program with other standards laboratories.

1. Select state-of-the-art transfer instruments to be used as NBS transfer standards for the desired laser wavelengths and power or energy levels.

2. Using the appropriate NBS calibrating system, make at least ten runs at each wavelength and scale of interest, preferrably over a period of time (at least one month) to determine the average calibration coefficient.

3. Just before sending a NBS transfer standard to a MAP customer, make a calibration run, append the results to file, and use ASTM Control Chart Program /ASTM/ (see Appendix G) to verify that the transfer instrument is under statistical control.

4. Send transfer instrument to customer.

5. Customer then calibrates transfer instrument, using his own laboratory standards and techniques. NBS will respond to a customer's request for information pertaining to measurement format, precautions, etc.

6. Customer sends instrument back to NBS.

7. NBS makes another calibrating run on standard and appends these results to file.

8. NBS re-runs ASTM Control Chart Program to verify statistical control.

9. Customer sends company calibration data of individual runs to NBS.

10. NBS analyzes both customer and NBS data and, using program /D2/, produces a report of intercomparison with appropriate statistics and error statements.

11. NBS sends signed intercomparison report to customer.

12. If any problems exist and if the customer desires, NBS will provide consultation on measurement problems. 
A computer with permanent file storage and an interactive terminal can provide a very useful tool for data management with computer assistance. When a calibrated beam run is made on a particular transfer standard, the calibration value and other pertinent information is appended to the end of the permanent computer file created for this particular instrument. Some guidelines that have been used by NBS pertaining to laser transfer standards are:

\section{A. Format}

Arrange computer files so that the calibration data for each instrument, for each mode (power or energy), for each wavelength and for each meter scale can be identified, separated and treated statistically as an independent entity. This can be accomplished by having separate files for each instrument and when appropriate, separate files for power and energy measurement data for each instrument. Code numbers are used in the individual files to identify and separate sets of data according to wavelength and meter scale. A typical file is shown in Appendix D. Computer programs as described in Appendices D, E, F, G, H can be used to detect trends, shifts or excessive scatter for a specified set of data. Computer printouts in a neat, fixed and familiar format saves time in data analysis.

B. Discrete Power and Energy Levels

The power and energy levels used for calibration must be assessed by each individual Taboratory, such as AGMC, according to their needs and capabilities.

For example, the calibration runs for the NBS calibration and IMP Programs are usually made at discrete power and energy levels. The safety laws defining the four laser classifications, provide logical, discrete levels of nominal power at $1 \mathrm{~m}, 1 \mathrm{~mW}$ and $500 \mathrm{~mW}$.

The high interest in Q-Switched energy measurements at $1.064 \mathrm{~km}$ generates a need for calibration runs at the $0.1,1$ and $10 \mathrm{~J}$ level. Single-pulse measurements are usual1y made with the $0.1 \mathrm{~J}$ scale while multiple pulse runs require the higher scales.

A NBS MAP Program with AGIIC could be tailored to match the needs of AGMC with the capability of NBS.

C. Separate Calibration Coefficients for Each Scale and Wavelength

To more effectively utilize a limited staff, NBS only makes measurements at discrete power and energy levels as needed. No attempt is made to combine scales or wavelengths or to study linearity effects on a particular scale or between scales. Generally, we prefer to use a separate calibration value for each scale and wavelength.

D. Direct Calibrations

When possible, we calibrate the transfer standards directly with $C, K$ and $Q$ systems. This eliminates at least one step of calibration and generally improves the precision of our measurements. 
E. Using Mean or Average Calibration Coefficients

The simplest determination of the calibration coefficient for each scale is to take the mean or average of the individual calibration run values. A more complicated method is to use a least-squares fit of a straight line through a plot of meter readings versus energy or power levels, where the slope of the line equals the calibration coefficient. The 1east-squares method has the advantage that the greater scatter of the lower leve1 readings wi11 not unduly influence the calibration coefficient. However, this method has 1ittle advantage in calibrating our transfer standards where measurements on a particular scale are usually made at only one nominal power or energy level.

\section{F. Two-Sided 99 Percent Confidence Interval}

The NBS statistical analysis is based on the two-sided 99 percent confidence intervals of the average or least-squares calibration coefficient. The less conservative 95 percent interval would also be acceptable. Probably the most important thing is to state plainly what type of statistical analysis is being used. The equation for the 99 percent confidence interval, e, in percent for the calibration coefficient, $K$, is

$$
e(\%)= \pm \frac{100 \times t \times s}{k \times \sqrt{n}}
$$

where

$n$ is the number of measurements,

$K$ is the average calibration coefficient,

$s$ is the standard deviation of $n$ measurements, and

$t$ is the $t$-value from the table for Percentiles of the $t$ Distribution (see EXPERIMENTAL STATISTICS, NBS Handbook 91) for $t .975$ for $n-1$ degrees of freedom.

It is desirable to make e as smal1 as reasonable, either by making more measurements, $n$, or by combining data in such a way as to make $s / \sqrt{n}$ smaller. Of course, better instruments with better measuring techniques may give a smaller $s$ in the first place. The above equation appears in computer program, /D2/, which is described in Appendix $H$. The above program will take any set of numbers (up to 150 values), calculate the mean, standard deviation and the 90,95 and 99 percent confidence interval for the mean in percent.

\section{G. Status Categories}

The status of a transfer standard at any given wavelength and scale will fall into one of several categories.

1. Insufficient data status. Insufficient number of calibration runs at this wavelength and scale. Desirable to have at least ten runs for each data set. 
2. Inactive status. Sufficient number of calibration runs, but last run was taken over one year ago. This category may include old instruments, or wavelengths, no longer being maintained for the NBS calibration program.

3. Active status. This category includes the instruments at discrete wavelengths presently being used and maintained for our active calibration program. Generally, the last calibration run was made in the last three months. Measurements may be made periodically to maintain an active status.

4. Ready status. An instrument that, in the last few days, received a calibrating run, whose calibration value falls within the control chart limits of that instrument is considered to be in a ready status for that wavelength and scale. The instrument is ready to participate in a MAP program.

5. Repair status. An instrument needs repairs and is currently not available for calibration service.

Considering the different wavelengths and meter scales, it is highly probable that each instrument will fall into several status categories at the same time.

\section{CALIBRATION AND MAP REPORTS}

Calibration reports are provided to the customer for regular calibrations and formal MAP intercomparisons.

A. Regular Calibration Reports

For a regular NBS calibration, the customer sends his own transfer standard to NBS for measurement. NBS makes a number of calibration runs, $N$, and determines the mean value of the calibration coefficient. In addition, the uncertainty, $A$, of the mean, for $\mathrm{N}$ measurements is calculated at the 99 percent confidence interval using t-statistics. The uncertainty, B, of the NBS calibration system at the 99 percent confidence interval was determined, previously, as discussed in sections II and III. The total uncertainty, $C$, for this calibration is the sum of $A$ and $B$. A typical calibration report will contain the nominal energy or power, the number of measurements, $N$, the average (mean) calibration coefficient, the uncertainty, $A$, of $N$ measurements, the NBS system uncertainty, B, and the total uncertainty, $C$, at the 99 percent confidence level. For convenience, the uncertainties, $A, B$ and $C$ are given in percent.

B. MAP (Measurement Assurance Program) Reports

For a NBS MAP intercomparison, NBS sends a we17-evaluated NBS transfer standard to the customer (MAP participant) where he makes a number of measurements, $N$, using his calibration system to determine the mean calibration coefficient. The customer then 
returns the transfer standard to NBS with his evaluation of the calibration coefficient. NBS makes another calibration run on the transfer standard, appends these results to the previous data, and then calculates the latest mean value of the calibration coefficient, using the total number of measurements. In addition, the uncertainty, $D$, of the mean is determined at the 99 percent confidence interval using t-statistics. The uncertainty, $B$, of the NBS calibration system at the 99 percent confidence interval was determined, previously, for each laser wavelength and scale as discussed in Sections II and III.

The total uncertainty, $C$, for this intercomparison is the sum of D and B. A typical MAP report will contain the designation of the NBS transfer standard, wavelength of intercomparison, nominal power or energy level, number of customer measurments, $N$, customer's reported value of calibration coefficient, NBS reported values of calibration coefficient, NBS total uncertainty, $C$, and percent difference between customer and NBS. 


\section{REFERENCES}

1. Jennings, C. A., West, E. D., Evenson, K. M., Rasmussen, A. L., and Simmons, W. R., NBS Tech. Note 382 (1969).

2. West, E. D. and Churney, K. L., Theory of isoperibol calorimetry for laser and power energy measurements, J. App 1. Phys., 41, 2705-2712 (May 1970).

3. West, E. D., Case, W. E., Rasmussen, A. L., and Schmidt, L. B., A reference calorimeter for laser energy measurements, J. Res. Nat. Bur. Stand. (U.S.), 76A (Phys. and Chem.), No. 1, 13 (Jan.-Feb. 1972).

4. West, E. D. and Case, W. E., Current status of NBS low-power laser energy measurement, IEEE Trans. Instrum. Meas. IM-23, 722 (December 1974).

5. West, E. D. and Schmidt, L. B., Spectral-absorptance measurements for laser calorimetry, J. Opt. Soc. Am., 65, 573-578 (May 1975).

6. Franzen, D. L. and Schmidt, L. B., Absolute reference calorimeter for measuring high power laser pulses, Applieo Optics 15, 3225 (December 1976).

7. West, E. D. and Schmidt, L. B., A system for calibrating laser power meters for the range 5-1000 $\mathrm{H}$, NBS Tech. Note 685 (May 1977).

8. Franzen, D. L., Precision beam splitters for $\mathrm{CO}_{2}$ laser, Applied Optics, 14, 647-652 (March 1975).

9. Danielson, B. L., Measurement procedures for the optical beam splitter attenuation device BA-1, NBSIR 77-858 (May 1977).

10. Miles, R. W. and Case, W. E., Verifying the accuracy of data acquisition system voltmeters, to be published as a NBSIR. 


\section{APPENDICES}

\section{APPENDIX A \\ Computer Program /SL/ for Electrical Calibration Factor}

Computer program /SL/ uses electrical calibration data to find the best straight-line fit through zero and a plot of corrected rise values versus corresponding energy values using a linear least-squares calculation. The program calculates the electrical calibration factor (reciprocal of slope of line), standard deviation of residuals and 99 percent confidence interval for the slope according to Experimental Statistics, by M.G. Natrella, NBS Handbook 91 , Paragraph 5-4.2.1. To do a least-squares fit, the program requires two columns of input data, where the first column is corrected rise values in microvolts and the second column is the corresponding values for energy in joules. A print-out is shown for input data File /444/, a computer run of /SL/, using File /444/ and a listing of Program /SL/. 
COPY /444/ TOO TEL

$\begin{array}{ll}198.743 & 0.967611 \\ 900.345 & 4.38715 \\ 88.4 .802 & 4.39903 \\ 1001.61 & 4.87603 \\ 623.318 & 3.19365 \\ 368.361 & 1.50149 \\ 383.745 & 1.86801 \\ 418.135 & 2.03697 \\ 832.416 & 4.05753 \\ 68.7373 & 1.335819 \\ 450.298 & 2.19321 \\ 130.44 & 0.637567 \\ 436.327 & 2.12373 \\ 190.161 & 0.925799 \\ 575.695 & 2.80253 \\ 147.137 & 0.720135 \\ 402.746 & 1.96238 \\ 541.485 & 2.63676 \\ 534.266 & 2.69097 \\ 659.583 & 3.21219 \\ 568.536 & 2.76487 \\ 569.731 & 2.77135 \\ 616.301 & 3.90386 \\ 869.624 & 4.23512 \\ 617.519 & 3.90434 \\ 870.9093 & 4.23512 \\ 617.9332 & 3.904265\end{array}$


BA

BASIC $-5.15 \quad 73-11-13$

$>$ LOAD /SL/

$>$ RUN

THIS IS 940 SLOPE PROGRAM. USES AN INPUT 2 COLUMN

ELECTRICAL DATA FILE TO FIND SLOPE, B, OF LINE, $Y=E X$, THRU ORIGIN, STD. DEV. OF RESIDUALS, AND $99 \%$ CONFIDENCE INTERVALS ON SLOPE ACCORDING TO

NA TRELLA 5-4.2.1

TYPE IN 2 COLUMN ELECTRICAL FILE IN / /? / 444/

NO. OF RUNS IN INPUT FILE = 27

MI CROVOLTS

198.743

900.345

884.802

1601.61

623.318

308.361

383.745

418.135

832.416

68.7373

450.298

130.44

436.327

190.161

575.605

147.137

402.746

541.485

534.266

659.583

568.536

569.731

616.301

869.624

617.519

870.003

617.9332
JOULES

.967611

4.38715

4.30903

4. 87603

3.03365

1. 50149

1. 86801

2. 93697

4.05753

.335819

2. 19321

. 637567

2.12373

.925799

2.8ด253

.720035

1. 96238

2.63676

2. 60097

3. 21219

2. 76487

2.77135

3. 90385

4.23512

3.00434

4.23512

3. 04265
THIS K (JOULES/MILLIVOLT)

4.268654

4.872743

4.87005

4.868192

4.866938

4.86926

4.867842

4.871561

4.874402

4.885542

4.870575

4.887818

4.86729

4.868501

4.868842

4.893637

4.8725

4. $\varepsilon: 69498$

4.868305

4. 870032

4.86314

4.864313

4.874014

4.870059

4.265178

4.267937

4.861796

SLOPE, $B=$

205.3703

ELECTRICAL K $=4.869254$

STANDARD DEVIATION OF SLDPE $=.2884916 E-91$

STANDARD DEVIATION OF RESIDUAL (Y'S) =

.4311138

DEGREES OF FREEDOM $=26$

T VALUE FOR ABOVE D.F. $=2.778818$

$99 \%$ CONF. INT. FOR SLOPE $=+$ OR - . 0801666

$99 \$$ CONFIDENCE INTERVAL IN $\%=.3903513 E-\emptyset 1$

RANGE FACTOR FOR ABOVE NO. OF MEASUREMENTS IS 3.828

99\% IMPRECISION IN JOULES IS . $1893574 \mathrm{E}-\emptyset 1$ 
10 PRINT" THIS IS 949 SLOPE PROGRAM. USES AN INPUT 2 COLUMN"

29 PRINI" ELECTRICAL DATA FILE TO FIVD SLOPE, B, OF LINE,"

30 PRINI"Y $=B X$, THRU ORIGIN, STD. DEV. OF RESIDUALS, AND 99\%"

40 PRINT"CONFIDENCE INTERVALS ON SLOPE ACCORDING TO"

50 FRINT" NATRELLA $5-4.2 .1 "$

50 DIM $K(2 \theta \theta), X(2 \theta \theta), Y(2 \theta \theta), Z(2 \theta \theta)$

7ด PRINI" TYPE IN 2 COLUMN ELECTRICAL FILE IN / /";

8 INPUTAS

90 OPENA\$, INPUI

100 FORI $=1$ TO2OO

110 INPUT FILE Y(I),X(I)

$129 \operatorname{IFEOF}(9)=1$ THENI\&ด

$140 \quad N=I$

150 NEXTI

160 PRINT" OVER 290 POINIS"

170 STOP

180 PRINT" NO. OF RUNS IN INPUT FILE =",N

190 IFN $>$ OIHEN22月

200 PRINI" NO DATA IN FILE ",A\$

216 STOP

$220 \quad A=\emptyset$

221 PRINT"MICROVOLTS JOULES THIS $K$ (JOULES/MILLIVOLT)"

222 FOR I $=1$ TON

223 PRINTY (I),X(I), $1000 * X$ (I) $/ Y(I)$

224 NEXII

225 PRIN I

$230 \quad E=\emptyset$

$240 \mathrm{C}=\emptyset$

250 FORI $=1$ TON

$260 A=A+X(I) * Y(I)$

$270 \quad E=E+X(I) * X(I)$

$280 \mathrm{C}=\mathrm{C}+\mathrm{Y}(\mathrm{I}) * Y(I)$

290 NEXT I

$300 B=A / E$

310 PRIN I" SLOPE, $B=", B$

$320 \quad B 1=1000 / B$

330 PRINT" ELECTRICAL $K="$, BI

335 PRIN T

340 IFN 21 IHEN 410

350 PRINT"ZERO DEGREES OF FREEDOM"

360 STOP

$41 \Omega W=(C-(A * A / E)) /(N-1)$

40 D $D=W / E$

$430 S=S Q R(D)$

432 PRINT"STANDARD DEVIATION OF SLOPE =", $S$

$434 W I=S Q R(W)$

436 PRINI"STANDARD DEVIATION OF RESIDUAL (Y'S) = ",Wl

$\triangle 49 V=N-1$

450 I FV $<1$ THEN 48 ด

$460 \mathrm{I}=63.657$

47DGOTO660

480 I FV $<22$ THEN 510

$496 \mathrm{~T}=9.925$

50ดGOT0660

51 I FV $<3$ THEN 546

$\operatorname{sen} \mathrm{T}=5.841$

532GOTO660

540 I $F V \Leftrightarrow \triangle$ THE 1470

$556 \mathrm{~T}=4.604$

560 GO TO 660

570 I FV $>5$ IHEN 600

$580 \mathrm{I}=4.032$ 


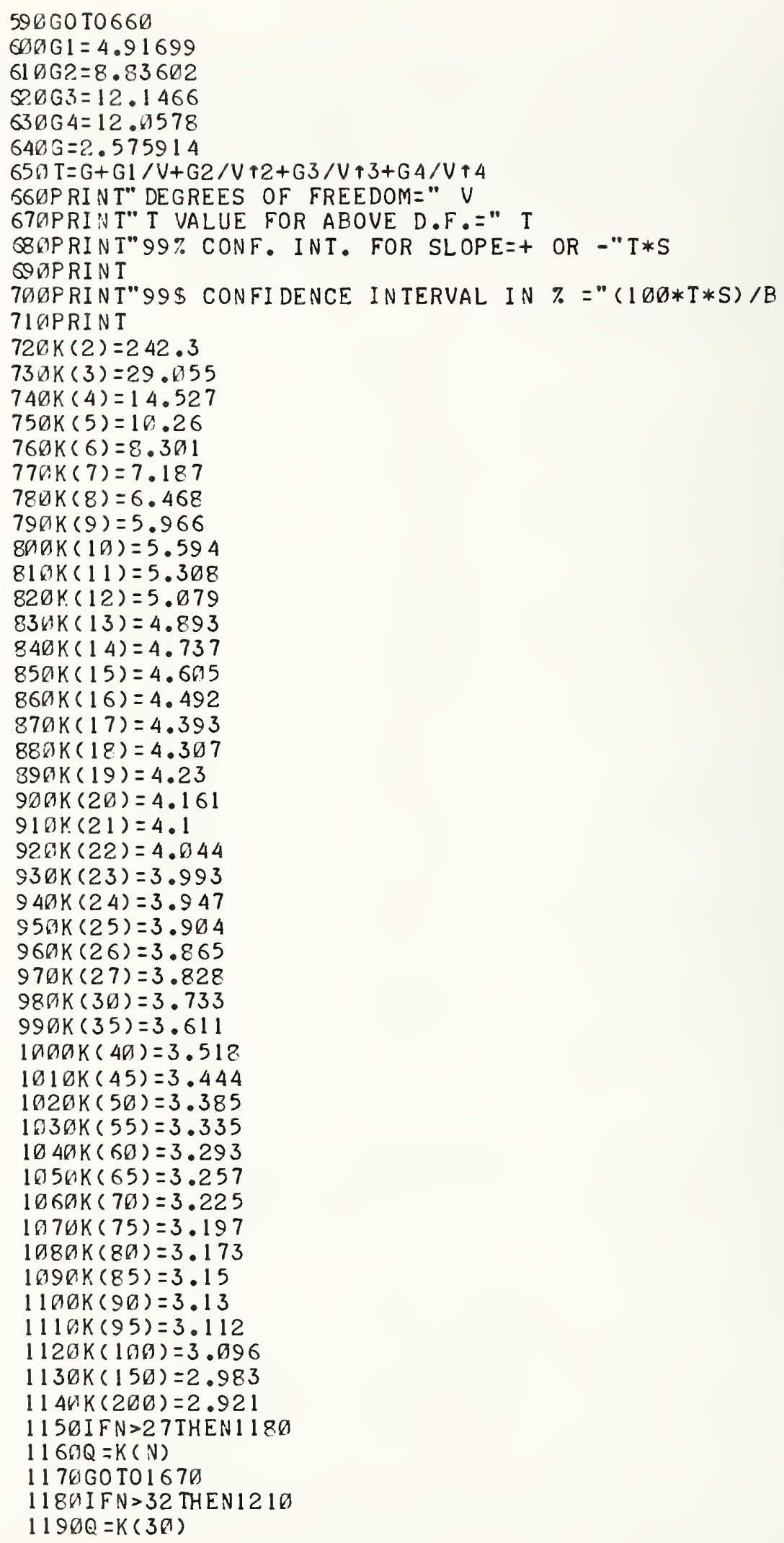


$1200 G 0 T 01670$

1210 IFN $>37$ THENI 240

$1220 Q=K(35)$

$12.30 \mathrm{GOTO} 1670$

124 I $F N>42$ THEN 1279

$12500=K\left(46^{1}\right)$

12.60GOTO167ด

1270 I FN > 47 THEN 1396

$12800=K(45)$

$1290 \mathrm{GOTO} 1670$

$13 B 0$ I FN $>52$ THEN 1336

$131 D Q=K(5(x))$

$1320 \mathrm{GOTO1670}$

1330 I FN > 57 THEN 1360

$1340 Q=K(55)$

$1350 G O T O 1670$

1360 I FN>62 THEN 1399

$1379 Q=K(60)$

1380GOTO1670

139 ดI $F N>67$ THEN 1420

$149 \oslash Q=K(65)$

141860 TO 1670

$142 D I F N>72$ THEN 1450

$1430 Q=K(70)$

$1440 G O T 01670$

1450 I FN > 77THEN $\mid 48$ I

$1468 Q=K(75)$

1470 GOTO1670

1480 I FN>82 THEN 1510

$1490 Q=K(80)$

$1590 \mathrm{GOTO} 1670$

151 AI FN>87 THEN 1540

$1520 Q=K(85)$

$1530 \mathrm{GOTO1} 670$

1540 I FN>92 THEN 1570

$1550 Q=K(90)$

1560 GOIO1670

1570 I FN $>97$ THEN 1600

$1580 Q=K(95)$

$1590 \mathrm{GOTO} 1670$

1690 I $F N>120$ THEN 1630

$1610 Q=K(190)$

$162.0 \mathrm{GOTO} 1670$

$16391 \mathrm{FN}>170$ THEN 1660

$1640 Q=K(150)$

$1650 \mathrm{GOTO1670}$

$1660 Q=K(200)$

$1670 \mathrm{GOTO} 1680$

168 GPRINT"RANGE FACTOR FOR ABOVE NO. OF MEASUREMENTS IS " $Q$ $1690 P R I N T$

$1692 P=S Q R(W) * Q / B$

169 4PRINT"99\% IMPRECISION IN JOULES IS "P

$17005 T O P$ 


\section{APPENDIX B}

Beamsplitter Ratio and D-Factor Derivation

A two-calorimeter beamsplitter configuration is shown in Fig. 1. In Experiment 1, Calorimeter 1 is in the low-level position and Calorimeter 2 is in the high-level position. In Experiment 2, the calorimeters are interchanged with Calorimeter 2 in the low-level position and Calorimeter 1 in the high-level position.

We assume for each beamsplitter run that the system is linear and stable over the energy range of the experiment. Let

$$
\mathrm{R} 12=\frac{\mathrm{U} 2}{\mathrm{U} 1},
$$

and

$$
R 21=\frac{U T^{\prime}}{U 2^{\top}}
$$

where

$$
\begin{aligned}
& \text { R12 -- beamsplitter ratio for Experiment } 1 . \\
& \text { R21 -- beamsplitter ratio for Experiment } 2 \text {. } \\
& \text { U1 -- energy to low-level calorimeter for Experiment } 1 . \\
& \text { U2 -- energy to high-level calorimeter for Experiment } 1 . \\
& U^{\prime} \text {-- energy to low-level calorimeter for Experiment } 2 . \\
& U 1^{\prime} \text {-- energy to high-level calorimeter for Experiment } 2 .
\end{aligned}
$$

Say we assume a small error, $\alpha$, between the two calorimeters, where a may be plus or minus. We also assume the two calorimeters perform equal1y we11, and we will split the error, $\alpha$, equally between them. For very smal1 $\alpha$, let the correction for Calorimeter 1 be $1+\alpha$, and the correction for Calorimeter 2 be $1-\alpha$ where we assume that for a very smal1 $\alpha$

$$
1+\alpha \simeq \frac{1}{1-\alpha}
$$

If we define the absolute beamsplitter ratio as $\mathrm{B9}$, Eq. (1) then becomes

$$
B 9=\frac{(1-\alpha) U 2}{(1+\alpha) U 1}
$$

and Eq. (2) becomes

$$
B 9=\frac{(1+\alpha) U 1^{1}}{(1-\alpha) U 2^{1}} .
$$

We have two unknowns, $B 9$ and $\alpha$. 
If we eliminate $\alpha$ by multiplying Eq. (4) by Eq. (5), the absolute beamsplitter ratio, B9, becomes

$$
\begin{gathered}
B 9^{2}=\frac{U 2(1-\alpha) U 1^{\prime}(1+\alpha)}{U 1(1+\alpha) U 2^{\prime}(1-\alpha)}, \\
B 9=\sqrt{\frac{U 2 U I^{1}}{U 1 U 2^{1}}} .
\end{gathered}
$$

As can be seen, we can find the ratio, B9, without evaluating the error $\alpha$. To find $\alpha$, we eliminate B9 by setting Eq. (4) equal to Eq. (5) to obtain

$$
\frac{U 2(1-\alpha)}{U 1(1+\alpha)}=\frac{U 1^{\prime}(1+\alpha)}{U 2^{\prime}(1-\alpha)}
$$

Substituting Eq. (3) in Eq. (8), we get

$$
\begin{aligned}
& \frac{U 2}{U 1(1+\alpha)^{2}}=\frac{U 1^{\prime}(1+\alpha)^{2}}{U 2^{\prime}}, \\
& (1+\alpha)^{2}=\sqrt{\frac{U 2 U 2^{\prime}}{U 11^{1}}} .
\end{aligned}
$$

Expanding $(1+\alpha)^{2}$ we obtain

$$
(1+\alpha)^{2}=1+2 \alpha+\alpha^{2}
$$

For small $\alpha$, we neglect $\alpha^{2}$ and Eq. (10) becomes

$$
\alpha=\frac{1}{2}\left(\sqrt{\frac{U 2 U 2^{\prime}}{U 1^{1} U 1}}-1\right) .
$$

As can be seen, $\alpha$ may be either plus or minus. In Program $/ \mathrm{ST2C} /$ we define $D=\alpha$. 


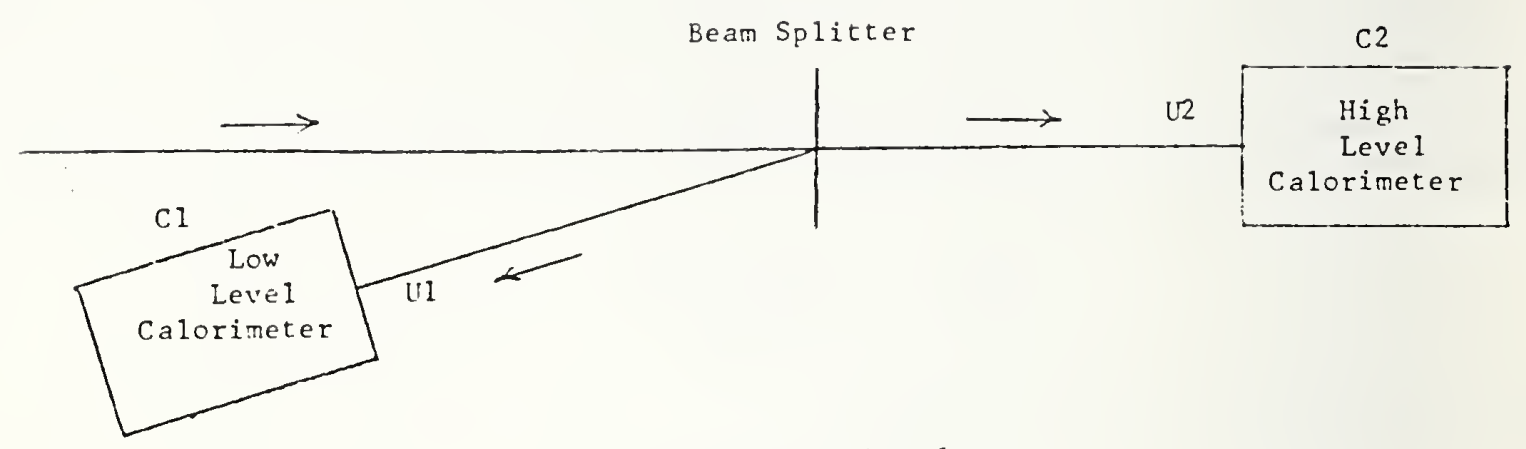

Experiment No. 1

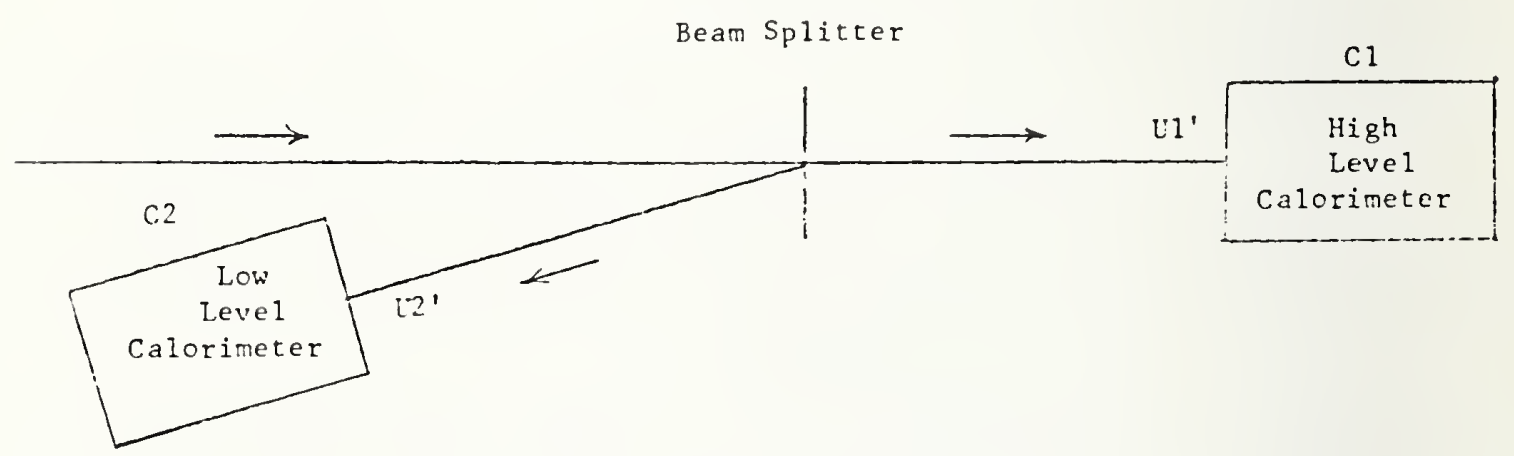

Experiment No. 2

Figure 1. 


\section{APPENDIX C}

Computer Program, /ST2C/ for Beamsplitter Ratio

Appendix $C$ includes a listing of Program /ST2C/ and the print-out of a computer run of /ST?C/ using input data files, $/ C /$ and /D/. A listing of similar programs for a threecalorimeter intercomparison is also shown for Program /ST12/. 
-COPY /C/ TO TEL

11.45573

11.44578

11.45999

11.45646

-COPY /D/ TO TEL

11.44814

11.44431

11.45393

11.45447

$B A$

BASIC-5.15 73-11-13

$>$ LOAD/ST2C/

RUN

THIS IS 94 A PROGRAM /ST2C/ DESIGNED TO FIND THE ABSOLUTE BEAM SPLITTER RATIO AND D FACTOR FOR EACH CALORIMETER WITH THE 99\% CONFIDENCE INTERVAL, USING 2 C SERIES CALORIMETERS IN A REGULAR BEAM

SPLI TTER SETUP. BEFORE RUNNING THE PROGRAM, PUT IN SCRATCH FILE /C/, A SINGLE COLUMN OF BEAM SPLITTER RATIOS FOR C41 LOW LEVEL AND C46 HIGH LEVEL

POSI TION. PUT IN FILE /D/, A SINGLE COLUMN

OF RATIOS FOR C 46 LOW AND C4I HIGH.

THE NO. OF VALUES IN EACH FILE SHOULD EXCEED 4

AND THE RATIO OF /C/ PTS. TO /D/ PTS. SHOULD

LIE BETWEEN 8 AND 1.2

IF BEAM SPLITTER VALUES IN FILES /C/ AND /D/ARE

IN ORDER, TYPE 1. OTHERWISE TYPE D.? 1

NO. IN $/ \mathrm{C} /=$

NO. IN $/ D /=4$

DEGREES OF FREEDOM =

99\% T VALUE FOR ABOVE DEG. OF FREEDOM =

ESTIMATE OF SIGMA = $.4817674 E-03$

3.728768

ABSOLUTE BEAM SPLITTER RATIO =

99\% OF THE TIME, THE BEAM SPLITTER RATIOS WILL BE

WI THIN A + OR - PERCENTAGE RANGE OF

.0635123

D FACTOR FOR C4I CALORIMETER =

1.000093

D FACTOR FOR C46 CALORIMETER =

IREATED EQUALLY, $99 \%$ OF THE TIME, THE D FACTORS WILL LIE WI THIN A + OR - PERCENTAGE RANGE OF $.3175615 E-\emptyset 1$

TYPE IN WAVELENGTH? . 5309

DATE IS $79 / 01 / 0516: 47: 36$

BEAM SPLITTER RATIOS IN FILE /C/

LOW LEVEL CA.L. HIGH LEVEL CAL. BEAM SPLIT. RATIOS RUN NO.

$\mathrm{C} 41$

C41

C $46 \quad 11.45573$

C41

C46 11.44578

C $46 \quad 11.45999$

C46 11.45646

C41

2

3 
BEAM SPLITTER RATIOS IN FILE /D/

LOW LEVEL CAL. HIGH LEVEL CAL. BEAM SPLIT. RATIOS RUN NO.

$\begin{array}{llll}\text { C46 } & \text { C } 41 & 11.44814 & 1 \\ \text { C46 } & \text { C } 41 & 11.44431 & 2 \\ \text { C46 } & \text { C } 41 & 11.45393 & 3 \\ \text { C46 } & \text { C } 41 & 11.45447 & 4\end{array}$

COPY /ST2C/ TO TEL

10 PRINT" THIS IS 940 PROGRAM /ST2C/ DESIGNED TO FIND THE"

20 PRINT"ABSOLUTE BEAM SPLITTER RATIO AND D FACTOR FOR EACH"

30 PRIN T"CALORIMETER WI TH THE 99\% CONFIDENCE INTERVAL, USING"

4) PRINT"2 C SERIES CALORIMETERS "IN A REGULAR BEAM"

59 PRINT"SPLITTER SETUP. PEFORE RUNNING THE PROGRAM, PUT IN"

64 PRINT"SCRATCH FILE /C/, A SINGLE COLUMN OF BEAM SPLITTER"

70 PRINT"RATIOS FOR CAI LOW LEVEL AND CA6 HIGH LEVEL"

80 PRINT"POSITION. PUT IN FILE /D/, A SINGLE COLUMN"

9D PRINT"OF RATIOS FOR CA6 LOW AND CAI HIGH."

100 PRINT" THE NO. OF VALUES IN EACH FILE SHOULD EXCEED 4"

105 PRINT"AND THE RATIO OF /C/ PTS. TO /D/ PTS. SHOULD"

107 PRIN T"LIE BETIUEEN .8 AND 1.2"

$11 \emptyset$ PRINT"IF BEAM SPLITTER VALUES IN FILES /C/ AND /D/ ARE"

120 PRINT"IN ORDER, TYPE 1 . OTHERWISE TYPE $\oslash . " ;$

130 INPUTA3

140 I FA3 $=1$ THEN 60

150 STOP

16 OPEN/C/, INPUT

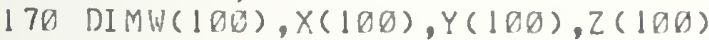

18 FOR.I $=1$ TO 100

190 INPUT FILEY(I)

200 IFEOF $(9)=1$ THEN23日

$210 \quad N 1=I$

220 NEXTI

225 GOT0310

230 PRINT"NO. IN /C/ =", NI

232 I FNI $>3$ THEN2 4 ด

236 PRINT"LESS THAN 5 VALUES I i /C/"

238 STOP

2. 40 CLOSE

250 OPEN/D/, INPUT

260 FOR I $=1$ TO100

270 INPUTFILEZ(I)

$280 \operatorname{IFEOF}(9)=1$ THEN33ด

$290 \quad \mathrm{~N} 2=\mathrm{I}$

390 NEXTI

310 PRINT" OVER 1 ด POINTS IN /C/ OR /D/"

320 STOP

330 PRIN T" NO. IN /D/ =", N2

332 IFN2 $>3$ THEN3 40

336 PRINT" LESS THAN 5 VALUES IN /D/"

338 STOP

$340 \mathrm{~S} 1=0$

$341 \mathrm{~N} 9=\mathrm{N} ! / \mathrm{N} 2$

342 IFN $9>1.2$ THEN3 45

343 IFN9 $<$. 8 THEN3 45

344 GOT0350

345 PRINT"NO. OF PTS. RATIO OUT OF RANGE"

346 STOP

350 FORI $=1$ TON 1

$360 X(I)=\operatorname{LOG}(Y(I))$

$370 \mathrm{SI}=\mathrm{S} 1+\mathrm{X}(\mathrm{I})$

380 NEX II 


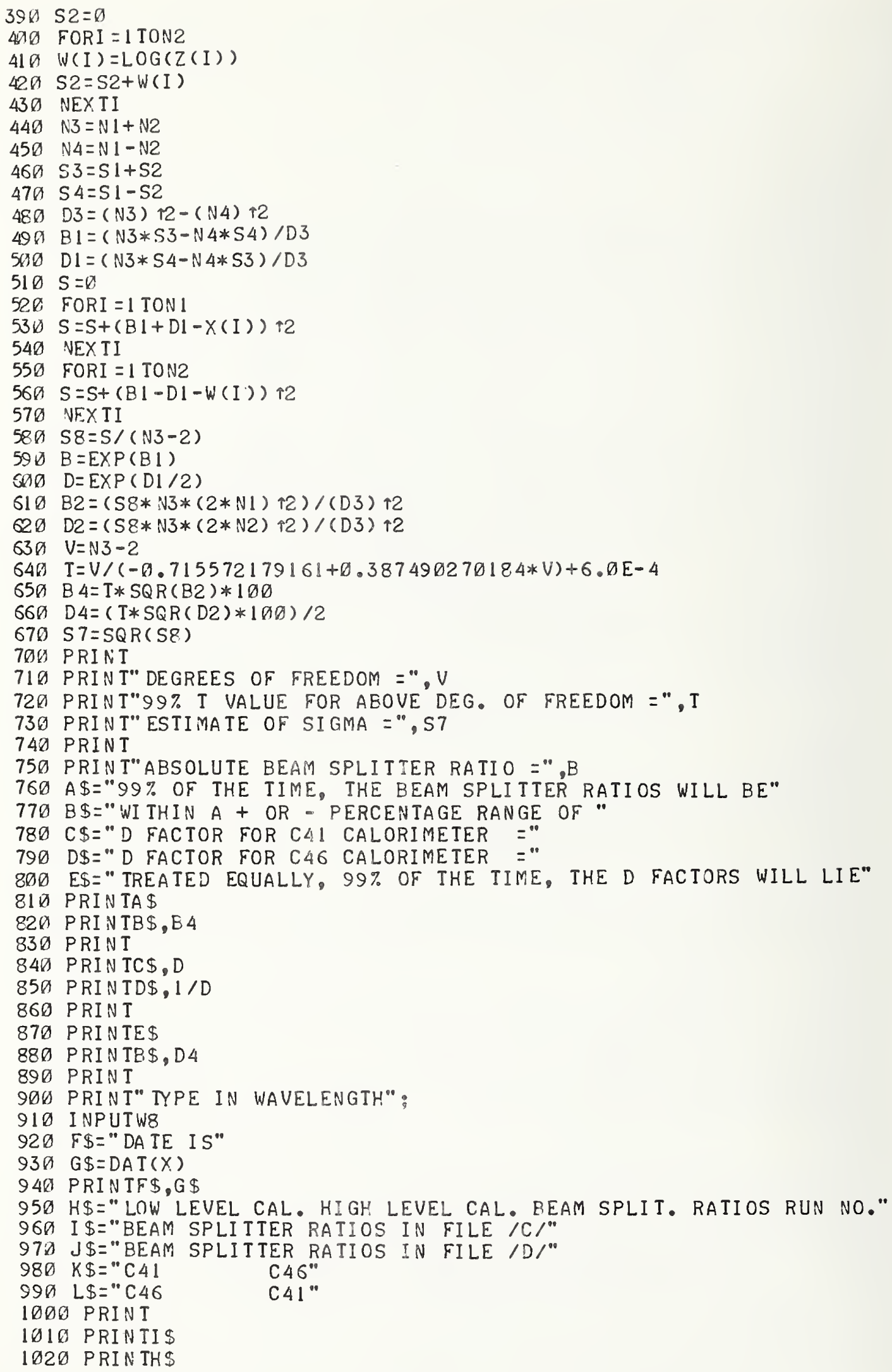


1030 FORI $=1$ TON 1

1040 PRINTK\$,Y (I) , I

1050 NEXTI

1060 PRINT

1070 PRINTJ\$

1880 PRIN TH $\$$

1990 FORI $=1$ TON2

11 ด0 PRINTL $\$, Z$ (I), I

1110 NEXTI

1200 END 
COPY /STI2/ TO TEL

10 PRINT" THIS IS 940 PROGRAM STATI2 FOR C SERIES CALORIMEIERS"

20 PRINT" THIS PROGRAM IS DESIGNED ONLY FOR 12 BEAM SPLITTER"

30 PRINT"RUNS OF 2 EACH FOR THE 6 POSSIBLE CONFIGURATIONS"

4 PRINT"OF 3 C SERIES CALORIMETERS TAKEN 2 AT A TIME"

50 PRINT" IN A BEAM SPLITTER SETUP"

55 GOTO12ด

6Ø PRINT"FOR INSTRUCTIONS FOR INPUT VALUES, TYPE 1 . ELSE $\emptyset "$;

7D INPUTA!

80 IFAI = 1 THEN 1 ดด

96 GOTO3DR

196 PRINT" TYPE BEAM SPLITTER VALUES IN A SINGLE COLUMN"

110 PRINT" TO SCRATCH DATA FILE /B/, USING THE FOLLOWIVG ORDER"

115 GOT0252

120 P $\$="$ SET LOW LEVEL CALORIMETER HIGH LEVEL CALOR. BEAM SPLITTER R."

$150 \mathrm{~J} \$=" 1 \mathrm{ST}$

$160 \mathrm{~K} \$=" 1 \mathrm{ST}$

$179 \quad \mathrm{~L} \$=" 1 \mathrm{ST}$

180 $M \$=" 1 S T$

$196 \quad N \$=" 1 S T$

$2000 \$=" 2$ ND

$210 \mathrm{R} \$=" 2 \mathrm{ND}$

$226 \mathrm{~S} \$=" 2 N D$

$230 \quad T \$=" 2 N D$

$240 \quad U \$=" 2 N D$

C 444

C 414

C 464

C414

C 464

C 444

C 444

C414

C 464

C414

$250 \quad \mathrm{~V} \$=" 2 N D$

C 464

251 GOTO6日

C444

C 413 "

C $443 "$

C413"

C 463 "

C443"

C $463 "$

C413"

C443"

C413"

C464"

C443"

252 PRINT

255 PRINTP\$

260 PRINTI\$

262 PRINTJ\$

264 PRINTK\$

266 PRINTLS

270 PRINTM\$

272 PRINTN\$

274 PRINTO\$

276 PRINTR\$

278 PRINTS $\$$

28 FRINTT\$

282 PRINTU\$

29 ด PRINTV\$

295 PRINT

300 PRINT"IF BEAM SPLITTER VALUES IN FILE /B/ ARE IN "

305 PRINT"ORDER, TYPE 1. ELSE ด";

310 INPUTA3

32.6 IFA3 $=1$ THEN340

330 STOP

340 OPEN/B/, INPUT

350 DIMV (15),W(12)

360 FORI $=1$ TO 15

370 INPUTFILEV(I)

380 I FEOF $(9)=1$ THEN 410

$390 \quad \mathrm{~V} 1=\mathrm{I}$

40 () NEXTI

410 IFNI $=12$ THEN 44 ด

420 PRINT" NO. OF VALUES DOESN'T $=12^{\prime \prime}$

430 STOP

449 FORI $=1$ TO 12 


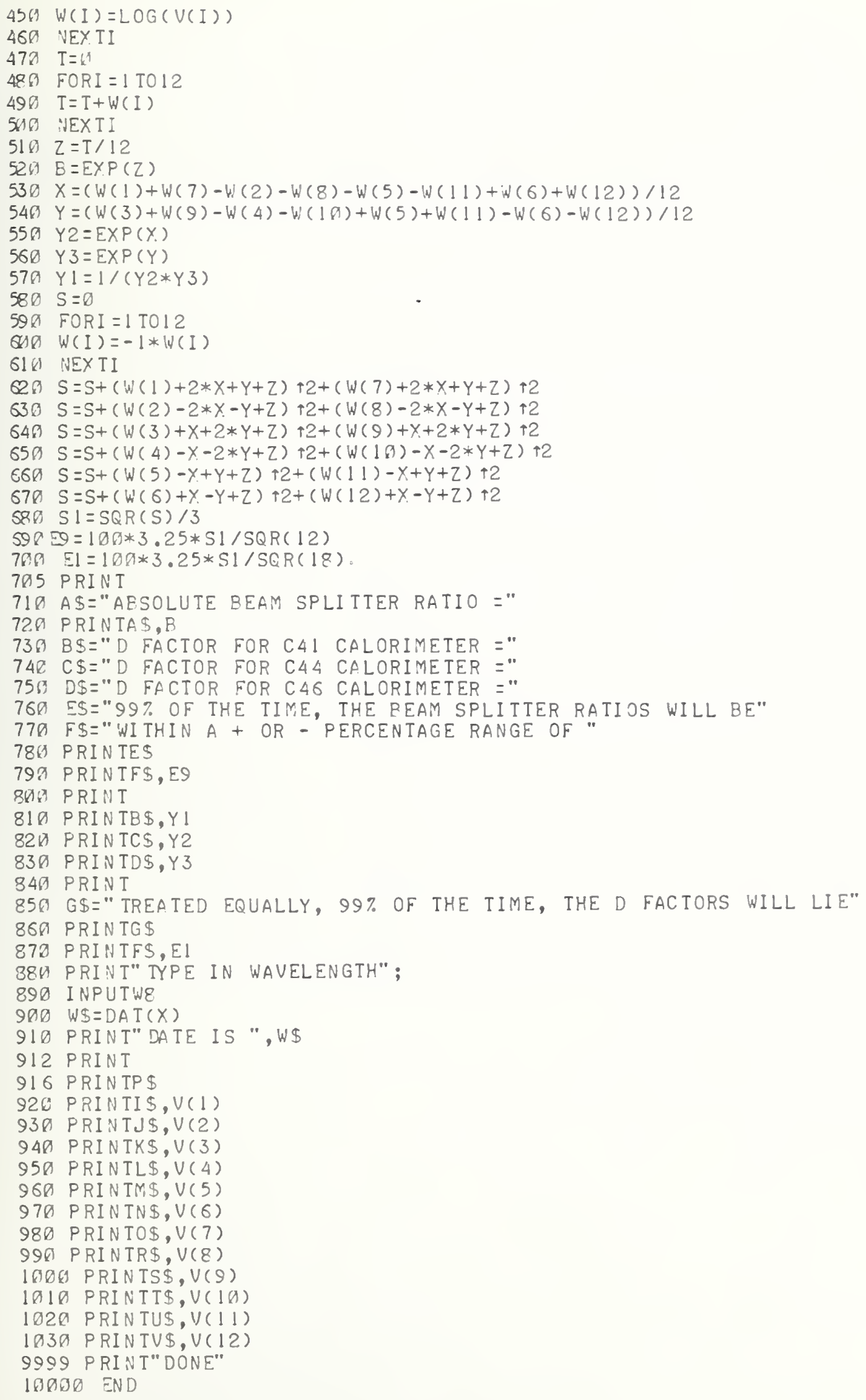




\section{APPENDIX D}

Computer Program /S6/ Used to Separate Calihration Values

According to Wavelength and/or Scale

Appendix D gives an example of how Program /S6/ can be used to separate and print out the Code 9 values from a typical power meter file to single column, File /A/. A listing of $/ \mathrm{S} 6 /$ is also included. 


\section{COPY /15/ TO IEL}

\begin{tabular}{|c|c|c|c|c|}
\hline $9.61527 E-01$ & 7891274 & $0.96825 E-.93$ & .6328 & 3464 \\
\hline $9.60122 E-01$ & 7801275 & ๑. $96904 E-93$ & .6328 & 3464 \\
\hline $9.6 B 756 E-01$ & 7801311 & $1.02274 E-03$ & .6328 & 3464 \\
\hline $9.64984 E-91$ & 7802112 & 1. $.2965 E-03$ & .6328 & 3464 \\
\hline $9.66780 E-01$ & 7892022 & $1.02753 E-.03$ & .6328 & 3464 \\
\hline $.61246 E-D 1$ & 7812033 & ๑.9831.7E-D3 & .6328 & 3464 \\
\hline $.63326 E-01$ & 7802061 & $1.10347 E-.03$ & .6328 & 3464 \\
\hline $.62 .951 \mathrm{E}-01$ & 78 \2092 & ด. $97222 E-.93$ & .6328 & 3.464 \\
\hline $.52048 E-.71$ & 7802172 & $1.89669 E-.96$ & 328 & 3465 \\
\hline $705-01$ & 7802173 & 1. $\$ 63995-96$ & .6328 & 32 \\
\hline $21 \bar{E}-\not 1$ & 7802212 & 1. $15054 E-D 6$ & .6328 & 3465 \\
\hline $.54587 E-11$ & 7802242 & 1.13 3 $33 E-66$ & .6328 & 3465 \\
\hline $.48927 E-D 1$ & 7892271 & $1.14445 E-06$ & .6328 & 3465 \\
\hline $25 E-91$ & 7803011 & $1.08595 E-\varnothing$ & .6328 & 3455 \\
\hline .60809 E-01 & 7803023 & $0.88009 E-003$ & .6328 & 3464 \\
\hline $.63434 \mathrm{E}-1$ & 780.5041 & ด. $22995 E-03$ & .6328 & 3464 \\
\hline 9. $49678 \mathrm{E}-01$ & 7805042 & $1.36646 E-96$ & .6328 & 3465 \\
\hline $2 E-01$ & 7806021 & 1.0 & - & 3 \\
\hline $83 E-01$ & $78 \% 6022$ & 6. $99335 E-03$ & 28 & 64 \\
\hline $9.61943 E-\emptyset 1$ & 7896023 & Q.95848E-133 & .6328 & 3464 \\
\hline $9.62947 E-01$ & 786,6261 & ․ $95590 E-03$ & .6328 & 3464 \\
\hline$E-\sqrt{2} 1$ & 78116264 & $576 E-36$ & & \\
\hline$E-\emptyset 1$ & 7807 & $24 E-03$ & .6 & \\
\hline$E-(0 !$ & 78070 & $43 E-96$ & .6 & 346 \\
\hline$E-01$ & 780 & $42 E-\$ 33$ & & \\
\hline$E-E 1$ & 780 & $2 E-06$ & & \\
\hline
\end{tabular}


$B A$

BASIC $-5.15 \quad 73-11-13$

$>L O A D / S 6 /$

RUN

USE TO COPY IST COLUMN DATA FROM A 6 COL. PONER OR ENERGY FILE SPECIFIED ACCORDING TO WAVELENGTH AND SCALE

TO SCRATCH DATA FILE /A/

TYPE IN 6 COLUMM INPUT FILE IN / / / / $15 /$

NO. OF VALUES IN FILE $=26$

TYPE 3Ø FOR ALL WAVELENGTHS; 1 FOR 1. $\emptyset 6 ; 2$ FOR .6471;

3 FOR .6328; 4 FOR .5145; 5 FOR. .4889; 6 FOR . 5399? 3

TYPE 30 FOR ALL CODE NOS. EXCEPT 99; 1 FOR CODE 1;

2 FOR CODE 2, ETC.?? 9

NO. OF SELECTED POINTS $=15$

TO PRINI SELECTED POINTS TO TELETYPE, TYPE 1. ELSE $\emptyset ? 1 \cdot$

.961527

.960122

.950756

.964984

.96678

.961246

.963326

.962951

.960809

.963434

.959383

.961943

.962947

.962273

.960248

TO PRIN I SELECIED POINTS TO FILE /A/, TYPE 1. ELSE $\oslash ? ~ 1$ NO. OF VALUES IN $/ A /=$

15

END

$>$ Q U I 
COPY /S6/ TO TEL

120 REM THIS IS PROGRAM STRIP6

130 PRINT "USE TO COPY IST COLUMN DATA FROM A 6 COL. FOWER OR ENERGY"

140 PRINT "FILE SPECIFIED ACCORDING TO WAVELENGTH AND SCALE"

150 PRINT "TO SCRATCH DATA FILE /A/"

$160 D I M_{1} A(100), Y(1 D D), D(100), F(100)$

174 DIM $B(100), C(100), E(100)$

180 PRINT "TYPE IN 6 COLUMN INPUT FILE IN $/ /$;

190 INPUT Q\$

2ดी GO TO 470

216 PRINT "TYPE 30 FOR ALL WAVELENGTHS; 1 FOR 1.06; 2 FOR .6471:"

226 PRINT "3 FOR .6328; 4 FOR .5145; 5 FOR.488ด; 6 FOR.53ด9";

236) INPUT W9

240 PRINT "TYPE 39 FOR ALL CODE NOS. EXCEPT 99; 1 FOR CODE $1 ; "$

256 PRIN T "2 FOR CODE 2, ETC.?";

26 INPUT C9

270 IF $W 3<>30$ THEN 290

280 GO TO $46 \theta$

29 IF $W 9<1$ THEN 320

300 W9 $=1.06$

316 GO TO 460

326) IF W9 $<-2$ THEN 350

$330 \quad W 9=0.6471$

340 GO TO 460

350 IF W9 $<3$ THEN 380

$360 w 9=0.6328$

37 GO TO 460

38 If $W 9<4$ THEN 410

$390 \quad W 9=0.5145$

400 GO TO 460

41 IF W/ $2>5$ THEN 432

42 () $W 9=9.488$

43 GO TO 460

432 I FW9 $<$ 6 THEN 449

$434 \mathrm{~W}=0.5309$

436 GOTO 46 月

440 PRINT "NO SUCH WAVELENGTH. TRY AGAIN"

450 GO TO 210

46 GO TO 659

470 OPEN Q\$, INPUT

480 A\$: "CALIBRATION RUN NO. POW. OR ENER. WAVE. CAL. SCALE"

SOAFORI $=1$ TO 1 OD

510 INPUTFILEA(I), B(I),C (I), D(I), E(I), F(I)

526IFEOF $(9)=1$ THEN570

$530 \quad \mathrm{~V}=\mathrm{I}$

540 NEXT I

55 ด PRIN T "OVER 1 ด POINTS"

56 ST STP

5769 PRINT "NO. OF VALUES IN FILE $=", N$

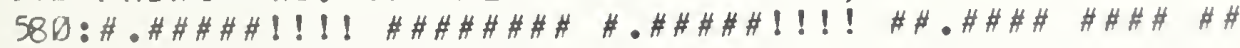

2Q $\mathrm{NI}=0$

640 GO TO $21 \%$

65) FOR $I=1$ TO $\mathrm{N}$ 
569 IF $F(I)=99 \quad$ THEN 730

679 IF $W 9=3$ IHEN 690

S8Q) IF $D(I)<$ W IHEN 73ด

69 If IF $C 9=36$ THEN 71 ด

$7 D($ I $F \quad F(I)<C 9$ THEN $73 \emptyset$

$710 \quad \mathrm{~N} I=\mathrm{N} 1+1$

$72 \emptyset Y(N 1)=A(I)$

730 NEXI I

740 PRINT "NO. OF SELECTED POINTS = "NI

741 PRINT" TO PRINT SELECTED POINTS TO TELETYPE, TYPE 1. ELSE $\emptyset "$; 742 INPUTQ

743 I FQ $=1$ THEN 745

744 GOTO750

745 FORI $=1$ ION 1

746 PRINTY (I)

747 NEX.TI

75UPRINT" TO PRINT SELECTED POINTS TO FILE /A/, TYPE 1. ELSE $\emptyset "$; $755 I$ NPUT $P$

769 IF $P=1$ THEN 780

776 GO TO 850

780 OPEN/A /,OUTPUT

$31 \emptyset$ FOR I $=1$ TO N1

82ด PRINTFILEY (I)

$83 \emptyset$ NEXI I

840 PRINT "NO. OF VALUES IN $/ A /=", N I$

850 PRINT "END"

860 END 


\section{APPENDIX E}

Computer Program, /RU/, a RUNSUM Proaram to Detect Trends in Statistical Data

Program /RU/ is a RUNSUM program to detect trends in statistical data. The difference (residual) between each data point and the mean is compared with the standard deviation starting with the first point. As the program progresses point-by-point, a running total, RUNSUM, is kept according to the following rules.

1. A residual less than $1 \sigma$, add 0.

2. $A$ " " $2 \sigma$, " 1 .

3. A " " $" 3 \sigma, " 2$.

4. A " " $" 4 \sigma, " 3$.

5. A " " $" 5 \sigma$, " 4 .

6. A "greater " $5 \sigma$, " 5 .

7. When a residual changes sign, RUNSUM is set to 0 , before proceeding to Steps 1 through 6 .

When the RUNSUM value equals 5 or greater, a trend is indicated. A listing of /RU/ is shown in Appendix E, as well as a printout of a typical computer run on Program /RU/. 
QUI T

-COPY /RU/ TO TEL

129 REM THIS IS PROGRAM RUNSUM

136. PRINT "A RUNSUM TEST PROGRAM TO DETECT TRENDS IN A SINGLE" 149 PRINT "COLUMN DATA FILE /A/"

145 OPEN/A/, INPUT

$150 \quad V=0$

180 DIM S(200), T(200),Z(200)

190 FOR $I=1$ TO2B

2Aด INPUT FILE Z(I)

210 IFEOF $(9)=1$ THEN27ด

$236 N=I$

240 NEXI I

250 PRINT "OVER 2Q POINTS"

260 STOP

$27 \%$ FOR $I=1$ TO $N$

280 IF $I=1$ THEN 319

$290 S(I)=S(I-1)+Z(I)$

300 GO TO 320

$318) S(I)=Z(I)$

32冈 NEXT I

$33 \pi \quad J=S(N) / N$

340 FOR $I=1$ TO $N$

350 IF $I=1$ THEN 380

$360 T(I)=T(I-1)+(Z(I)-J) \uparrow 2$

370 G0 TO 390

388 $T(I)=(Z(I)-J) \uparrow 2$

390 NEXT I

$4 Q D U=\operatorname{SQR}(T(N) /(N-1))$

$410 F \$=$ "AVERAGE:"

420 GOTO1110

430 PRINTF\$, J

440 G\$=" STANDARD DEVIATION:"

45ด PRINTG\$, V3

46 H $H=$ "PERCENT STANDARD DEVIATION:"

470 PRINTH\$, 10Q,*V3/J

$48 \emptyset \quad V 5=V 3$

$496 \quad K 1=J$

$500 \quad P=0$

$510 . R=0$

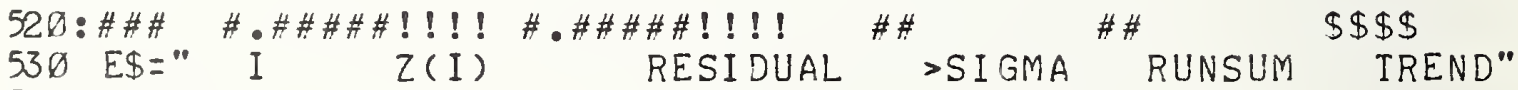

540 PRIN T

550 PRINT E\$

560 FOR $I=1$ TO $N$

57Q $D=Z(I)-K I$

58 IF $Z(I)>K I$ THEN 640

599 IF $P=-1$ THEN $62 \emptyset$ 


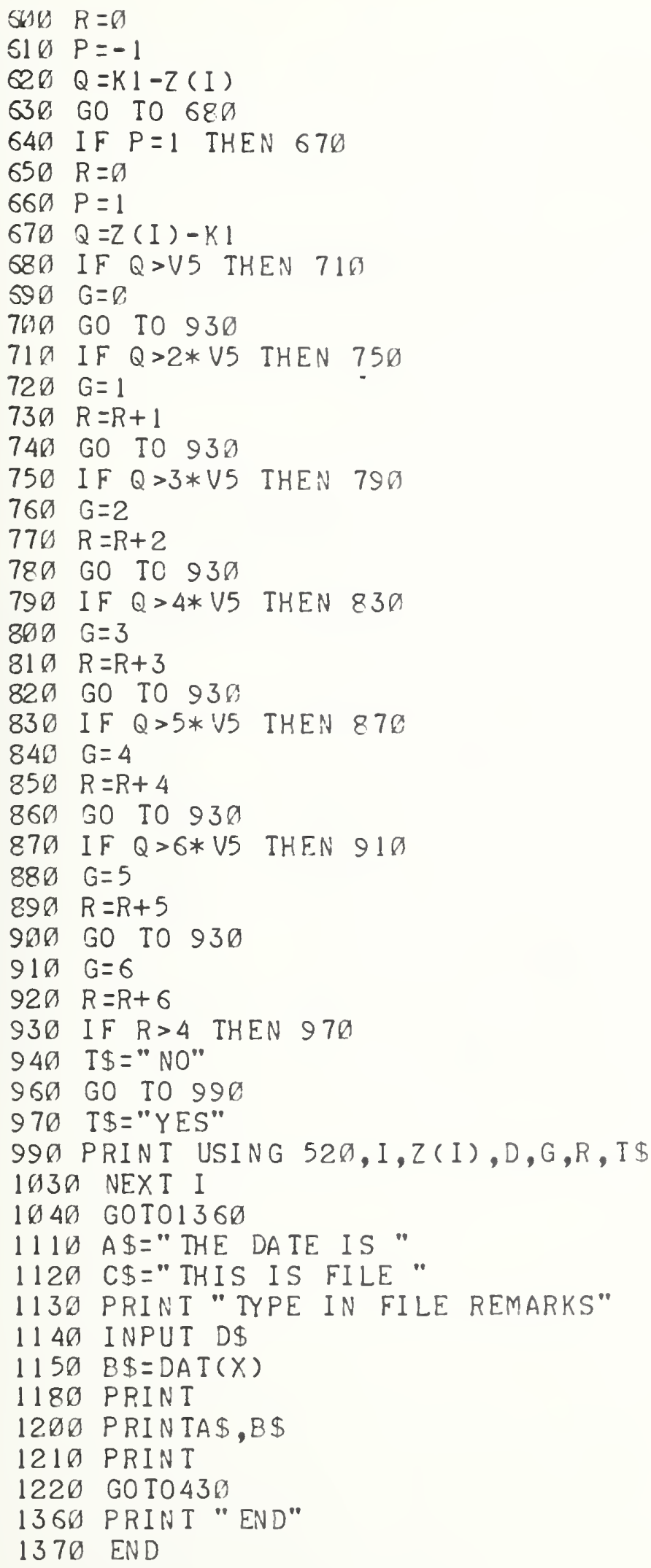


BA

BASIC-5.15 73-11-13

$>$ LOAD /RU/

ЖUN

A RUNSUM TEST PROGRAM IO DETECT IRENDS IN A SINGLE COLUMN DATA FILE /A/

TYPE IN FILE REMARKS

? SIL15 AT I MILLIWATT AT .6328

THE DATE IS $79 / 01 / 88 \quad 16: 40: 33$

AVERAGE: $\quad .9621819$

STANDARD DEVIATION:

PERCENT STANDARD DEVIATION:

$.1966743 E-62$

.2044045

\begin{tabular}{|c|c|c|c|c|c|}
\hline I & $Z(I)$ & RESI DUAL & $>S I G M A$ & RUNSUM & TREND \\
\hline 1 & $9.61527 E-\emptyset 1$ & $-.06549 E-02$ & $\emptyset$ & 9 & No \\
\hline 2 & $9.60122 \mathrm{E}-01$ & $-.20599 E-02$ & 1 & 1 & NO \\
\hline 3 & $9.60756 E-01$ & $-.14259 E-02$ & $\emptyset$ & $i$ & NO \\
\hline 4 & $9.64984 \mathrm{E}-01$ & $2.80207 E-03$ & 1 & 1 & NO \\
\hline 5 & $9.66780 E-\emptyset 1$ & $4.59807 E-03$ & 2 & 3 & NO \\
\hline 6 & $9.61246 E-01$ & $=.09359 E-02$ & 9 & $\emptyset$ & NO \\
\hline 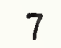 & $9.63326 E-01$ & $1.14407 \mathrm{E}-03$ & Ø & $\emptyset$ & NO \\
\hline 8 & $9.62951 E-01$ & $0.76907 \mathrm{E}-03$ & $\theta$ & $\emptyset$ & NO \\
\hline 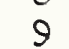 & $9.60809 E-01$ & $=13729 E-02$ & b & $\emptyset$ & NO \\
\hline 10 & $9.63434 \mathrm{E}-\varnothing 1$ & $1.25207 \mathrm{E}-03$ & $\varnothing$ & $\emptyset$ & NO \\
\hline 11 & $9.59383 E-01$ & $-.27989 \mathrm{E}-02$ & 1 & 1 & NO \\
\hline & $9.61943 \mathrm{E}-01$ & $-.23893 E-03$ & $D$ & 1 & NO \\
\hline 1 & $9.62947 \mathrm{E}-01$ & $0.76507 \mathrm{E}-03$ & 0 & 0 & NO \\
\hline 1 & $9.62273 \mathrm{E}-01$ & $0.91067 \mathrm{E}-04$ & $\emptyset$ & 0 & NO \\
\hline & $9.60248 E-01$ & $-.19339 E-92$ & $\emptyset$ & D & NO \\
\hline
\end{tabular}

END 
APPENDIX $F$

Computer Program, /PL/, a Plottina Routine for a Single Column of Data

Appendix $F$ contains a listing and a sample run of Plot Program /PL/. 
COPY /PL/ TO TEL

120 REM THIS IS PROGRAM PLOT

136 PRINT "A PLOT OF PERCENT DIFFERENCE FROM THE AVERAGE OF A SINGLE" 140 PRINT "COLUMN OF DATA IN FILE /A/"

$150 \quad N 9=290$

169 DIM T(N9), W(N9), $P(N 9), Q(N 9), R$ ( N9)

170 PRINT "TI TLE OF PLOT"

18 I NPUT L\$

199 OPEN/A/, INPUT

2D日 FOR I $=1$ TO2@ด

210 INPUT FILEP(I)

220) IF EOF( 9$)=1$ THEN27Ø

$230 \quad N=I$

240 NEXT I

250 PRINT "OVER 20Ø POIN TS"

260 S IOP

$27 \emptyset \mathrm{S}=\emptyset$

280 FOR I $=1$ TO N

$290 \mathrm{~S}=\mathrm{S}+\mathrm{P}(\mathrm{I})$

30 NEXT I

$31 \emptyset \quad A 1=S / N$

320 FOR $I=1$ TO $\mathrm{N}$

$330 R(I)=109 *(P(I)-A 1) / A 1$

340 NEXT I

350 AS $=$ "NO. OF POINTS:"

360) PRINT A\$, N

370 B $\$=" A V E R A G E: "$

39 () PRINTB\$,A 1

406 FOR $I=1$ TO N

410 IF $I=1$ THEN 440

$42 \emptyset W(I)=W(I-1)+R(I) \uparrow 2$

430 GO TO 450

$440 W(I)=R(I) \uparrow 2$

450 NEXT I

460 IF $N=1$ THEN 2290

$470 V=\operatorname{SQR}(W(N) /(N-1))$

480 C $\$="$ STANDARD DEVIATION:"

$490 V 9=V * A 1 / 100$

500 PRIN TC\$, V9

510 D $\$=" 1$ SIGMA IN PERCEN T ="

520 PRIN ID\$, $V$

530 E\$ $=$ "3 SIGMA IN PERCENT ="

540 PRINTE\$, 3*V

$55 \emptyset$ FOR $K=1$ TO $N$

560 IF $K>1$ THEN 590

$570 \quad C=R(K)$

580 GO TO $62 \emptyset$

590 IF $R(K)>C$ THEN 610

6月, GO TO 620

$610 \mathrm{C}=\mathrm{R}(\mathrm{K})$ 


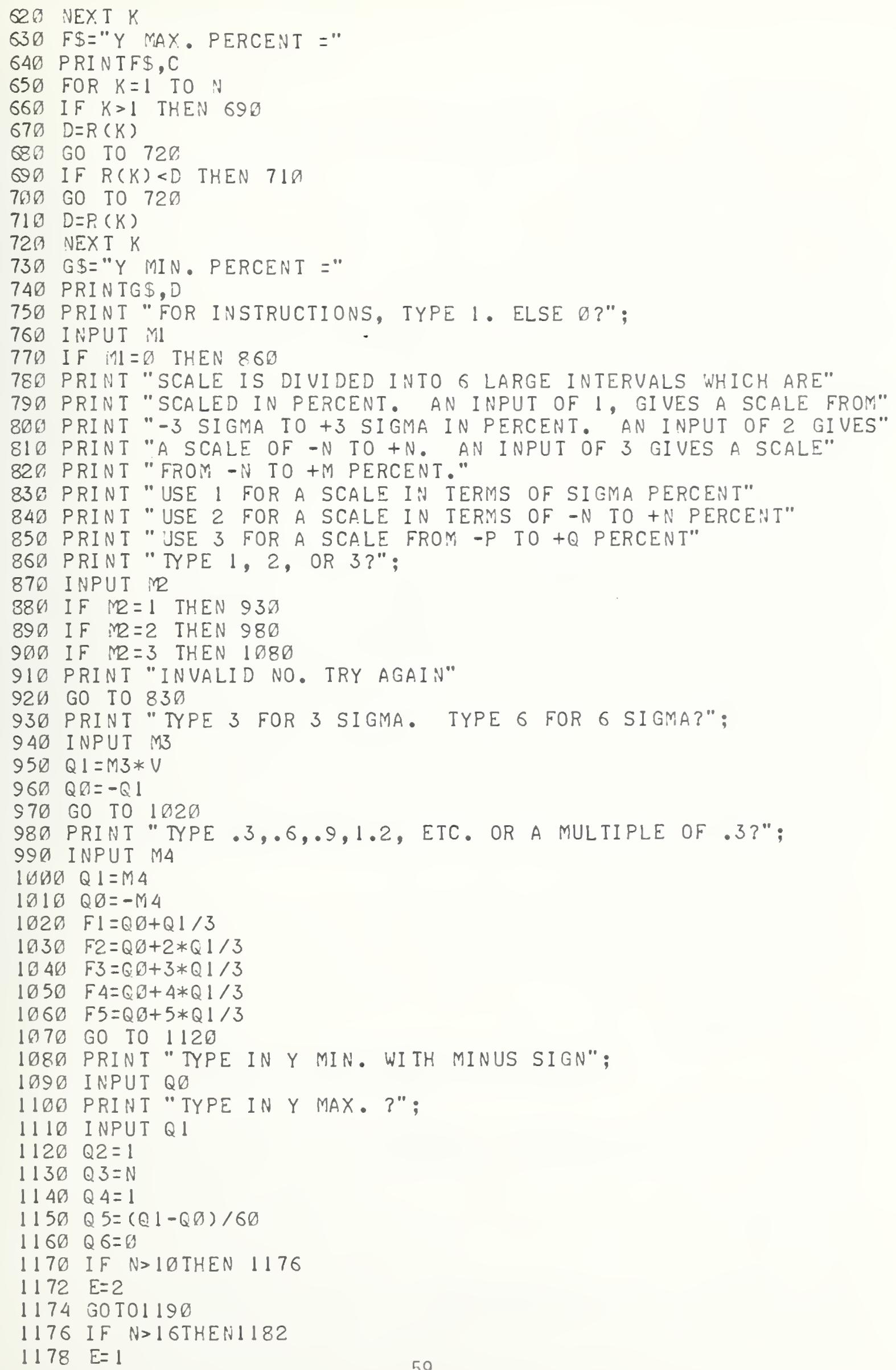


1180 GOTO1190

$1182 \quad E=\emptyset$

1190 PRINT"FOR PLOT MOVE PAPER AND TYPE 1. ELSE 0

$120 \emptyset$ INPUT EO

1210 IF $E=9$ THEN 2301

$1230 \quad$ L9 $=0$

1256 FOR $X=Q 2$ TO $Q 3$ STEP $Q 4$

$1260 Y=R(X)$

1270 IF $E=0$ THEN 1370

1280 IF $E=1$ THEN $134 \%$

1300 PRIN T

1349 PRIN T

1370 IF Q $6=\square T H E N 1790$

1380 IF $Q 6=20$ THEN 1450

1400 PRINT $X$;

1430 GO TO 1496

1450 PRINT $X$

1480 Q $6=10$

$1490 \quad 07=Q 6+2 * Q 5$

$1500 Z=07+0.5 * Q 5$

1510 IF $Z<Y$ THEN 1700

1520 Q $6=Q 6+1$

1530 IF $Z-Y>2 * Q 5$ THEN 1660

1540 IF $Z-Y>Q 5$ THEN 1610

1560 PRIN T " +"

1570 GO TO 2090

1610 PRINT " +"

1620 GO TO 2090

1660 PRIN T "+"

1670 GO TO 2996

$1700 \quad Q 7=67+3 * Q 5$

1720 PRINT " ";

1730 GO TO 1596

1760 Q $6=Q 6+1$

1770 GO TO 2690

1790 PRINT" ",LS

$1792 \mathrm{~T} \$=D A T(X)$

1794 PRIN T" DATE IS ", T\$

1809 GO TO 1830

1830 H\$="PERCENT STANDARD DEVIATION: "

1850 PRINTH $\$, V$

1860 GO TO 1890

1880 IF LS $=1$ THEN $191 \%$

1890 PRIN TB\$,AI

1960 GO TO 1930

1930 I $\$="$

1950 PRIN T I\$

1960 GO TO 1980

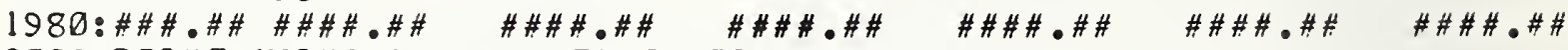
2000 PRINT USING $1980, Q 6, F 1, F 2, F 3, F 4, F 5, Q 1$

2010 GO TO 2030

2030 J $\$="$ I......

2050 PRINT J\$

2080 GO TO 1450

2090 NEX I X

2100 GOT02300

2290 PRINT" ONLY O VALUE IN FILE /A./ "

2300 PRIN T" END"

2310 END 
BA

BA SIC-5.15 73-11-13

$>L O A D / P L /$

×RUN

A PLOT OF PERCENT DIFFERENCE FROM THE AVERAGE OF A SINGLE COLUMN OF DATA IN FILE /A/

II TLE OF PLOI

? SIL15 AT I MILLIWATT AT .6328

NO. OF FCINTS: 15

AVERAGE: .9621819

STANDARD DEVIATION:

1 SIGMA IN PERCENT =

3 SIGMA IN PERCENT =

$Y$ MAX. PERCENT $=$

$Y$ MIN. PERCENT =

\section{TYPE 1 O ELSE 0 ? ?}

FOR INSTRUCTIONS, TYPE 1. ELSE Q?? 1

SCALE IS DIVIDED INTO 6 LARGE INTERVALS WHICH ARE

SCALED IN PERCENT. AN INPUT OF 1, GIVES A SCALE FROM

-3 SIGMA TO +3 SIGMA IN PERCENT. AN INPUT OF 2 GIVES

A SCALE OF - $N$ TO + N. AN INPUT OF 3 GIVES A SCALE

FROM - N TO + M PERCENT.

USE 1 FOR A SCALE IN TERMS OF SIGMA PERCENT

USE 2 FOR A SCALE IN TERMS OF - N TO + N PERCENT

USE 3 FOR A SCALE FRCM $-P$ TO $+Q$ PERCENT

TYPE 1,2, OR 3?? 2

TYPE .3,.6,.9,1.2, ETC. OR A MULTIPLE OF .3?? .6

FOR PLOT MOVE PAPER AND TYPE 1. ELSE ด? 1 


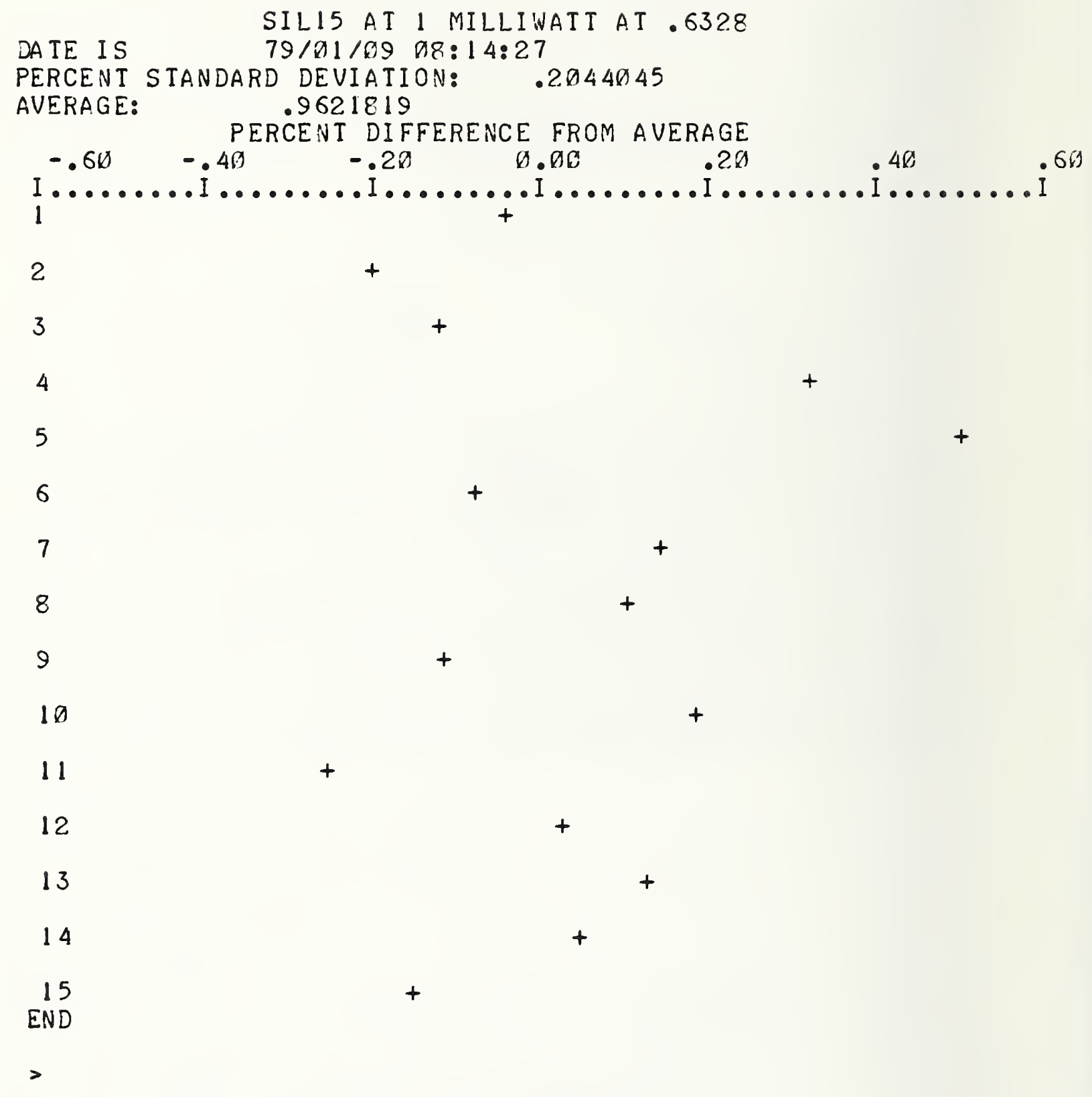


APPENDIX G

Computer Program /ASTM/, an ASTM Prooram to Provide 2 Control Charts Appendix G contains a listing and a sample run of Program /ASTM/. 
16 PRINT" TYPE 1 TO SKIP DIRECTIONS. ELSE $0 "$;

$2 A$ INPUT A9

3ด IFA9 $=1$ THEN 150

49 PRINT" THIS PROGRAM PROVIDES 2 CONTROL CHARTS; ONE FOR INDIVIDUALS, $X:$

59 PRINT"AND ONE FOR MOVING RANGE, R, OF TWO OBSERVATIONS. SEE ASTM"

6 PRINT" MANUAL ON QUALI TY CONTROL OF MATERIALS, PAGE 135, FOR DETAILS."

7ด PRIN T" CONTROL CHART \# 1 DISPLAYS INDIVIDUAL RESIDUAL READINGS"

8 O PRIN T" IN PERCENT WITH CONTROL LIMITS VERSUS RUN NO." "

96 PRINT" CONTROL CHART \#2 DISPLAYS MOVING RANGE VALUES WITH"

92 PRINT" CONTROL LIMITS VERSUS RUN NO."

1月ด PRINT" CONTROL LIMITS SHOULD BE BASED ON AT LEAST 15 INDIVIDUAL"

110 PRINT" MEASUREMENTS. THIS PROGRAM NEEDS AT LEAST 1 ด POINTS TO RUN." 120 PRINT"SINGLE COLUMN INPUT DATA MUST BE IN FILE /A/ BEFORE RUNNING."

$150 . N 9=200$

160 DIM $P(N 9), R(N 9), G(N 9)$

170 PRINT "TI TLE OF PLOT"

180 INPUT LS

190 OPEN/A/, INPUT

200 FOR $I=1$ TO2

210 INPUT FILEP(I)

22. IF EOF $(9)=1$ THEN2 70

$230 \quad V=I$

240 NEXT I

250 PRINT "OVER 2øด POINTS"

260 STOP

$274 \mathrm{~S}=\emptyset$

280 FOR $I=1$ TO $\mathrm{N}$

290 $S=S+P(I)$

300 NEXI I

$310 \mathrm{Al}=\mathrm{S} / \mathrm{N}$

320 FOR $I=1$ TO $N$

33 A $R(I)=100 *(P(I)-A 1) / A 1$

340 NEX.T I

$350 A \Phi="$ NO. OF POINTS:"

36日) FRINT A\$, N

362 I FN>9 THEN365

363 PRINT"PROGRAM NEEDS AT LEASI 10 POINTS TO RUN."

364 STOP

365 IFN>1 4 THEN37\%

366 PRINT"PROGRAM SHOULD HAVE AT LEAST 15 POINTS TO SET GOOD CONTROL LI

376 B $\$=$ "AVERAGE:"

390 PRINTB $\$, A 1$

$\angle 2$ V $T=\theta$

422 FORI $=2$ TON

$424 G(I)=A B S(P(I)-P(I-1))$

$426 T=T+G(I)$

42.7 NEXTI

$428 R=T /(N-1)$

429 R $5=1019 * R / A 1$

43 G $U=2.66 * R$

$440 \quad H=3.267 * R$

8Пด FRINT" TO PLOT \#1, TYPE 1. TO PLOT \#2, TYPE 2. ELSE $\emptyset "$;

818 INPUTA 5

815 I FA $5=B$ THEN23 Dด

816 FOR $I=1$ TO1ด

817 PRINT 


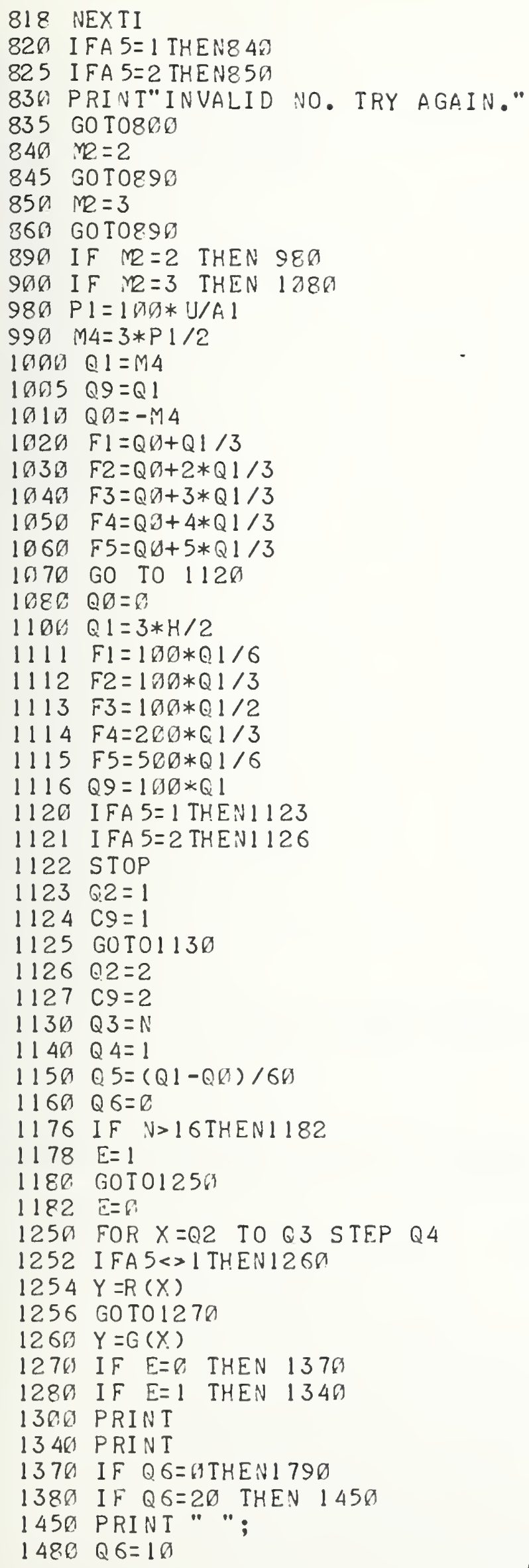




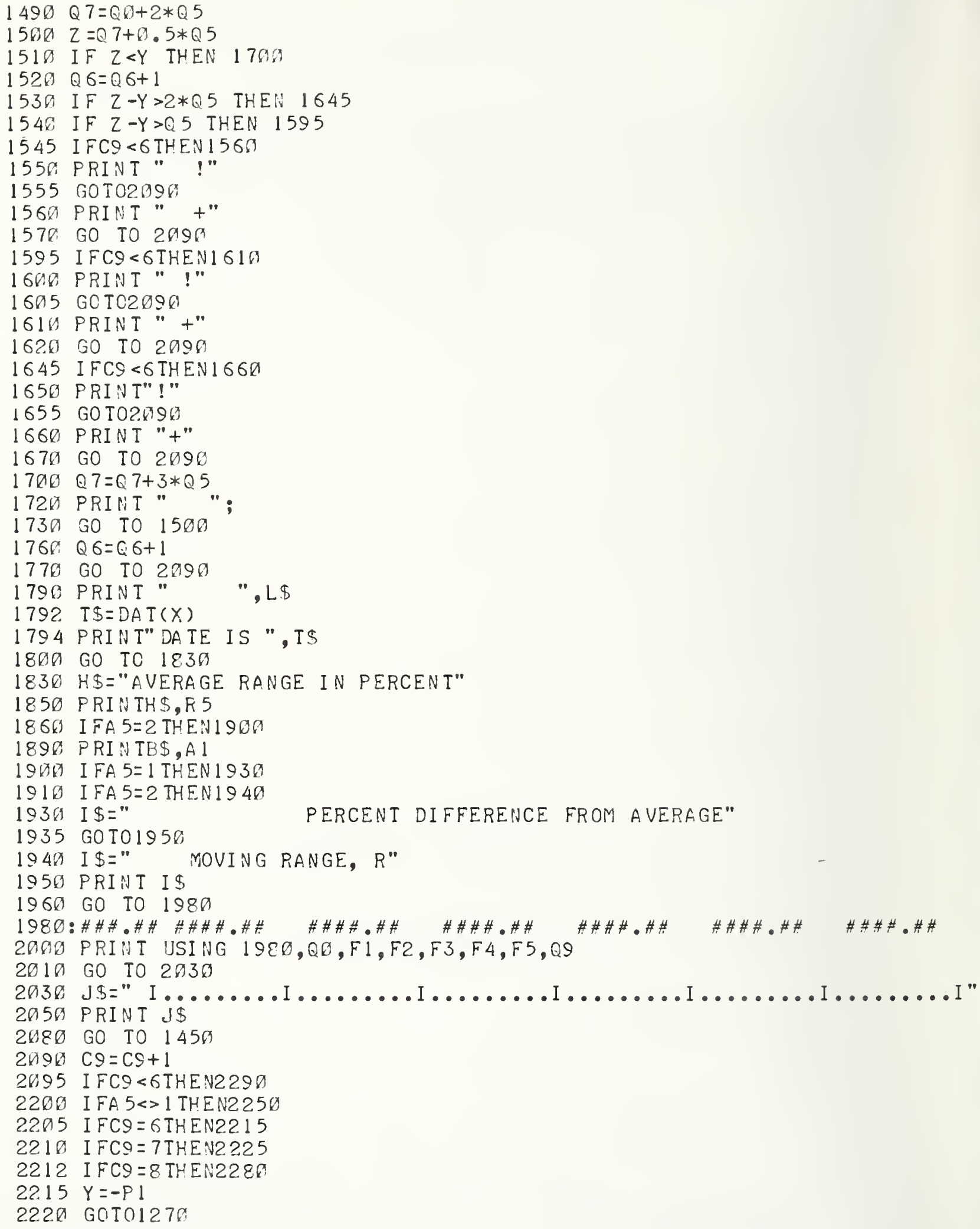


$2225 \quad \mathrm{Y}=\mathrm{Pl}$

2235 GOTO1270

2250 IFC9 $=6$ THEN226日

2255 IFC9 $=7$ THEN2265

2257 IFC9 $=8$ THEN2286

$2260 \quad Y=\varnothing$

2262 GOTO1270

$2265 \mathrm{Y}=\mathrm{H}$

2275 GOIO1270

$2280 \quad C 9=1$

2290 NEXTX

2292 FORI $=1$ T02

2293 PRIN T

2294 NEXTI

2295 GO T08ดด

2300 PRI NN T" END"

2310 END 
BA.

BASIC-5.15 73-11-13

>LOAD /ASTM/

RUN

TYPE 1 TO SKIP DIRECTIONS. ELSE $\emptyset ?$

THIS PROGRAM PROVIDES 2 CONTROL CHARTS; ONE FOR INDIVIDUALS, $X$, AND ONE FOR MOVING RANGE, $R$, OF TWO OBSERVATIONS. SEE ASTM

MANUAL ON QUALITY CONTROL OF MATERIALS, PAGE 105, FOR DETAILS. CONTROL CHARI \#I DISPLAYS INDIVIDUAL RESIDUAL READINGS

IN PERCENT WITH CONTROL LIMITS VERSUS RUN NO.

CONTROL CHART \#2 DISPLAYS MOVING RANGE VALUES WITH

CONTROL LIMI TS VERSUS RUN NO.

CONTROL LIMITS SHOULD BE BASED ON AT LEAST 15 INDIVIDUAL

MEASUREMENTS. THIS PROGRAM NEEDS AT LEAST $1 \emptyset$ POINTS TO RUN.

SINGLE COLUMN INPUT DATA MUST BE IN FILE /A/ BEFORE RUNNING.

TI TLE OF PLOT

? SILI5 AT 1 MILLIWATT AI .6328

NO. OF POINTS: 15

AVERAGE:

.9621819

TO PLOT \#1, TYPE 1. TO PLOT \#2, TYPE 2. ELSE ด? 1 


$$
\begin{array}{ll} 
& \text { SILI5 AT } 1 \text { MILLIWATT AT } .6328 \\
\text { DATE IS } & 79 / 01 / 99 \text { 98:50:36 }
\end{array}
$$

AVERAGE RANGE IN PERCENI .231119

AVERAGE:

.9621819

PERCENT DIFFERENCE FROM AVERAGE

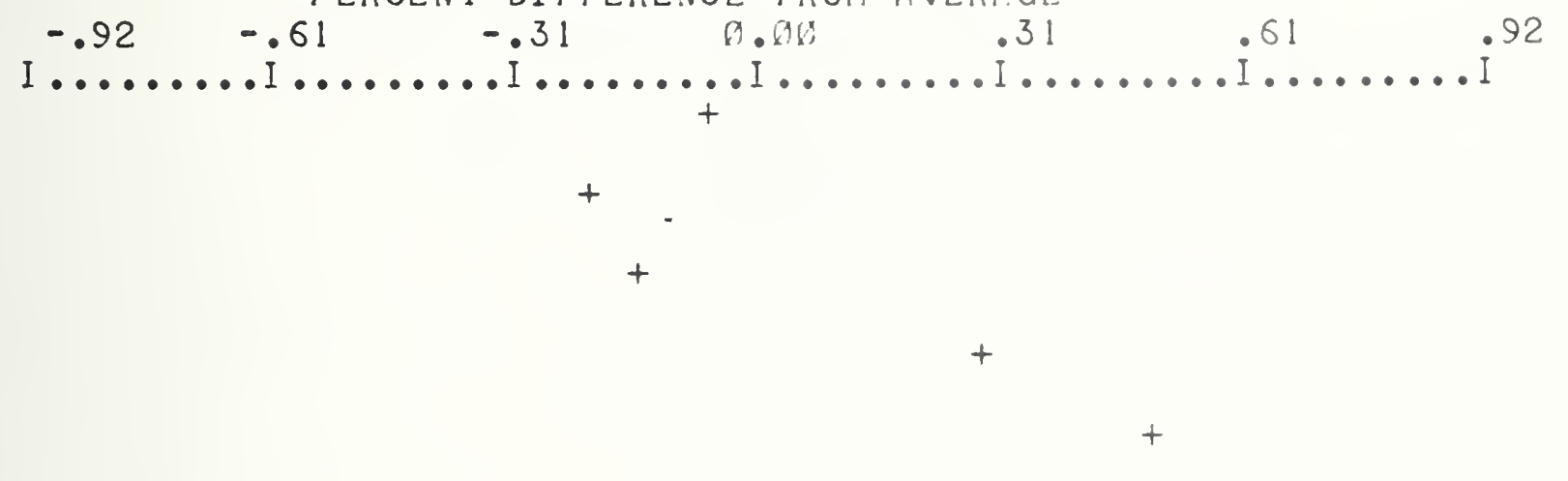

!

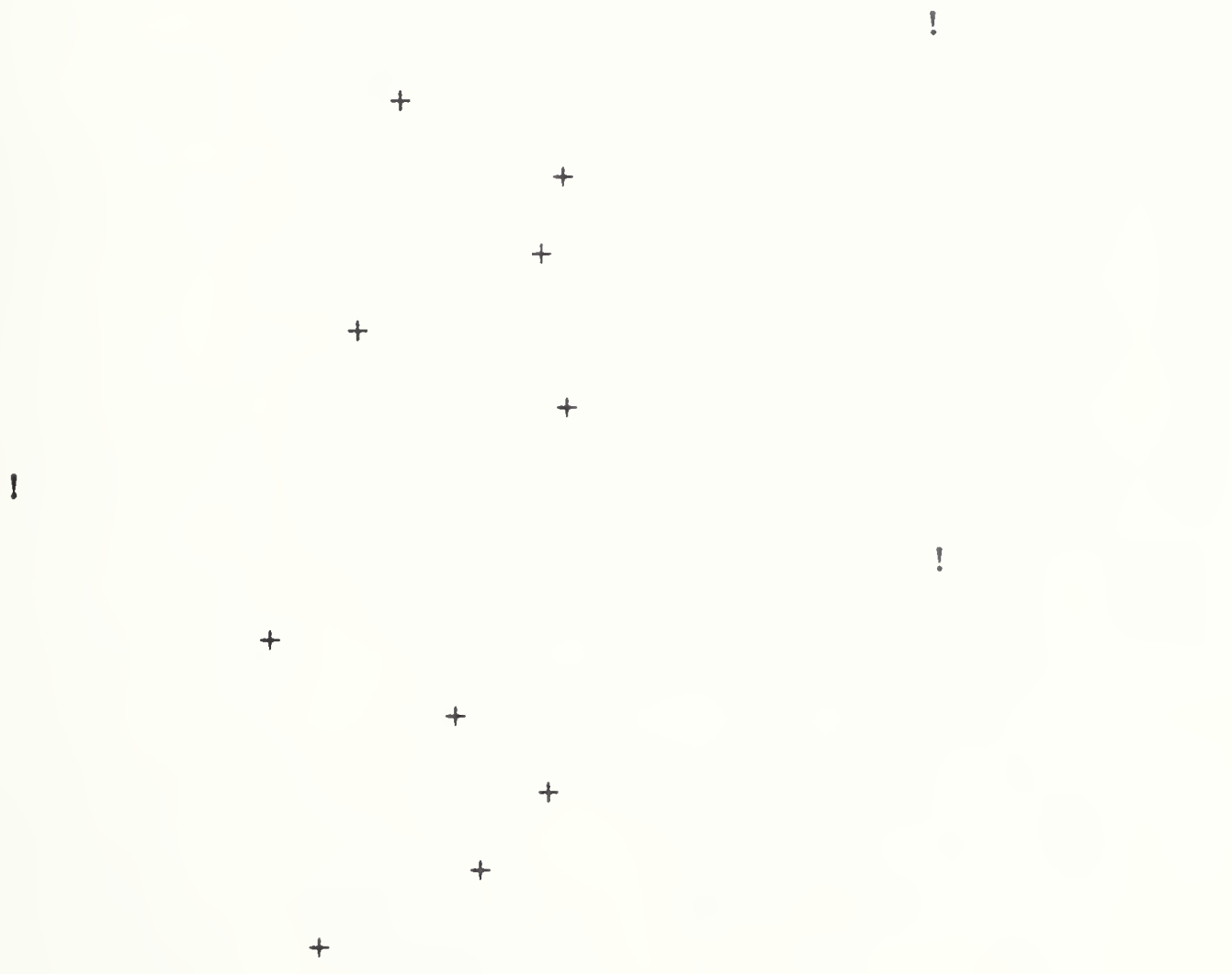

$!$ 
TO PLOT \#1, TYPE 1. TO PLOT \#2, TYPE 2. ELSE ø? 2

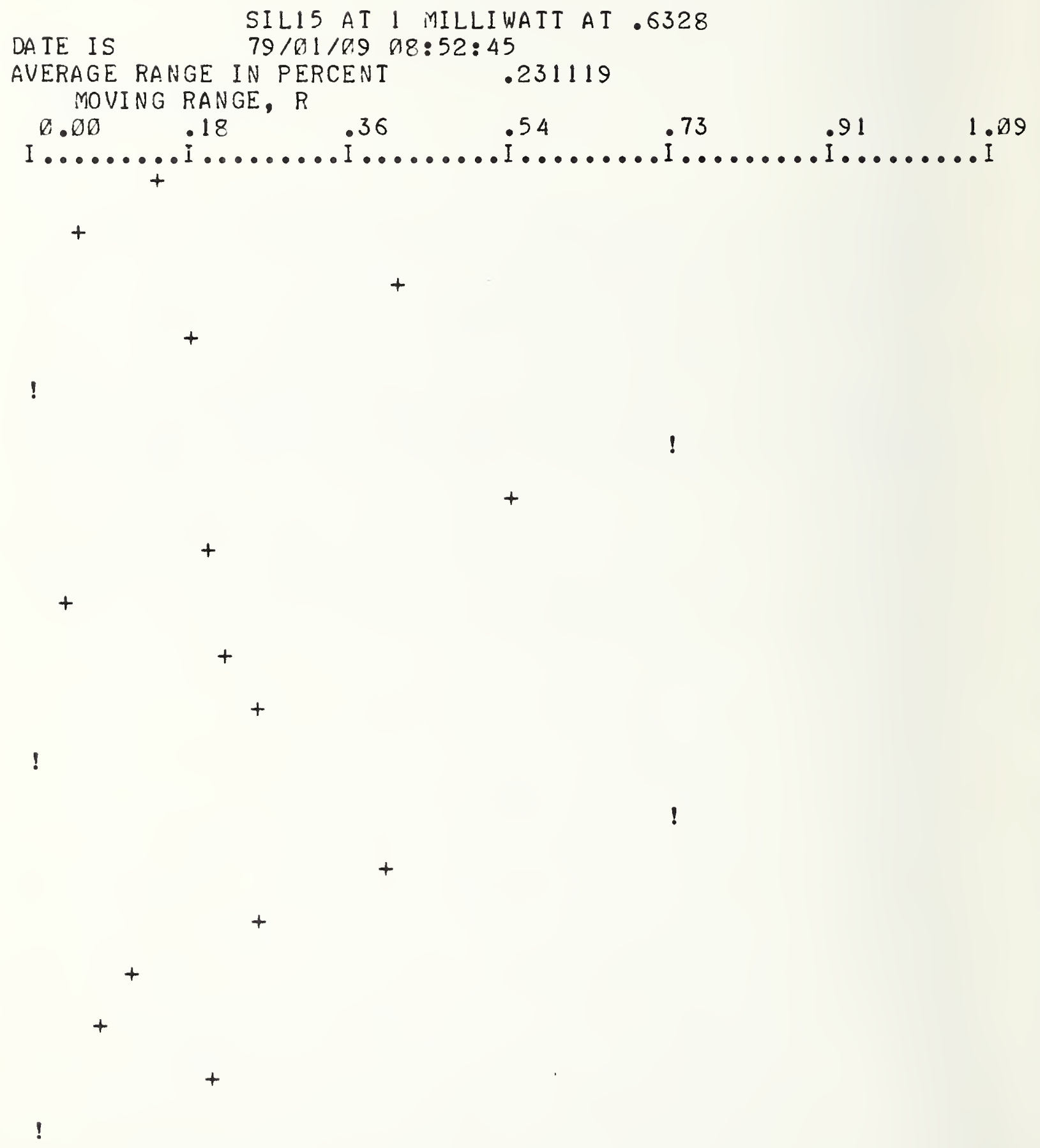


APPENDIX H

Computer Program, /02/, a Statistical Program to Provide Average, Standard Deviation 90\%, 95\%, and 99\% Confidence Interval Data

Appendix $H$ contains a listing and a sample run of Program /D2/. 
129 REM THIS IS PROGRAM DEV2

13. REM LAST REVISED ON JAN. 9, 1978

140 PRINT "A PROGRAM TO GIVE AVERAGE, STANDARD DEVIATION, 96\%, 95\% AND" 150 PRIN T "99\% CONFIDENCE INTERVALS FOR A SINGLE COLUMN OF DATA"

160 PRINT "IN FILE /A/"

1769 DIM $X(150), K(15 \theta), S(150), H(15 \theta)$

175 DIMY (150)

180 OPEN/A/, INPUT

198 FORI $=1$ TO1 50

200 INPUTFILEX (I)

210 I FEOF $(9)=1$ THEN260

$220 \quad N 1=I$

230 NEXT I

240 PRINT "OVER 150 POINTS IN FILE /A/"

250 STOP

260 A $\$="$ NO. OF POINIS IN /A/ $="$

261 PRINT"FOR STATISTICS ON RECIPROCALS, TYPE 1. ELSE D";

262 INPUTA9

263 I FA9 $=1$ THEN265

264 GOTO28日

265 PRIN T" VALUES IN $/ X /$ RECIPROCALS"

266 FOR I $=1$ TON 1

$267 Y(I)=X(I)$

$268 X(I)=1 / Y(I)$

269 PRINT Y(I),X(I)

270 NEX.TI

280 IF $N 1 \ll 1$ THEN 310

$29 \emptyset$ PRIN T "ZERO DEGREES OF FREEDOM"

300 STOP

$310 B \$=" F I R S T$ VALUE IN FILE $/ A /="$

$330 \mathrm{C} \$="$ LAST VALUE IN FILE $/ A /="$

350 FOR $I=1$ TO NI

360 IF $I=1$ THEN 390

$370 S(I)=S(I-1)+X(I)$

380 GO TO 400

$39 \emptyset \quad S(I)=X(I)$

400 NEXI I

$410 \mathrm{~J}=\mathrm{S}(\mathrm{N} 1) / \mathrm{N} 1$

$44 \emptyset \mathrm{J} \emptyset=J$

450 D\$="AVERAGE = "

470 FOR $I=1$ TO N1

480 IF $I=1$ THEN 510

$490 H(I)=H(I-1)+(X(I)-J) \uparrow 2$

500 GO TO 520

$510 H(I)=(X(I)-J) \uparrow 2$

$52 \emptyset$ NEXT I

$539 R=S Q R(H(N 1) /(N 1-1))$

$560 \mathrm{R} \emptyset=\mathrm{R}$

$579 E \$="$ STANDARD DEVIATION = "

$59 \emptyset \quad F \$=" P E R C E N T$ STANDARD DEVIATION $="$

592 T\$="PERCENT STANDARD ERROR = "

594 US ="EST. OF STD. ERROR = SQR ROOT (STD. DEV SQUARED/NO. OF MEAS.)" 596 US="SEE NBS SPECIAL PUB. 3ø0, VOL. 1, PAGE 71-1203" 


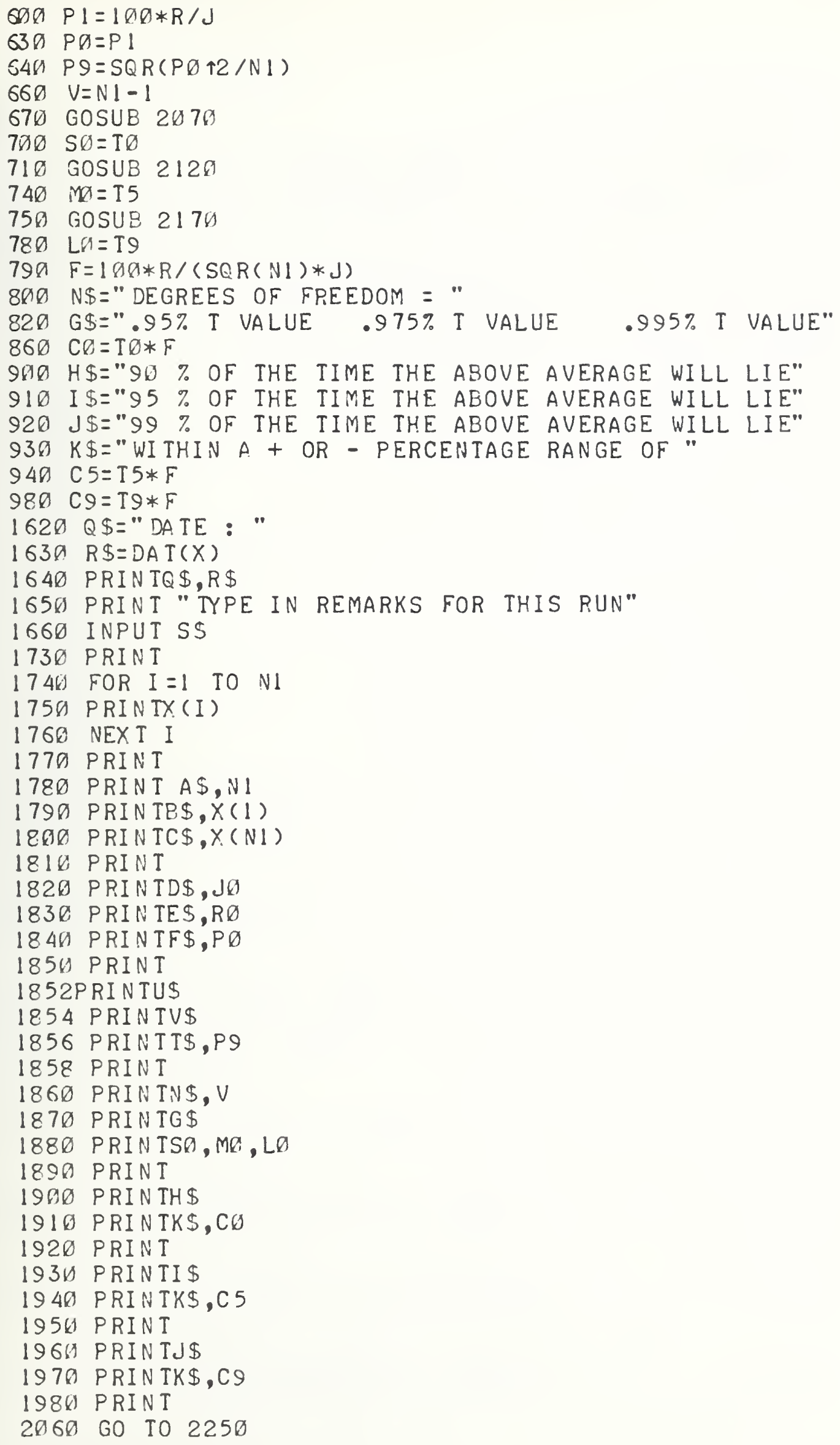


2ด7ด IF $V>4$ THEN 2100

$2080 \mathrm{~T} \emptyset=15.116+V *(-12.1829+V *(3.8945-0.4135 * V))$

2090 RE TURN

$2100 \mathrm{~T} \theta=V /(-0.559925368278+0.60784409253 * V)+6.0 E-4$

2110 RETURN

2120 IF $V>4$ THEN 2150

2130 T5 $=34.958+V *(-31.3655+V *(10.208-1.0945 * V))$

2140 RETURN

$2150 \mathrm{~T} 5=V /(-\emptyset .6115993191+\emptyset .5101102332 * V)+6.0 E-4$

2160 RETURN

2170 IF $V>1$ THEN 220 ด

2180 T9 $=63.657$

2190 RETURN

2200 IF $V>5$ THEN 2230

$2210 \mathrm{~T} 9=35.362+V *(-20.6568+V *(4.6965-0.36367 * V))$

2220 RETURN

$223 \emptyset \mathrm{T} 9=\mathrm{V} /(-\emptyset .715572179161+\emptyset .387490270184 * V)+6.0 E-4$

2240 RETURN

2250 PRIN T" DONE"

2260 END 
$-B A$

BASIC $-5.15 \quad 73-11-13$

$>$ LOAD /D2/

RUN

A PROGRAM TO GIVE AVERAGE, STANDARD DEVIATION, 96\%, 95\% AND 99\% CONFIDENCE IN TERVALS FOR A SINGLE COLUMN OF DATA

IN FILE /A /

FOR STATISTICS ON RECIPROCALS, TYPE 1. ELSE $\emptyset ?$

DATE : $\quad 79 / 01 / 09$ Q9:0ด:54

TYPE IN REMARKS FOR THIS RUN

? SILIS AT I MILLIHATT AT .6328

.961527

.960122

.960756

.964984

.96678

.961246

.953326

.962951

.960809

.963434

.959383

.961943

.962947

.962273

.961248

NO. OF POINIS IN $/ A /=15$

FIRST VALUE IN FILE /A/ $=\quad .961527$

LAST VALUE IN FILE /A./ = .960248

AVERAGE $=\quad .9621819$

STANDARD DEVIATION = $\quad .1966743 E-802$

PERCENT STANDARD DEVIATION $=.2944945$

EST. OF STD. ERROR = SQR ROOT (STD. DEV SQUARED/NO. OF MEAS.)

SEE NBS SPECIAL PUB. 300, VOL. 1, PAGE 71-1203

PERCENT STANDARD ERROR $=\quad .5277702 E-01$

DEGREES OF FREEDOM =

$.95 \%$ I VALUE .975\% T VALUE

1.76163

2.144569

14

$.995 \%$ I VALUE

2.973446

$90 \%$ OF tHE TIME the above average WILL LiE WI THIN $A+O R$ - PERCENTAGE RANGE OF

.9929736

$95 \%$ OF THE TIME THE ABOVE aVERAge WILL LIE 'NITHIN A + OR - PERCENTAGE RANGE OF

.113184

99 \% OF THE TIME THE ABOVE AVERAGE IILL LIE WITHIN A + OR - PERCENTAGE RANGE OF

DONE

$>Q U I T$ 
APPENDIX I

Computer Program, /S7B/, Used to Separate Beamsplitter

Ratios for Different Code Numbers

Appendix I contains a listing of Program, /S7B/, that is used to separate and print to Scratch File /A/ those beamsplitter ratios of interest. 
120 REM THIS IS PROGRAM STRIP7P

130 PRINT "USE TO COPY ALL REAM SPLITTER RATIOS OR ACCORDIVG TO CCDE"

140 PRINT "NO. FROM A 7 COLUMN BEAM SPLITTER CONTROL FILE FROY."

150 PRINT "SPECFIED FILE TO SCRATCH DATA FILE/A/"

$160 N=150$

170 DIM $A(N), P(N), C(N), D(N), E(N)$

$18 \Omega$ DIM $F(N), G(N), Y(N)$

19 月 $N 2=0$

290 PRINT "TYPE IN 7 COLUMN. EEAM SPLITTER FILE IN $/ /$;

216 INPUT Q

22风 OPENQS, INPUT

23Ø AD=" TOTAL NO. OF POINTS IN FILE $="$

$240 \mathrm{~B} \$="$ NO. OF POINTS IN FILE $/ \mathrm{A} /="$

250 FOR $I=1$ TO 156

260 INPUT FILEA(I), B(I ), C (I), D(I),E(I),F(I), G(I)

270 IF $E O F(9)=1$ THEN32,

$280 \quad N=I$

290 NEXT I

3ดØ PRINT "OVER 15ด POINTS"

$316,5 T O P$

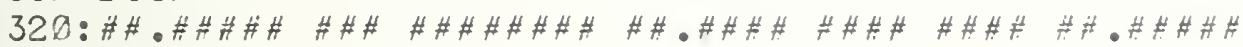

360 PRINTAS, N

371 PRIN T

38 Q $V I=N$

430 PRINT "TYPE CODE NUYBER. OTHERWISE TYPE 999 FOP ALL CODE NOS.";

448) I NPUT R9

480 FOR $I=1$ TO NI

499 IF R9 $=999$ THEN 510

56 (I) IF $B($ I $)<R 9$ THEN 540

$51 \varnothing \quad \mathrm{N} 2=\mathrm{N} 2+1$

$52 \varnothing \quad Y(N 2)=A$. ( I )

549 NEX. I I

55ด PRINT"NO. OF SELECTED POINTS = "N2

560 PRIN T" TO PRINT SELECTED POINTS TO TELETYPE, TYPE 1 . ELSE $3{ }^{\prime \prime}$;

$57 \varnothing$ INPUTQ

580 I $F Q=1 T H E N 699$

590 GOTO630

600 FORI $=1$ T ON2

510 PRINTY (I)

Q2, VEXTI

630 PRINT" TO PRINT SELECTED POINTS TO FILE /A/, TYPE 1. ELSE G";

640 INPUTP

650 IFP $=1$ THEN670

660 GOTO999

679 OPEN/A/,OUTPUT

\&Q FORI =1 TON2

SQ PRINTFILEY (I)

7⿹勹 NEXII

713 PRIN IB $\$$, N2

999 PRIN T" END"

1ดดด END 


\section{APPENDIX $J$}

Two Typical Electrical Clibration Files, /444/ and /44CC/, as Stored on the Computer

Two typical electrical calibration files are shown in Appendix J. File /444/ is a twocolumn file, where the first column has corrected rise values and the second column has corresponding values of energy (joules). Such a file is kept for each calorimeter for each scale that is maintained.

The /44CC/ file is for all the electrical calibration runs for $\mathrm{C} 44$, regardless of scale. Going from left to right, the values are energy in joules, calibration coefficient in joulesper-millivolt, resistance of the calibrating heater, cooling constant, time of energy input, residual data fit in percent, and run number. 


\begin{tabular}{|c|c|c|c|c|c|c|}
\hline 0405 & 4.87637 & 190.8579 & 6.001119 & 2.72 & 1.11 & 60279.73 \\
\hline 3.1409 & 4.8757 & 100.2500 & $0.0 Я 1117$ & 272 & D. 68 & 7073 \\
\hline .9676 & 4.86866 & 100.8410 & 6.6901108 & 208 & 0.66 & 973 \\
\hline & 4.86600 & 180.8427 & 8.001112 & 112 & $n .2 v$ & \\
\hline 87 & 4.87273 & 100.8550 & 0.001112 & 240 & 0.83 & 70120 \\
\hline 60,7 & 4.87193 & 100.8420 & 0.001106 & 288 & 0.39 & 7 \\
\hline & 4.87005 & 100.8360 & {$[1.0131110$} & 88 & ๑. 78 & \\
\hline & 4.87187 & 100.8340 & (月. & 12 & 2.53 & 7 \\
\hline 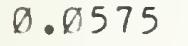 & 4.91141 & 190.8370 & ด.ดด10? & 12 & 2.44 & \\
\hline & 4.88487 & $100.837 \varnothing$ & 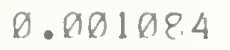 & 12. & 2.47 & \\
\hline r 5 & 4.85522 & 100.8360 & ด.Яด1120 & 12 & 2.25 & 7 \\
\hline 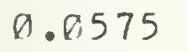 & 4.87 & ด. 8340 & 0.011149 & 12 & 3.04 & \\
\hline • & 4. & 100.8340 & ด. ๑ИЯ9स5 & 12 & $1.9 \emptyset$ & \\
\hline - & 4. & 100.8 .330 & 0.001061 & 12 & 2.57 & 7018 \\
\hline 10 & 4.86819 & 100.8340 & 0.001099 & & 1).92 & \\
\hline$r$ & 4. & 190.8337 & n. & 2 & a. 44 & 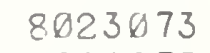 \\
\hline & & 50 & 0.0 & & $a .31$ & \\
\hline & 4.8 & 0.8439 & Ø.๑ & 4 & 1.21 & \\
\hline 1. & 4.86 & 100.8440 & ด.ดด11ด1 & k) 4 & 0.31 & \\
\hline & 4.86004 & 100.8500 & ด.ดด1112 & 48 & 0.28 & \\
\hline & & x. 8 & ด.ดด1134 & 268 & 0.28 & 12 \\
\hline & & 20 & ด. & & 0.34 & 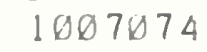 \\
\hline & & $3 n$ & 0.0 & 140 & 1.78 & \\
\hline & 4. & 100.8410 & 1111 & & 0.21 & \\
\hline & 4.88554 & 100.8510 & 0.06 & 148 & 1.94 & \\
\hline 2 . & 4.87057 & 100.8430 & ด. ดด & 268 & 0.31 & 2 \\
\hline ด. 6 & & 100. & $0 . \varnothing$ & 228 & $\emptyset$ & \\
\hline 2 . & 4. & 18 & 0.8 & & 0.36 & \\
\hline & 4.86850 & 100.8600 & ด. 6018 & 172 & 0.34 & \\
\hline & 4.86592 & 100.8600 & 0.001160 & 148 & 1.60 & \\
\hline & & 18 & Q). & 76 & 1 & 5 \\
\hline & 4 & 10 & $\theta .2$ & 176 & 0.2 & \\
\hline & & 1 & $\emptyset$. & 40 & ด. 51 & \\
\hline & 4.8 & 100.7790 & ด.ดด1182 & 44 & ด. 44 & \\
\hline .25 & 4.8 & 100.7890 & 0.001141 & 84 & 1.47 & \\
\hline & 4. & $D$ & 0. & 84 & 0.70 & \\
\hline & 4. & .7 & $\emptyset$. & 208 & 1 & \\
\hline$\cdot 7$ & 4.89 & 100.7970 & ด. ด & 164 & $\emptyset$ & \\
\hline & 50 & 100.8090 & 0.001 & 164 & $\varnothing$ & \\
\hline & & 18 & 0.001122 & 220 & $\emptyset$ & 88 \\
\hline & 4. & .8 & $0 . \ell$ & 32 & & 80 \\
\hline & 4. & 100.8 & $\theta . \theta$ & 380 & & \\
\hline & 4. & 100.8 & 0.0 & 300 & & \\
\hline & 4. & 100.8 & 0.601150 & 250 & 0.43 & iil \\
\hline & & 18 & $\emptyset$. & 300 & & 10 \\
\hline & & 18 & 0.8 & 180 & & \\
\hline 21 & 4.8 & 100.8 & 0.0 & 180 & 0.2 & \\
\hline & & 19 & ด. & 300 & 0.33 & \\
\hline & & 100. & 0.8 & $(8)$ & & \\
\hline & & 100.8 & 0.0 & 22 & & \\
\hline & & 100.7 & Q. .80 & 20 & & \\
\hline & & 18 & ด.ดด1123 & & 2 . & \\
\hline & & & ด. & 360 & 0.06 & \\
\hline
\end{tabular}




$\begin{array}{rrrrrrr}3.0039 & 4.87401 & 100.8470 & 0.001171 & 300 & 0.00 & 1019076 \\ 4.2351 & 4.87006 & 100.8506 & 0.001160 & 40 & 0.00 & 1019076 \\ 23.2933 & 4.86271 & 100.8506 & 0.001179 & 220 & 0.00 & 1019076 \\ 0.3213 & 4.85913 & 100.8541 & 0.001108 & 300 & 0.01 & 7508131 \\ 3.0043 & 4.86517 & 100.8671 & 0.001123 & 300 & 0.00 & 7608132 \\ 4.2351 & 4.86794 & 100.8568 & 0.001129 & 40 & 0.00 & 7608133 \\ 23.2926 & 4.85935 & 100.8475 & 0.001138 & 220 & 0.01 & 7508134 \\ 0.3213 & 4.86283 & 100.8446 & 0.001066 & 300 & 0.01 & 7711081 \\ 3.0043 & 4.86180 & 100.8437 & 0.001083 & 300 & 0.01 & 7711082 \\ 21.1637 & 4.85518 & 100.8278 & 0.001097 & 200 & 0.01 & 7711083\end{array}$

COPY /444/ TO TEL

$\begin{array}{ll}198.743 & 0.967611 \\ 980.345 & 4.38715 \\ 884.802 & 4.30903 \\ 1901.61 & 4.87603 \\ 623.318 & 3.03365 \\ 308.361 & 1.50149 \\ 383.745 & 1.86801 \\ 418.135 & 2.03697 \\ 832.416 & 4.05753 \\ 68.7373 & \emptyset .335819 \\ 450.298 & 2.19321 \\ 130.44 & 0.637567 \\ 436.327 & 2.12373 \\ 190.161 & 0.925799 \\ 575.605 & 2.80253 \\ 147.137 & 0.7201935 \\ 402.746 & 1.96238 \\ 541.485 & 2.63676 \\ 534.266 & 2.60097 \\ 659.583 & 3.21219 \\ 568.536 & 2.76487 \\ 569.731 & 2.77135 \\ 616.301 & 3.00386 \\ 869.624 & 4.23512 \\ 617.519 & 3.00434 \\ 870.093 & 4.23512 \\ 617.9332 & 3.004265\end{array}$


Computer File, /YT/, a Typical Beamsplitter File for a Given Laser Wavelength

A typical beamsplitter file, /YT/, is shown in Appendix $\mathrm{K}$. From left to right, the columns are beamsplitter ratio, code number, run number, wavelength, low-level calorimeter, high-level calorimeter, and energy (joules) to high-level calorimeter. Such a file exists for each beamsplitter and for each wavelength being maintained. Also shown is a run of Program /S7B/, which can be used to separate and print first column beamsplitter ratio to scratch File $/ A /$. In addition, a plot of all the beamsplitter values is shown in a computer run of /PL/. 


\begin{tabular}{|c|c|c|c|c|c|c|}
\hline 11.64580 & 12. & 76030501 & 1.0600 & 3464 & 3413 & $12.84 \times 5 \pi$ \\
\hline 11.64710 & 12 & $76: 38592$ & 1.0600 & 3464 & 3413 & $879 \%$ \\
\hline 1.64140 & 10 & 761135003 & 1.0600 & 3464 & 3413 & 821 \\
\hline 11.66460 & 10 & 7603594 & 1.9600 & 3464 & 3413 & 69950 \\
\hline 11.64220 & 10 & 7603082 & 1.0600 & 3464 & & $59 \pi$ \\
\hline $6466 n$ & 16 & 76030883 & $1.0,600$ & 3464 & 3413 & 535 \\
\hline 60 & 12 & 7603151 & 1.0600 & 3464 & & 800 \\
\hline 770 & 12 & 7603152 & 1.0600 & 3464 & & \\
\hline 4770 & 12 & 7604021 & 1.9600 & 3464 & 3413 & 10.96980 \\
\hline 1920 & 12 & 7604022 & $1.8: 600$ & 3464 & 3413 & $10.0054 x$ \\
\hline 10 & 9 & 76014281 & 1.0600 & 3414 & & 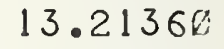 \\
\hline 290 & 9 & 7604282 & 1.0600 & 3414 & & 969 \\
\hline 66840 & 9 & 7604283 & 1.0600 & 3414 & 3463 & 280 \\
\hline 470 & 9 & $76 n 4284$ & 1.0600 & 3414 & & \\
\hline 123 & 15 & 7608091 & 1.0600 & 3414 & 3443 & 18. \\
\hline & 15 & 76 & 1.0600 & 3414 & 32 & \\
\hline 114 & 17 & 76 & 1.0600 & 3414 & & \\
\hline 580 & 17 & 7508 & 1.06000 & 3414 & 3463 & .76773 \\
\hline & 16 & 768 & 1.0600 & 3444 & 3 & \\
\hline 25 & 16 & 765 & 600 & 3444 & 3413 & 71 \\
\hline 597 & 19 & 7608172 & 1.0600 & 3444 & 3463 & 18.85 \\
\hline & 19 & 766 & $\phi \emptyset$ & 3444 & & \\
\hline & 20 & 764 & 10 & 3464 & 43 & 4 \\
\hline 1 & $2 \emptyset$ & 7608257 & 1.9600 & 3464 & 3443 & 39 \\
\hline & 18 & & 690 & 64 & 13 & \\
\hline 4213 & 18 & 7608264 & 1.0600 & 3464 & 3 & 2 \\
\hline & 8 & 7609241 & 1.0600 & 3464 & 3. & \\
\hline & 8 & 761 & 1. & 3464 & 3 & \\
\hline 81 & 8 & 7619262 & 1.0600 & 3464 & 3413 & 33 \\
\hline & 8 & 76 & 1.0500 & 3464 & 34 & \\
\hline & 8 & 7612301 & 1. & 3464 & 3 & 12.33 \\
\hline & 8 & 7701262 & 1.9600 & 3464 & 3413 & \\
\hline & 10 & 7703181 & 1.0600 & 3464 & 3413 & 20.6 \\
\hline & 9 & 7801691 & 1.96000 & 3414 & 3463 & 16.5 \\
\hline 9418 & 9 & 7802072 & 1.0600 & 3414 & 3463 & \\
\hline & 9 & 7803131 & 1.0600 & 3414 & 3463 & \\
\hline - & 9 & 780418 & 1.0600 & 3414 & 3463 & 107010 \\
\hline & 9 & & 1.06018 & $34 !$ & 3463 & \\
\hline & 9 & $78 \times 5$ & 1.0600 & 34. & 3463 & \\
\hline & 9 & 78060 & 1.960 & & $14<^{2}+2$ & \\
\hline & & & 1 & & & \\
\hline
\end{tabular}


USE TO COPY ALL BEAM SPLITTER RATIOS OR ACCORDING TO CODE NO. FROM A 7 COLUMN BEAM SPLITTER CONTROL FILE FROM SPECFIED FILE TO SCRATCH DATA FILE /A/ TYPE IN 7 COLUMN BEAM SPLITTER FILE IN //? /YT/ TOTAL NO. OF POINTS IN FILE =

41

TYPE CODE NUMBER. OTHERWISE TYPE 999 FOR ALL CODE NOS.? 999 NO. OF SELECTED POINTS = 41

TO PRINT SELECTED POINTS TO TELETYPE, TYPE 1. ELSE ด? 1 11.6458 11.6471 11.6414 11.6646 11.6422 11.6466 11.6506 11.6477 11.6477 11.6492 11.6621 11.6629 11.6684 11.6647 11.64823 11.63684 11.66714 11.6558

11.67485

11.711825

11.68597

11.65184

11.66475

11.62801

11.64934

11.64213

11.66588

11.66757

11.67301

11.66211

11.66426

11.65047

11.61917

11.69477

11.69418

11.69064

11.66568

11.68531

11.68272

11.69516

11.69019

TO PRINT SELECTED POINTS TO FILE /A/, TYPE 1 . ELSE $\emptyset ? 1$ NO. OF POINTS IN FILE /A/ = 41

END 


\section{QUI T}

$B A$

BA SI C $-5.15 \quad 73-11-13$

ᄂOAD /PL/

×RUN

A PLOT OF PERCENT DIFFERENCE FROM THE AVERAGE OF A SINGLE COLUMN OF DATA IN FILE /A/

II TLE OF PLOT

? S72 BEAM SPLITTER RATIOS AT 1.064

NO. OF POINTS: 41

AVERAGE: $\quad 11.66209$

STANDARD DEVIATION:

1 SIGMA IN PERCENT =

$.2007786 E-91$

3 SIGMA IN PERCENT =

.1721635

$Y$ MAX. PERCENT $=$

.5164904

$Y$ MIN. PERCENT =

.3957746

FOR INSTRUCTIONS, TYPE 1. ELSE $0 ? ? 1$

SCALE IS DIVIDED INTO 6 LARGE INTERVALS WHICH ARE

SCALED IN PERCENT. AN INPUT OF 1 , GIVES A SCALE FROM

-3 SIGMA TO +3 SIGMA IN PERCENT. AN INPUT OF 2 GIVES

A SCALE OF - N TO + N. AN INPUT OF 3 GIVES A SCALE

FROM - N TO + M PERCENT.

USE 1 FOR A SCALE IN TERMS OF SIGMA PERCENT

USE 2 FOR A SCALE IN TERMS OF - N TO + N PERCENT

USE 3 FOR A SCALE FROM $-P$ TO +Q PERCENT

TYPE 1, 2, OR 3?? 2

TYPE .3,.6,.9,1.2, ETC. OR A MULTIPLE OF .3??.45

FOR PLOT MOVE PAPER AND TYPE 1. ELSE $\emptyset ? 1$ 
S72 BEAM SPLITTER RATIOS AT 1.064

DATE IS 79/91/99 D9:15:16

PERCENT STANDARD DEVIATION: $\quad .1721635$

AVERAGE: $\quad 11.66209$

PERCENT DIFFERENCE FROM AVERAGE

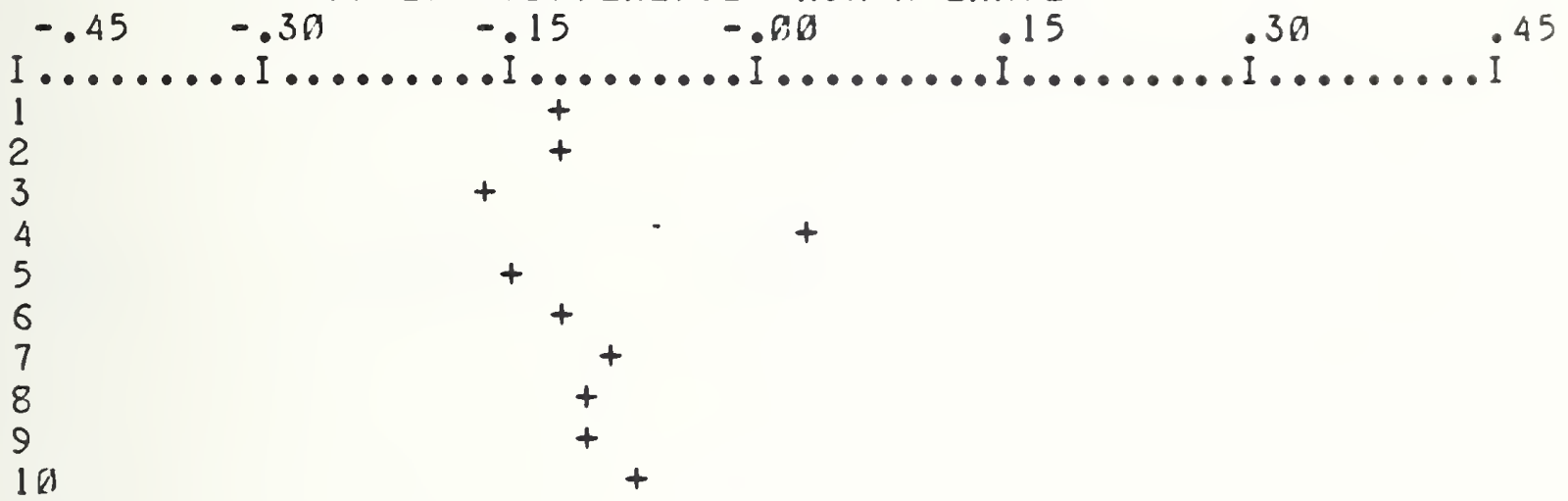

$11+$

$12+$

13

14

15

16

17

18

19

$2 \emptyset$

21

22

23

24

25

26

27

28

29

$3 n$

31

32

$33+$

$+$

$+$

34

35

36

37

38

39

46)

41

END

$+$

$+$

$+$

$+$

$+$

$+$

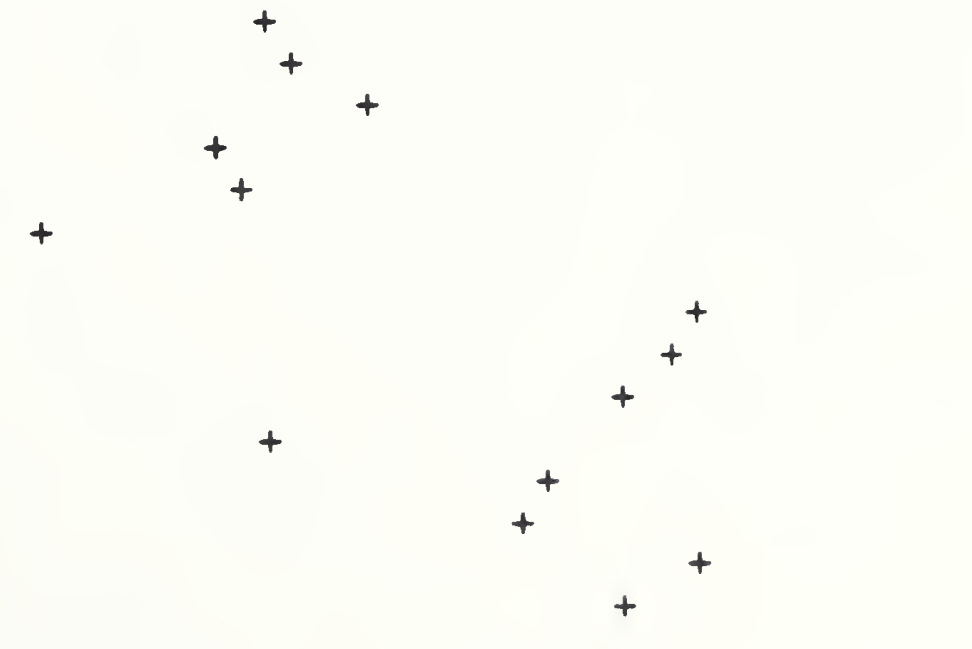

85 


\section{APPENDIX L}

Table L Defines Code Numbers for Different Beamsplitter Configurations

Table L.1, as shown in Appendix L, defines the code numbers used in the beamsplitter files to designate the various combinations of windows and calorimeters used by NBS in a three-calorimeter/beamsplitter configuration. 
TABLE L.

\begin{tabular}{cllll} 
Code No. & $\begin{array}{c}\text { Low Leve1 } \\
\text { Calorimeter }\end{array}$ & $\begin{array}{c}\text { Low Leve1 } \\
\text { Window }\end{array}$ & $\begin{array}{c}\text { High Level } \\
\text { Calorimeter }\end{array}$ & $\begin{array}{c}\text { High Level } \\
\text { Window }\end{array}$ \\
\hline 1 & C44 & BK7A-3 & C46 & FS-12 \\
2 & C46 & FS-12 & C44 & BK7A-3 \\
3 & C41 & FS-7 & C44 & FS-6 \\
4 & C44 & FS-6 & C41 & FS-7 \\
5 & C41 & FS-10 & C44 & BK7A-3 \\
6 & C44 & BK7A-3 & C41 & FS-10 \\
7 & C41 & FS-10 & C46 & FS-12 \\
8 & C46 & FS-12 & C41 & FS-10 \\
9 & C41 & FS-7 & C46 & FS-8 \\
10 & C46 & FS-8 & C41 & FS-7 \\
11 & C46 & FS-8 & C44 & FS-6 \\
12 & C44 & FS-6 & C46 & FS-8
\end{tabular}




\section{APPENDIX M}

Computer File, /CMAT/, Contains All Required C-series Parameters

In Appendix M, a copy of File /CMAT/ is shown that contains all the parameters needed by the $C$-Series calibrating system to calculate the value of the calibrating beam. Also shown is a computer run and listing of Program $/ \mathrm{DOC} /$, which documents the values found in $/ \mathrm{CMAT} /$. 
COPY /CMAI/ TO IEL

$\begin{array}{ll}10 & 41 \\ 12 & 0.9999 \\ 11 & 4.24443 \\ 3 & 4.25255 \\ 4 & 4.25675 \\ 9 & 1.90647 \\ 11.6587 & 0.9321 \\ 11.545 & 0.9365 \\ 11.5288 & 0.9394 \\ 11.4270 & 0.9285 \\ 11.4372 & 0.9291 \\ 1.06 & 1.23 \\ .6471 & .99 \\ .5328 & .99 \\ .5145 & .94 \\ .4880 & .92 \\ 4 & 1.27 \\ 0 & 0 \\ .5309 & 0.93 \\ 11.45235 & 0.9293\end{array}$

44
1
4.86211
4.86926
4.87101
0.999886
0.9331
0.9314
0.9312
0.9291
0.9296
1.29
.96
.96
.97
.95
0
0
.96
0.9299

46

1

4.94741

4. 94878

4.95214

9. 999649

0.9301

0.9294

0. 9293

0.9281

0.9286

1.42

1.09

1.09

1.17

1.15

0

a

1.16

0.9287 
$>R U N$

THIS 940 PROGRAM /DOC/ IS USED TO DEFINE AND DOCUMENT THE ELEMENTS IN /CMAT/ MATRIX.

\begin{tabular}{|c|c|c|c|}
\hline 10 & 41 & 44 & 46 \\
\hline 12 & .9999 & 1 & 1 \\
\hline 11 & 4.24443 & 4.86211 & 4.94741 \\
\hline 3 & 4.25255 & 4.86926 & 4.94878 \\
\hline 4 & 4.25675 & 4.87 & 4.95214 \\
\hline 9 & 1.00047 & .999886 & .999649 \\
\hline 11.6587 & .9321 & .9331 & .9301 \\
\hline 11.545 & .9305 & .9314 & .9294 \\
\hline 11.5288 & $.93 \not 14$ & .9312 & .9293 \\
\hline $\begin{array}{l}11.427 \\
11.4372\end{array}$ & $\begin{array}{r}9285 \\
9291\end{array}$ & - 9251 & .9281 \\
\hline $\begin{array}{l}1.04512 \\
1.06\end{array}$ & $\begin{array}{l}9291 \\
1.23\end{array}$ & $\begin{array}{l}.9296 \\
1.29\end{array}$ & $\begin{array}{l}.9286 \\
1.42\end{array}$ \\
\hline .6471 & .9 & .96 & 1.09 \\
\hline .6328 & .9 & .96 & 1.09 \\
\hline .5145 & .94 & .97 & 1.17 \\
\hline$\dot{4}^{488}$ & $i_{1.27}^{92}$ & $\ddot{0}^{95}$ & 1.15 \\
\hline$\emptyset$ & $\emptyset$ & Ø & 0 \\
\hline $\begin{array}{l}5309 \\
11.45235\end{array}$ & $\begin{array}{l}.93 \\
.9293\end{array}$ & .96 & 1.16 \\
\hline
\end{tabular}

ELECTRICAL CALIBRATION CONSTANTS, $K$, IN JOULES PER MILLIVOLT SEE LATEST BLUE BOOK TABLE A.1.1

$\begin{array}{ll}\text { CALORIMETER } & \text { SCALE } \\ \text { C41 } & \text { IE3 } \\ \text { C41 } & 1 E 4 \\ \text { C41 } & 1 E 5\end{array}$

ELECTRICAL K

4.24443

4.25255

4.25675

$\begin{array}{lll}C 44 & 1 E 3 & 4.86211 \\ \text { C4 } 4 & 1 E 4 & 4.86926 \\ \text { C44 } & 1 E 5 & 4.87 \\ & & \\ \text { C46 } & 1 E 3 & 4.94741 \\ \text { C46 } & 1 E 4 & 4.94878 \\ \text { C46 } & 1 E 5 & 4.95214\end{array}$

$\begin{array}{lcr}\text { CALORIMETER } & \text { ABSORPTION } & \text { D FACTOR } \\ \text { C41 } & : 9999 & 1.00047 \\ \text { C44 } & 1 & .999886 \\ \text { C46 } & 1 & .999649\end{array}$

$\begin{array}{lll}\text { GEOMETRIC MEAN } & \text { BEAM SPLITTER RATIOS } \\ \text { WAVELENGTH } & \text { BEAM SPLITTER RATIO } \\ 1.06 & 11.6587 & \\ .6471 & 11.545 & \\ .6328 & 11.5288 & \\ .5309 & 11.45235 & \\ .5145 & 11.4372 & \\ .488 & 11.427 & 90\end{array}$


'NINDOW TRANSMISSION VALUES

WA VELENGTH

CA LORIMETER

C41

$\mathrm{C} 44$

C46

WAVELENGTH

CALORIMETER

C41

C4 4

$\mathrm{C} 46$

WA VELENGTH

CA LORIMETER

C41

C4 4

C46

WA VELENGTH

CALORIMETER

C41

C4 4

C46

WA VELENGTH

CA LORIME TER

C41

$\mathrm{C} 44$

C46

WA VELENGTH

CALORIMETER

C4!

$\mathrm{C} 44$

C46
1.06

WINDOW

FS7

FS6

FS8

.6471

WI NDOW

FS 7

FS6

FS8

.6328

WINDO'N.

FS7

FS6

FS8

.5309

WINDOW

FS 7

FS6

FS8

.5145

WINDOW

FS7

FS6

FS8

.488

WIN DOW

FS 7

FS6

FS8
TOTAL TRANSMISSION

.9321

.9331

.9301

TOTAL TRANSMISSION

.9305

.9314

.9294

TOTAL TRANSMISSION

.93 प 4

.9312

.9293

TOTAL TRANSMISSION .9293

.9299

.9287

TOTAL TRANSMISSION .9291

.9296

.9286

TOTAL TRANSMISSION

.9285

.9291

.9281

DELIVERED BEAM UNCERTAINITY VALUES

AT THE 99\% CONFIDENCE INTERVAL

$\begin{array}{ll}\text { WAVELENGTH } & 183 \\ 1.06 & 1.23 \\ .6471 & .9 \\ .6328 & .9 \\ .5309 & .93 \\ .5145 & .94 \\ .488 & .92\end{array}$

$1 E 4$

1.29

.96

.96

.96

. 97

.95

$1 E 5$

1. 42

1.09

1.09

1.16

1.17

1.15

DELIVERED BEAM UNCERTAINITY.AT THE 99\% CONFIDENCE LEVEL AT THE 1 MICROWATT LEVEL IS 1.27 
TABLE A - BEAM SPLITTER CODE NUMBERS

\begin{tabular}{lcccc} 
CODE NO. & LOW LEVEL & \multicolumn{2}{c}{ HIGH LEVEL } \\
& CALORIMETER & WINDOW & CALORIMETER & WINDOW \\
3 & C41 & FS7 & C44 & FS6 \\
12 & C44 & FS6 & C46 & FS8 \\
10 & C46 & FS8 & C41 & FS7 \\
11 & C46 & FS8 & C44 & FS6 \\
4 & C44 & FS6 & C41 & FS8 \\
9 & C41 & FS7 & C46 &
\end{tabular}

COPY /DOC/ TO TEL

16 PRINT" THIS 949 PROGRAM /DOC/ IS USED TO DEFINE AND DOCUMENT"

20 PRINT" THE ELEMENTS IN /CMAT/ MATRIX."

25 PRIN T

26 PRIN T

27 PRIN T

30 DI $Y B(20,4)$

4 OPEN/CMAT/, INPUT

50 FORI $=1$ TO2 19

\$) FOR $\mathrm{J}=1 \mathrm{TO} 4$

7V, INPUT FILE B(I,J)

8月 NEXTJ

96 NEXTI

S5 MAT PRINT B

$100 A \$(1)=" C 41 "$

110 A $\$(2)=" C 44 "$

$126 \quad A \$(3)=" C 46 "$

$136 \mathrm{~B} S(1)=" 173 "$

$140 B S(2)=" 1 E 4 "$

$150 B \$(3)=" 1 E 5 "$

160 C $\$="$ CALORIMETER"

17 (日) DS $="$ SCALE"

172 ES=" ELECTRICAL K"

$174 F \$=" A B S O R P T I O N "$

176 G $\$=" D$ FACTOR"

178 I $S=$ "WAVELENGTH"

180 J\$ $\$$ "BEAM SPLITTER RAIIO"

182 K\$="WINDOW"

184 L $\$="$ TOTAL IRANSMISSION"

186 MS="FS 7"

$188 N \$=" F S 6 "$

190 P $\$=" F S 8 "$

$192 Z S(1)=" F S 7 "$

$194 Z \$(2)=" F S 6 "$

$196 Z S(3)=" F S 8 "$

209 PRINT" ELECTRICAL CALIBRATION CONSTANTS, $K$, IN JOULES PER MILLIVOLT" 204 PRIN T"SEE LATEST PLUUE BOOK TABLE A.1.1" 


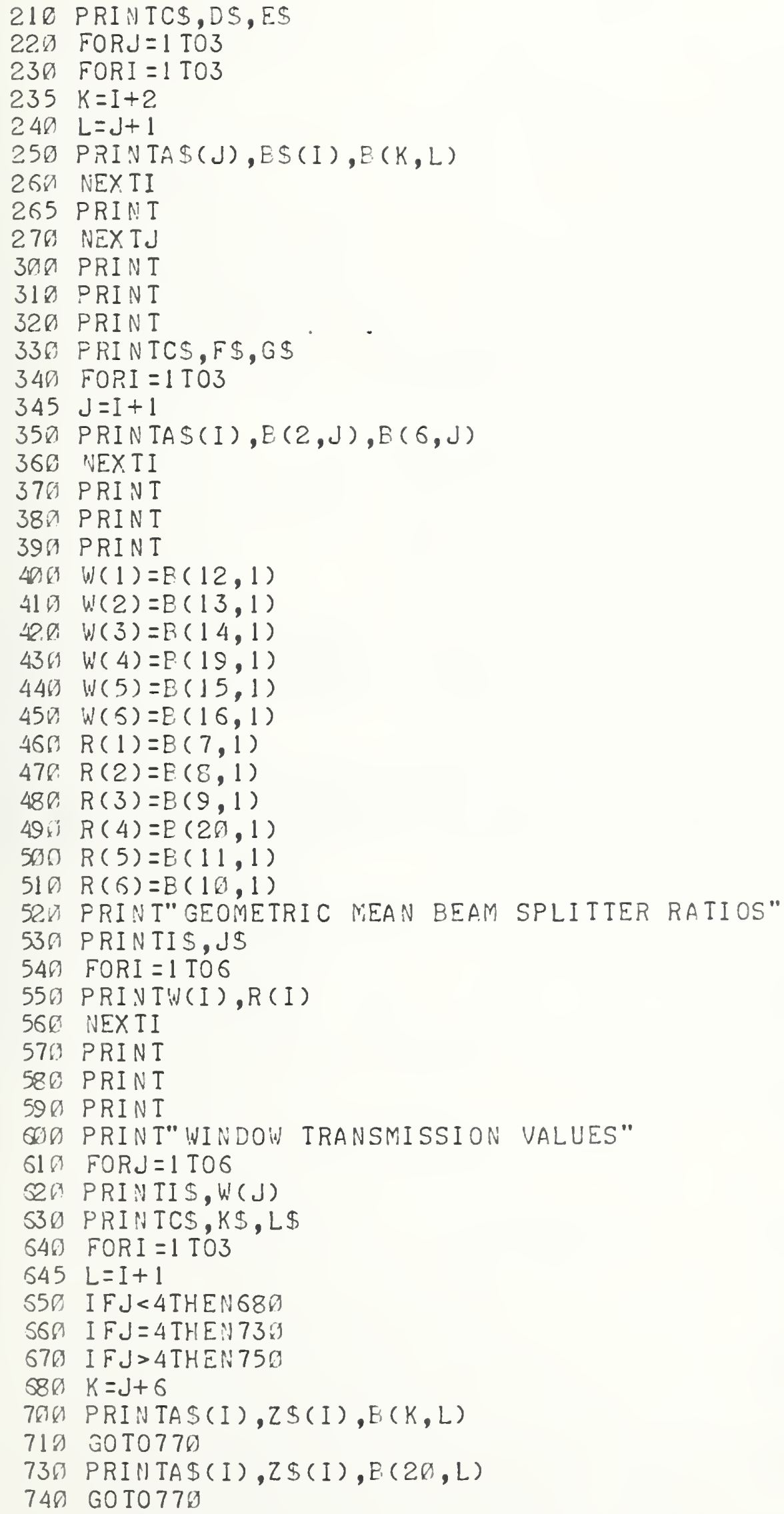


750 IFJ $<5$ THEN 764

766 PRINTA\$(I),Z\$(I),B(11,L)

762 GOTO77D

764 PRINTA $\$(I), Z \$(I), B(16, L)$

770 NEXII

789 PRIN I

799 NEXIJ

792. PRIN T

794 PRIN T

796 PRIN T

8 8ด PRIN T" DELIVERED BEAM UNCERTAINI TY VALUES"

805 PRINT"AT THE 99\% CONFIDENCE INTERVAL"

810 PRINTI\$,B $\$(1), B \$(2), B \$(3)$

826 PRINTH(1), $P(12,2), P(12,3), P(12,4)$

830 PRIN TW(2), $B(13,2), B(13,3), B(13,4)$

840 PRINTW(3), $B(14,2), B(14,3), B(14,4)$

850 PRINTW(4), $B(19,2), B(19,3), P(19,4)$

860 PRINTW(5), $B(15,2), E(15,3), B(15,4)$

870 PRINTW(6), $E(15,2), B(16,3), B(16,4)$

880 PRIN T

890 PRIN T

960 PRIN I

$91 \emptyset$ PRIN T" DELIVERED BEAM UNCERTAINITY AT THE $99 \%$ CONFIDENCE LEVEL" $92 \emptyset$ PRINI"A I THE 1 MICROWAT I LEVEL IS ",B $(17,2)$

930 PRIN T

940 PRIN I

956 PRIN I

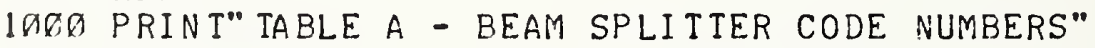

1010 PRIN T" CODE NO.

1015 PRIN T"

LOW LEVEL

$1020 \quad N 9=1$

$1040 \times \$=" \mathrm{C} 41 "$

$1045 \quad \mathrm{U} \$=M \$$

$1048 \quad$ V $\$=N \$$

1050 Y $\$=" C 44^{\circ}$

1ด60 GOIO1738

$1070 \times 5=" C 44^{\circ}$

1075 US $=N \$$

1078 VS $=P \$$

1080 Y $\$={ }^{\circ 0} \mathrm{C} 46^{\circ 0}$

1096 GOTO1738

$1100 \times \$=" \mathrm{C} 46^{\circ}$

$1105 \cup S=P S$

$1108 \quad V \$=M \$$

$1110 Y \$=" C 41 "$

1120 GOI01738

$1130 \times \$=" C 46 "$

$1135 \quad$ US $=P \$$

$1138 \quad$ VS $=N \$$

$1140 \quad Y \$=" \mathrm{C} 44^{\circ}$

1150 GOTO1738

$1160 \times \$=" C 44 "$

$1165 \quad$ US $=N \$$

$1168 \quad V \$=M \$$

1170 Y $S=" C 41 "$ 


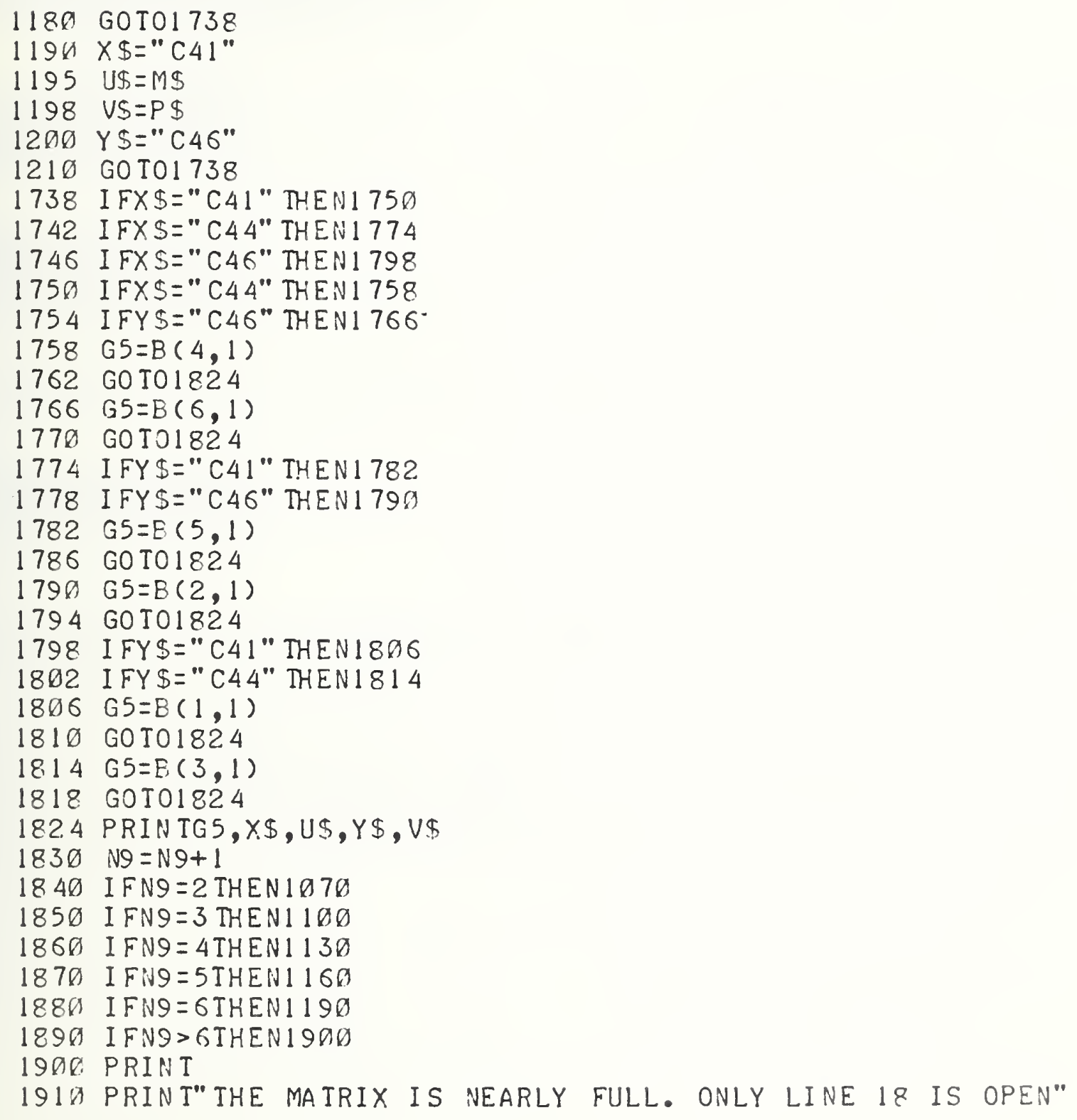


NBS.114A (REV. 9-78)

\begin{tabular}{|c|c|c|c|}
\hline $\begin{array}{l}\text { U.S. DEPT. OF COMM. } \\
\text { BIBLIOGRAPHIC DATA } \\
\text { SHEET }\end{array}$ & $\begin{array}{l}\text { 1. PUBLICATION OR REPORT NO. } \\
\text { NBSIR 79-1619 }\end{array}$ & 2. Gov'ticcession No & 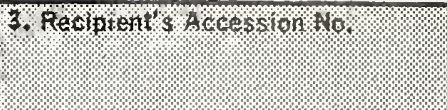 \\
\hline \multirow{2}{*}{\multicolumn{3}{|c|}{$\begin{array}{l}\text { 4. TITLE AND SUBTITLE } \\
\text { Quality Assurance Program for the NBS C, K, and Q } \\
\text { Laser Calibration Systems }\end{array}$}} & $\begin{array}{l}\text { 5. Publication Date } \\
\text { August } 1979\end{array}$ \\
\hline & & & 6. Performing Organization Code \\
\hline \multicolumn{3}{|l|}{$\begin{array}{l}\text { 7. AUTHOR(S) } \\
\text { W. E. Case }\end{array}$} & 8. Performing Organ. Report No. \\
\hline \multirow{2}{*}{\multicolumn{3}{|c|}{$\begin{array}{l}\text { NATIONAL BUREAU OF STANDARDS } \\
\text { DEPARTMENT OF COMMERCE } \\
\text { WASHINGTON, DC } 20234\end{array}$}} & 10. Project/Task/Work Unit No. \\
\hline & & & 11. Contract/Grant No. \\
\hline \multirow{2}{*}{\multicolumn{3}{|c|}{ 12. SPONSORING ORGANIZATION NAME AND COMPLETE ADDRESS (Street, city, State, ZIP) }} & 13. Type of Report \& Period Covered \\
\hline & & & 14. Sponsoring Agency Code \\
\hline
\end{tabular}

Document describes a computer program; SF-185, FIPS Software Summary, is attached.

16. ABSTRACT (A 200-word or less factual summary of most significant information. If document includes a significant bibliography or literature survey. mention it here.)

This report is a detailed procedure of how to set up and operate a Measurement Assurance Program (MAP) for a laser power and energy calibration facility. Items such as traceability, methods of selfchecking measurement consistency, computer documentation and statistical analysis are discussed.

17. KEY WORDS (six to twelve entries; alphabetical order; capitalize only the first letter of the first key word unless a proper name; separated by semicolons)

Calorimetry; laser beamsplitter system; laser calibration system; laser measurements; laser power calibration.

18. AVAILABILITY XXUnlimited

For Official Distribution. Do llot Release to NTIS

Order From Sup. of Doc., U.S. Government Printing Office, Wasinington, DC 20402, SD Stock No. SNỎ03-003-

XX Order From National Technical Information Service (NTIS), Springfield, VA. 2216

\begin{tabular}{|l|c|}
\hline $\begin{array}{l}\text { 19. SECURITY CLASS } \\
\text { (THIS REPORT) } \\
\text { UNCLASSIFIED }\end{array}$ & $\begin{array}{c}\text { 21. NO. OF } \\
\text { PRINTED PAGES } \\
102\end{array}$ \\
\hline $\begin{array}{l}\text { 20. SECURITY CLASS } \\
\text { (THIS PAGE) } \\
\text { UNCLASSIFIED }\end{array}$ & $\begin{array}{l}\text { 22. PriCe } \\
\$ 6.00\end{array}$ \\
\hline
\end{tabular}


- 


